TATIANE NUNES PEREIRA

\title{
ALIMENTAÇÃO E NUTRIÇÃO NA ATENÇÃO BÁSICA DO BRASIL: UMA ANÁLISE A PARTIR DA ACADEMIA, DAS EQUIPES E DA GESTÃO
}




\author{
UNIVERSIDADE DE BRASÍLIA \\ FACULDADE DE CIÊNCIAS DA SAÚDE \\ PROGRAMA DE PÓS-GRADUAÇÃO EM SAÚDE COLETIVA
}

TATIANE NUNES PEREIRA

\title{
ALIMENTAÇÃO E NUTRIÇÃO NA ATENÇÃO BÁSICA NO BRASIL: UMA ANÁLISE A PARTIR DA ACADEMIA, DAS EQUIPES E DA GESTÃO
}

Dissertação apresentada como requisito para a obtenção do Título de Mestre em Saúde Coletiva pelo Programa de Pós-Graduação em Saúde Coletiva da Universidade de Brasília.

Orientadora: Prof ${ }^{a}$. Drª ${ }^{a}$. Leonor Maria Pacheco Santos.

BRASÍLIA 


\title{
ALIMENTAÇÃO E NUTRIÇÃO NA ATENÇÃO BÁSICA NO BRASIL: UM OLHAR A PARTIR DA ACADEMIA, DAS EQUIPES E DA GESTÃO
}

Dissertação apresentada como requisito para a obtenção do Título de Mestre em Saúde Coletiva pelo Programa de Pós-Graduação em Saúde Coletiva da Universidade de Brasília.

Orientadora: Prof ${ }^{a}$. Drª. Leonor Maria Pacheco dos Santos.

\author{
BANCA EXAMINADORA \\ Leonor Maria Pacheco dos Santos - presidente \\ Faculdade de Ciências da Saúde \\ Universidade de Brasília \\ Elisabetta Gioconda Iole Giovanna Recine \\ Faculdade de Ciências da Saúde \\ Universidade de Brasília \\ Patricia Constante Jaime \\ Faculdade de Saúde Pública \\ Universidade de São Paulo
}




\section{AGRADECIMENTOS}

À Leonor, pela confiança e oportunidade, pelas contribuições à dissertação e pelo apoio na solução dos problemas.

Às professoras queridas da banca. À Patricia, pela escuta compreensiva, ajudas e sugestões, pela amizade, conversas, coerência e exemplos ao longo desses anos que contribuíram tanto para minha formação pessoal, profissional e acadêmica. Obrigada por abrir meus olhos estudantes para a nutrição no SUS. Será sempre minha inspiração de vida e serei sempre grata por tudo. À Betta, pelo estímulo e apoio, pelas discussões sobre o mestrado ou seu tema em inúmeras reuniões e almoços de intervalo, pela disciplina leve e inspiradora e pela leitura cuidadosa e sugestões. Muito obrigada!

À equipe altamente qualificada da CGAN, especialmente à turma de pós-graduação (Ana Luisa, Ana Spaniol, Carol, Eduardo, Marifê, Mônica e Vivian), pelas conversas tranquilizadoras, pelas trocas e por ajudarem a solucionar questões; a minha equipe querida (Simone, Carol, Re, Marcela e Gilsmin), pela compreensão, pela parceria e pela escuta paciente; e à Michele, pelas conversas, apoio em tantos momentos e contribuições com a dissertação.

À Renata, pelas contribuições e parceria no artigo de revisão.

À Adri, pela leitura cuidadosa e contribuições ao artigo da Mostra e pelo apoio de sempre.

Ao Wallace, por me ajudar e acalmar inúmeras vezes e pelos trabalhos conjuntos. Obrigada por abrir espaço em sua disciplina e me deixar vivenciar um pouquinho da experiência como docente.

Aline, Dani, Fabi, Mônica, Paula, Rubem, amigas e amigo mais que queridos que, mesmo com os quilômetros de distância que nos separam, estão sempre no coração. Agradecimento especialíssimo à Fabi, por me salvar em tantas crises pessoais e acadêmicas, pela "orientação", pelas conversas, conselhos e apoio logístico; obrigada por me ensinar e ajudar a não "morrer louca" durante esses anos.

Aos amigos também tão queridos de Brasília, Carol, Julio, Lari irmã, Dalila, Simone, $\mathrm{Gi}$, a quem quase sempre disse não às saídas e encontros, principalmente durante 
esse último ano. Obrigada pelo apoio, pelas distrações, pelas conversas e desculpem por não ter sido uma amiga tão boa esses últimos tempos.

Aos colegas de mestrado, Kimi, Dani, Ari, Carol, que compartilharam das dores e delícias desse período.

Aos responsáveis pelo PMAQ, Eudes e Davllyn, pela ajuda com projeto, banco e dúvidas sobre o programa.

Aos trabalhadores e trabalhadoras, gestores e gestoras, pesquisadores e pesquisadoras, que defendem o SUS, a SAN e a democracia em seu cotidiano e são os verdadeiros responsáveis por garantir à população os direitos à saúde e à alimentação.

E a minha família, principalmente a minha mãe e ao meu padrinho, por todo empenho para garantir educação e pelo incentivo constante às minhas decisões. À tia Ana e à tia Jô, pelo carinho de sempre. 


\section{RESUMO}

Introdução: O desenvolvimento de ações de alimentação e nutrição no âmbito da atenção básica é reconhecidamente estratégico para o alcance do propósito da Política Nacional de Alimentação e Nutrição. Contudo, descrições das ações de alimentação e nutrição neste ponto de atenção, sejam essas realizadas pela academia, ou pelas equipes de atenção básica, ainda são insuficientes para compreensão mais detalhada. Assim, o objetivo dessa dissertação é analisar as ações de alimentação e nutrição no âmbito da Atenção Básica no Brasil. Método: Foi realizada uma revisão sistemática da literatura científica e análise das experiências aprovadas na IV Mostra de Experiências em Atenção Básica/ Saúde da Família. Resultados: Foram avaliados 88 artigos e 81 relatos da IV Mostra. Verificou-se distanciamento da academia das necessidades, com sua atenção da academia voltada mais à realização de pesquisas de diagnóstico nutricional, enquanto que as equipes desenvolvem majoritariamente ações de promoção da alimentação adequada e saudável e prevenção/ tratamento do excesso de peso, sendo essas realizadas de forma multidisciplinar e com articulação intersetorial. Considerações Finais: Os resultados são complementares entre si por permitir obtenção do retrato nacional do que pesquisadores e equipes têm desenvolvido na atenção básica, possibilitando reflexões sobre suas práticas, necessidades e dificuldades, que direcionem a ação de gestores e temas a serem priorizados na realização de pesquisas na área.

Palavras-chave: Atenção Primária à Saúde; Nutrição em Saúde Pública; Saúde Pública; Alimentação; Programas e Políticas de Nutrição e Alimentação 


\begin{abstract}
Introduction: Develop nutrition actions on primary health care is recognized as strategic for achieving the purpose of Food and Nutrition National Policy. However, descriptions of actions at this point of care, realized by academics or health teams, are still insufficient for further understand. Thus, the aim of this research is to analyze food and nutrition actions on primary health care of Brazil. Method: A systematic review of the scientific literature was carried out and the analysis of the abstracts approved in the 4th Primary Care / Family Health Showcase. Results: It was evaluated 88 papers and 81 abstracts from Showcase. There was a distancing of the academy from the epidemiological priorities and management needs, with its attention of the academy turned more to the accomplishment of nutritional diagnosis researches, whereas the teams develop mainly actions of promotion of the adequate and healthy feeding and prevention / treatment of the excess weight, realized in a multidisciplinary way and with intersectoral articulation. Final Considerations: Results are complementary to each other in order to obtain the national description of what researchers and teams have developed in primary care, and what factors influence the performance of actions by the teams, allowing reflections on their practices, needs and difficulties, which can direct action of managers and themes to be prioritized in conducting research in the area.
\end{abstract}

Keywords: Primary Health Care; Nutrition; Public Health; Feeding; Nutrition Programs and Policies 


\section{LISTA DE FIGURAS}

Figura 1 Consumo alimentar de adolescentes, adultos e idosos - 22 2015

Figura 2 Prevalência de desnutrição e excesso de peso na 26 população acompanhada pela atenção básica, por faixa etária - 2015

Figura 1 Fluxograma de seleção dos estudos. Brasil, 2015. 


\section{LISTA DE TABELAS}

Caracterização geral das ações de alimentação e nutrição

Tabela 1 na atenção básica aprovadas na IV Mostra de Experiências em Atenção Básica/Saúde da Família. Brasil, 2014.

Detalhamento das ações de alimentação e nutrição na

Tabela 2 atenção básica aprovadas na IV Mostra de Experiências em Atenção Básica/Saúde da Família. Brasil, 2014.

Tabela 3 Caracterização das atividades em grupo e das ações de atenção nutricional integral. Brasil, 2016.

Tabela 4 Características da equipe e profissionais responsáveis, motivação, aprendizados e desafios. Brasil, 2016. 


\section{LISTA DE QUADROS}

Quadro 1 Características dos artigos. Brasil, 2015.

Quadro 2 Características das ações. Brasil, 2015.

Quadro 3 Descrição das ações de alimentação e nutrição. Brasil, 61 2015. 


\section{LISTA DE ABREVIATURAS E SIGLAS}

$A B$

Atenção Básica

A\&N Alimentação e Nutrição

AM Aleitamento Materno

AME Aleitamento Materno Exclusivo

CdP Comunidade de Práticas

Consea Conselho Nacional de Segurança Alimentar e Nutricional

Cosems Conselhos de Secretarias Municipais de Saúde

DCNT Doenças Crônicas Não-Transmissíveis

eAB Equipes de Atenção Básica

Erica Estudo de Riscos Cardiovasculares em Adolescentes

ESF Estratégia Saúde da Família

eSF Equipe de Saúde da Família

FAO/ONU Organização das Nações Unidas para Agricultura e Alimentação

IBGE Instituto Brasileiro de Geografia e Estatística

IDH-m Índice de Desenvolvimento Humano Municipal

NASF Núcleo de Apoio à Saúde da Família

NBCAL Norma Brasileira de Comercialização de Alimentos para Lactentes

OMS Organização Mundial de Saúde

PAB Piso de Atenção Básica

PAAS Promoção da Alimentação Adequada e Saudável

PMAQ-AB Programa de Melhoria do Acesso e da Qualidade na Atenção Básica

PNAB Política Nacional de Atenção Básica

PNAN Política Nacional de Alimentação e Nutrição

PNDS Pesquisa Nacional de Demografia e Saúde

PNPS Política Nacional de Promoção da Saúde

PNS Pesquisa Nacional de Saúde

POF Pesquisa de Orçamentos Familiares

RAS Rede de Atenção à Saúde

RP Razão de Prevalência

SAN Segurança Alimentar e Nutricional 
Sisvan Sistema Nacional de Vigilância Alimentar e Nutricional SUS Sistema Único de Saúde

UBS Unidade Básicas de Saúde

VAN Vigilância Alimentar e Nutricional 
1. INTRODUÇÃO

2.1 PERFIL ALIMENTAR E NUTRICIONAL DA POPULAÇÃO BRASILEIRA

2.2 ALIMENTAÇÃO E NUTRIÇÃO NA ATENÇÃO BÁSICA E MELHORIA DO PERFIL ALIMENTAR E NUTRICIONAL ................................................................................ 28

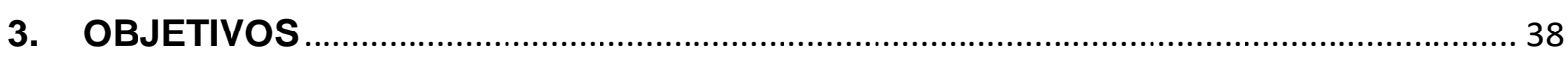

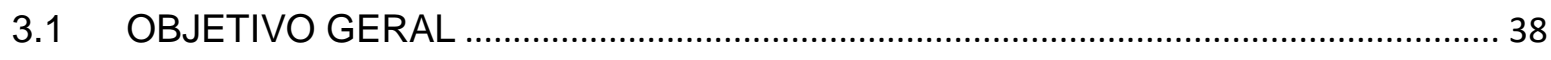

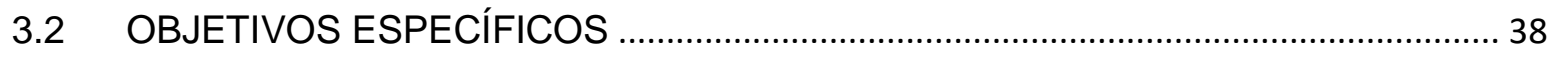

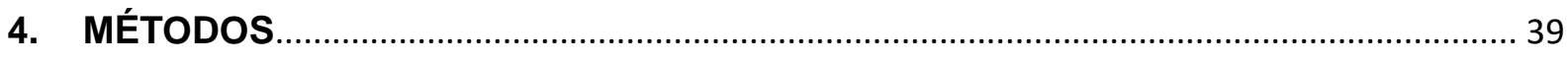

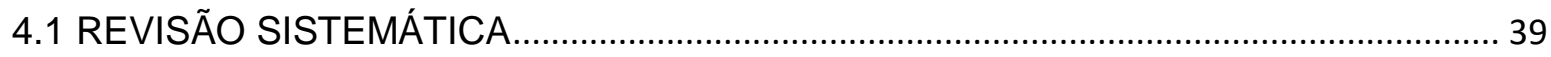

4.2. DESCRIÇÃO DOS RELATOS DA IV MOSTRA NACIONAL DE EXPERIÊNCIAS EM

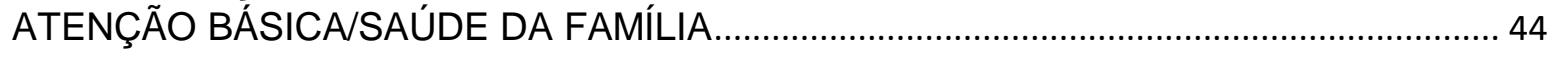

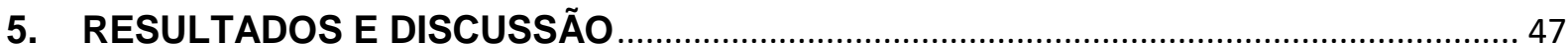

5.1 ALIMENTAÇÃO E NUTRIÇÃO NA ATENÇÃO PRIMÁRIA À SAÚDE NO BRASIL: UMA REVISÃO SISTEMÁTICA DA PRODUÇÃO CIENTÍFICA

5.2 AÇÕES DE NUTRIÇÃO NO BRASIL: DESCRIÇÃO A PARTIR DA IV MOSTRA NACIONAL DE EXPERIÊNCIAS DA ATENÇÃO BÁSICA/SAÚDE DA FAMÍLIA ................. 81

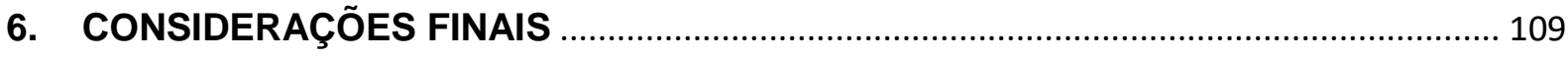

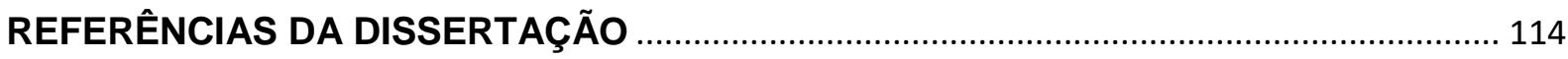

ANEXO - APROVAÇÃO DO COMITÊ DE ÉTICA EM PESQUISA ……………………….... 128 



\section{INTRODUÇÃO}

A saúde e o desenvolvimento econômico de um país estão intrinsecamente relacionados. O investimento em capital humano contribui para melhor autoavaliação de estado de saúde da população, da mesma forma que uma melhor educação e um estado de saúde mais adequado impactam positivamente sobre a economia. Há maior possibilidade de se ter maior renda, quanto melhor for a garantia e o acesso a esses direitos básicos. Assim, um país deve ter como uma de suas prioridades o investimento em capital humano com a garantia de direitos sociais, a fim de manter seu crescimento econômico (Campino e Machado, 2005).

Da mesma forma que o estado de saúde tem consequências para o crescimento econômico, sendo a nutrição adequada e a alimentação saudável fatores condicionantes e determinantes da saúde (CNDSS, 2008), doenças e agravos relacionados a esses fatores afetam o bem-estar e a saúde da população, impactando negativamente no desenvolvimento físico e cognitivo, comprometendo o sistema imune, aumentando a suscetibilidade a doenças transmissíveis e não-transmissíveis e limitando o alcance do potencial humano, o que reduz a produtividade e resulta em consequências sociais econômicas e sociais negativas para indivíduos, famílias, comunidades e Estados (FAO/WHO, 2014a).

Estima-se que a desnutrição tenha sido causa de significantes perdas mundiais de produtividade ao longo dos anos: durante o século $X X$ houve prejuízo de cerca de $8 \%$ no PIB mundial anual e a perda foi de $6 \%$ na primeira metade do século XXI, sendo a melhoria atribuída à melhor nutrição da população da América Latina a partir dos anos 2000 (Horton e Steckel, 2013). Assim, é necessário que governantes considerem investimentos em nutrição como meio para o crescimento econômico ao invés esperar que melhorias em nutrição somente sejam resultantes de seu desenvolvimento (IFPRI, 2016a).

A elaboração de políticas efetivas de alimentação e nutrição ( $A \& N$ ) exige que países levem em consideração o perfil alimentar e nutricional e as características específicas de seu território, visto que diferenças no desenvolvimento econômico e o grau de desigualdade na distribuição de renda implicam diferentes problemas de saúde pública relacionados à $\mathrm{A} \& \mathrm{~N}$ com distintos determinantes que precisam de estratégias específicas para seu enfrentamento (IFPRI, 2016a). A desnutrição e as 
carências nutricionais possuem uma multiplicidade de determinantes diferentes dos que levam ao excesso de peso e às doenças crônicas não transmissíveis (DCNT), por exemplo. Entre esses determinantes, estão a interação entre dietas de baixa qualidade, o comprometimento do estado de saúde e ambientes e comportamentos não saudáveis, todos influenciados por fatores como instabilidade política, desenvolvimento econômico, conflitos, desigualdades e dimensões da globalização (IFPRI, 2016a; Buss e Pellegrini Filho, 2007).

Muitos países, como o Brasil, convivem concomitantemente com as duas faces da insegurança alimentar e nutricional como problemas de saúde pública, seguindo da redução da desnutrição para o crescimento da obesidade, quadro chamado de transição nutricional (Monteiro, 2000).

Nesse contexto, a desnutrição, as carências nutricionais, a obesidade e as doenças crônicas relacionadas à alimentação são desafios globais complexos e multidimensionais, que, para seu enfrentamento, exigem a criação de ambientes políticos favoráveis e a realização de escolhas políticas adequadas ao contexto local, que contem com a participação de diversos atores e com investimentos financeiros para a implementação de ações sustentáveis, intersetoriais, baseadas em evidências, que ajam sobre os determinantes da alimentação e tornem os ambientes propícios à adoção de comportamentos saudáveis e à erradicação da má-nutrição (FAO/WHO, 2014a; IFPRI, 2015).

No Brasil, em 1990, a alimentação foi definida como um dos fatores determinantes e condicionantes da saúde constantes na Lei Orgânica do Sistema Único de Saúde (SUS) (Brasil, 1990), tendo sido ainda reconhecida como um direito social pela Constituição Federal, a partir de 2010 (Brasil, 2010a), sendo indissociável à educação, à saúde, ao trabalho, à moradia, ao transporte, ao lazer, à segurança, à previdência social, à proteção à maternidade e à infância e à assistência aos desamparados (Brasil, 2015a). Tais direitos devem ser garantidos pelo Estado por meio de políticas públicas (Brasil, 1988).

De meados da década de 80 , pouco antes da publicação da Constituição Federal, aos dias atuais, diversas políticas sociais, incluindo as de A\&N, foram desenvolvidas, impactando no perfil nutricional da população, sendo essas mais fortemente implementadas a partir de 2003, quando a erradicação da fome e da miséria se tornou prioridade governamental (FAO, 2014a; IFPRI, 2016a). Até então, as ações, inclusive no âmbito do setor saúde, apesar de também terem contribuído 
para a melhoria do cenário, eram majoritariamente direcionadas às mulheres e crianças, com abordagens assistencialistas ou emergenciais, realizadas, principalmente, a partir da distribuição de alimentos, direta ou indiretamente, e com pouca ou nenhuma participação social; diretrizes neoliberais e práticas populistas prevaleciam sobre as necessidades e direitos da população (Barros e Tartaglia, 2003; Vasconcelos e Batista Filho, 2011).

No final dos anos noventa, foi publicada a primeira versão da Política Nacional de Alimentação e Nutrição no âmbito do setor saúde, sendo a primeira política na área a destacar a necessidade de construção de ações intersetoriais e articulações com outros segmentos da sociedade e do setor produtivo para alcance de seu propósito e considerar a alimentação como direito humano, contribuição fundamental para a área (Arruda e Arruda, 2011; Rigon, Schmidt e Bógus, 2016).

A partir de 2003, as ações de segurança alimentar foram colocadas no centro de prioridades de governo e houve criação de ambiente político favorável à implementação de ações efetivas de $A \& N$, que incluiu a publicação de marcos legais, dando institucionalidade às políticas relacionadas à segurança alimentar e nutricional (SAN), e a criação de estruturas de governança, que permitiram articulação e implementação de políticas intersetoriais. Além de ser garantido o envolvimento da sociedade civil, com a recriação do Conselho Nacional de Segurança Alimentar e Nutricional (Consea), e capacidade técnica e financeira para a implementação das políticas e ações (IFPRI, 2016b).

Além disso, houve investimento em outras políticas, especialmente no tocante à transferência de renda, valorização do salário mínimo, ampliação do acesso à saúde e à educação, universalização do acesso à água e fortalecimento da agricultura familiar (MDS, 2013; FAO, 2014a; Consea, 2015). Tais esforços impactaram em melhorias socioeconômicas e dos indicadores de saúde e nutrição da população brasileira, levando à redução da desnutrição e da insegurança alimentar e nutricional e à saída do Brasil do Mapa da Fome da Organização das Nações Unidas para Agricultura e Alimentação (FAO/ONU) em 2014 (FAO, 2014b). O Brasil é reconhecido internacionalmente por ser um dos poucos países do mundo em que o tema segurança alimentar foi considerado uma prioridade política, sendo referência no combate à fome (FAO, 2014a; IFPRI, 2016b; Rocha, Jaime e Rea, 2016).

Apesar dos avanços, a obesidade e as doenças crônicas relacionadas à $A \& N$ continuam crescentes no país e a desnutrição, as carências nutricionais e a 
insegurança alimentar ainda podem ser identificadas em populações específicas, como povos e comunidades tradicionais, povos indígenas, população negra e outros grupos em maior vulnerabilidade social (MDS, 2007; Ministério da Saúde, 2010; IBGE, 2014; Consea, 2015), representando desafios a serem enfrentados pelo Poder Público. Nesse sentido, os sistemas de saúde podem ter papel estratégico (IFPRI, 2016a), desde que haja investimentos e implementação de ações articuladas com outros setores.

Nesse contexto, diversos são os compromissos pactuados nacional e internacionalmente pelo Brasil, que contam com protagonismo do setor saúde, e incluem ações a serem desenvolvidas no âmbito do Sistema Único de Saúde (SUS) para enfrentamento de todas as formas de má-nutrição.

Destacam-se, em âmbito internacional, os compromissos assumidos em 2016 no âmbito da 69ª Assembleia Mundial de Saúde, a Declaração de Roma e o Marco de Ação resultantes da $2^{2}$ Conferência Internacional de Nutrição, realizada em 2014, e a Década de Nutrição 2016-2025 da ONU, por meio dos quais o país compromete-se a implementar iniciativas e envidar esforços na prevenção e controle de todas as formas de má-nutrição, reconhecendo a importância dos sistemas de saúde para sua efetividade (FAO/WHO, 2014a; 2014b; UN, 2016; WHO, 2016).

No contexto nacional, a realização da promoção da alimentação adequada e saudável, o controle do crescimento da obesidade na população e o enfrentamento de carências nutricionais específicas e da desnutrição em povos indígenas e quilombolas foram metas intersetoriais pactuadas para o próximo quadriênio no principal plano de governo (Plano Plurianual 2016-2019) e no Plano Nacional de Segurança Alimentar e Nutricional 2016-2019. Ainda, metas relacionadas às doenças crônicas, incluindo a obesidade, correspondem a compromissos do Plano Nacional de Ações Estratégicas para o Enfrentamento às Doenças Crônicas Não-Transmissíveis 2011-2022 (Ministério da Saúde, 2011a; Brasil, 2016; Caisan, 2016). Políticas nacionais, como a Política Nacional de Alimentação e Nutrição (PNAN) e Política Nacional de Promoção da Saúde (PNPS) também reconhecem a necessidade de o governo agir para superar estes desafios (Ministério da Saúde, 2012a; 2014a).

Contudo, para cumprimento de tais compromissos, no que cabe ao setor saúde, é necessário que os sistemas de saúde tenham a nutrição como tema transversal e garantam a oferta de cuidado integral e contínuo aos cidadãos, incluindo ações desde a promoção da saúde à prevenção, tratamento e reabilitação de doenças, levando em 
consideração as necessidades e vulnerabilidades relacionadas à alimentação e nutrição de grupos específicos (FAO/OMS, 2014a).

No sistema de saúde brasileiro (SUS), a organização e a oferta de ações de A\&N são norteadas pela Política Nacional de Alimentação e Nutrição (PNAN), publicada originalmente em 1999 e revisada em 2011, sendo reconhecido em seu texto que as ações de $A \& N$ devem ser transversais a todos os pontos da Rede de Atenção à Saúde (RAS) (Ministério da Saúde, 2012a) e ter a atenção básica (AB) como principal lócus de atuação para implementação, por ser um espaço privilegiado para a promoção da saúde e prevenção de agravos, além de propiciar a realização de diagnóstico, tratamento, reabilitação e redução de danos relativos às doenças relacionadas à $A \& N$ (Ministério da Saúde, 2011b; 2012a).

Apesar de a $A B$ ser reconhecida como estratégico ponto de atenção da RAS para a realização de ações de $A \& N$ no SUS, descrições dessas ações na $A B$, sejam realizadas pela academia ou pelas equipes de atenção básica, ainda são insuficientes para sua compreensão mais detalhada. Nesse sentido, conhecer as ações desenvolvidas na $A B$ na área de $A \& N$ é fundamental para identificar lacunas $e$ potencialidades da gestão e das equipes de $A B$, subsidiando a reorganização de sistemas e serviços de saúde e a tomada de decisão dos gestores públicos quanto à definição de problemas e orientação das estratégias desenvolvidas para a promoção da alimentação adequada e saudável e para o enfrentamento de todas as formas de má-nutrição, justificando a realização deste estudo. 


\section{REVISÃO BIBLIOGRÁFICA}

\subsection{PERFIL ALIMENTAR E NUTRICIONAL DA POPULAÇÃO BRASILEIRA}

Nas últimas décadas, o Brasil passou por inúmeras transformações econômicas e sociais que levaram à redução da pobreza e da miséria, melhoria do poder aquisitivo, aumento da escolaridade e maior e mais qualificado acesso à saúde, o que impactou em seu perfil alimentar e nutricional da população, com redução da insegurança alimentar, fome e desnutrição (FAO, 2014a; Keefe, 2016). Paralelamente houve importante crescimento do excesso de peso, obesidade e outras doenças crônicas relacionadas à alimentação e nutrição, caracterizando um cenário de dupla carga de insegurança alimentar e nutricional no país.

Tal cenário pode ser explicado, entre outros fatores, pelo inadequado padrão alimentar, com aumento do consumo de alimentos ultraprocessados e redução de alimentos in natura e minimamente processados, observado em todas as faixas etárias e estratos de renda (IBGE, 2011a; Martins et al, 2013; Canella et al, 2014; Saldiva et al, 2014). O maior risco de dislipidemia em crianças, de doenças cardiovasculares e síndromes metabólicas em adolescentes e de obesidade em adultos já foi associado ao alto consumo de alimentos ultraprocessados (Tavares et al, 2012; Canella et al, 2014; Rauber et al, 2015).

Em 2013, o Brasil ocupava o 34ํlugar, dentre os 80 países monitorados na Euromonitor International, nas vendas per capita de alimentos e bebidas ultraprocessados (112,9kg). Quando comparado somente a países da América Latina Latina (Argentina, Bolívia, Chile, Colômbia, Costa Rica, Equador, Guatemala, México, Peru, República Dominicana, Uruguai e Venezuela), o Brasil ocupava o $7^{\circ}$ lugar nessas vendas, apresentando uma taxa média de crescimento anual de 2,1\% entre 2000 e 2013, menos da metade da taxa de países como Uruguai $(7,2 \%)$, Bolívia $(6,6 \%)$ e Peru $(5,8 \%)$ e mais do que o dobro da taxa da Costa Rica $(0,8 \%)$, Venezuela $(0,6 \%)$ e Argentina $(-0,3 \%)$. O Brasil também era o $2^{\circ}$ da América Latina nas compras per capita em restaurantes fast food em 2013 (PAHO, 2015). Em 2014 compunha a lista dos vinte países que mais consumiam refrigerante no mundo, ficando em $14^{\circ}$ (Euromonitor International, 2014). Destaca-se que quanto maior as vendas per capita 
de alimentos e bebidas ultraprocessados, maior a prevalência de obesidade no país (PAHO, 2015).

Quando observado o perfil alimentar por faixa etária, comparação entre inquéritos nacionais que possuem dados de aleitamento materno, mostrou importante aumento na prevalência de aleitamento materno exclusivo (AME) e na mediana de aleitamento materno (AM) entre 1975 e 2008, passando de 3,1\% para 41,0\% e de 2,5 para 11,3 meses, respectivamente, sendo sugerido que programas e ações de incentivo e proteção ao aleitamento materno implementados a partir da década de 80 podem ter influenciado tal aumento (Venancio, Saldiva e Monteiro, 2013).

Até os seis meses, quando a OMS recomenda aleitamento materno exclusivo, na Pesquisa Nacional de Demografia e Saúde (PNDS), realizada em 2006, foi verificado que mais de $30 \%$ das crianças consumiam outros tipos de leite e que a introdução de alimentos era uma prática em 14\% das crianças antes dos dois meses e em mais de $30 \%$ das crianças entre quatro e cinco meses (Ministério da Saúde, 2009a; Bortolini et al, 2013).

Análise de dados da PNDS 2006 também permitiu verificar que, entre as crianças de seis meses a dois anos de idade, em que é preconizado aleitamento materno e alimentação complementar saudável, houve baixo consumo diário de verduras $(12,7 \%)$, legumes $(21,8 \%)$ e carnes $(24,6 \%)$ e alto consumo de alimentos e bebidas de alta densidade energética e baixa qualidade nutricional, como refrigerantes $(40,5 \%)$, frituras $(39,4 \%)$, salgadinhos $(39,4 \%)$ e doces $(37,8 \%)$ e $38,5 \%$ na faixa de seis a 12 meses e $65,2 \%$ entre 13 a 24 não estavam em aleitamento materno (Bortolini, Gubert e Santos, 2012; Bortolini et al, 2013). Dados da Pesquisa Nacional de Saúde (PNS) de 2013 mostraram que 60,8\% das crianças menores de dois anos de idade consumiram biscoitos, bolachas ou bolo e que 32,3\% tomaram refrigerante ou suco artificial no dia anterior à pesquisa, não havendo diferença estatística entre residentes na área urbana e rural (Jaime et al, 2016).

Crianças acompanhadas pela atenção básica nessa faixa etária possuem padrão alimentar semelhante. Dados de 2015 do Sistema Nacional de Vigilância Alimentar e Nutricional (Sisvan) mostram que 59,4\% das 708.498 crianças até dois anos acompanhadas, com essas informações inseridas no sistema, estavam em aleitamento materno. Quando observadas as crianças entre seis e 23 meses, dentre as 38.566 acompanhadas, apenas $53,0 \%$ haviam sido amamentadas e $14,0 \%$ consumiram alimentos ricos em ferro na consulta anterior; enquanto que $56,0 \%$ 
consumiram algum tipo de alimento ultraprocessado, 40,0\%, biscoito recheado, 32,0\%, macarrão instantâneo e 27,0\%, bebidas adoçadas. Contudo, o consumo de alimentos ricos em vitamina $A$ tinha sido realizado por $63,0 \%$ das crianças (Sisvan, 2016).

Avaliação realizada a partir da II Pesquisa Nacional de Prevalência de Aleitamento Materno nas Capitais Brasileiras e Distrito Federal identificou associação entre a baixa escolaridade materna e a introdução de alimentação não saudável em crianças menores de um ano (Saldiva et al, 2014).

Entre a população brasileira acima de dez anos, dados da Pesquisa de Orçamentos Familiares (POF) 2008-2009 mostraram que arroz, feijão, café, pão de sal e carne bovina são os alimentos mais consumidos (Souza et al, 2013).

Entre os adolescentes, na mesma pesquisa, verificou-se que sucos e refrescos $(43,5 \%)$, óleos e gorduras $(36,7 \%)$ e refrigerantes $(28,2 \%)$ também apareceram com maior prevalência, a única fruta mencionada, entre os vinte alimentos mais consumidos, foi a banana (12,5\%) e não foi observada nenhuma hortaliça nesse grupo (Souza et al, 2013). Estudo mais recente (ERICA - Estudo de Riscos Cardiovasculares em Adolescentes), com representatividade para municípios de médio e grande porte em nível nacional e regional, realizado entre 2013 e 2014 com 71.791 estudantes de 12 a 17 anos, reafirmou os dados da POF 2008-2009, com pequenas diferenças: sucos e refrescos ficaram em terceiro lugar entre os alimentos mais consumidos (56,0\%), pães, em quarto (53,0\%), carne bovina, em quinto (52,0\%), e refrigerantes, em sexto lugar (45,0\%) (Souza et al, 2016), sendo sua prevalência mais do que o dobro do encontrado na POF.

Este consumo, apesar de ainda manter alimentos tradicionais na alimentação, implica o perfil nutricional inadequado desses adolescentes: é observada contribuição energética proveniente de açúcares livres e de ácidos graxos saturados acima do recomendado e inadequação de diversos micronutrientes, sendo o cálcio, fósforo, vitamina $E$, vitamina $A$ e sódio os que apresentaram maior inadequação (Souza et al, 2016). Apesar disso, observou-se que comportamentos alimentares saudáveis ainda são presentes no cotidiano desses adolescentes, como consumir café da manhã, realizar refeições compartilhadas com pais ou responsáveis e ingerir cinco ou mais copos de água por dia, sendo tais comportamentos influenciados por sexo, idade, escolaridade materna, tipo de escola (pública ou privada), turno de estudo ou região geográfica (Barufaldi et al, 2016). 
Dados da POF mostram que, quando comparados aos adultos e idosos, os adolescentes destacam-se pelo pior perfil dietético, com menores frequências de consumo de feijão e saladas e maiores frequências de consumo de alimentos ultraprocessados (refrigerantes, sucos e refrescos, biscoitos recheados, embutidos, sanduíches e salgados) (IBGE, 2011a), o que pode implicar o aumento do excesso de peso e doenças crônicas na população adulta nos próximos anos.

A PNS 2013, realizada com moradores maiores de 18 anos, mostrou que, mais de $70 \%$ da população adulta consome feijão regularmente, porém, somente $37,3 \%$ consomem cinco ou mais frutas/hortaliças e $54,6 \%$ realizam consumo regular de peixe e mais de $60,6 \%$ consomem leite integral. Ainda, o consumo de carne ou frango com excesso de gordura, o consumo regular de refrigerantes/sucos artificiais, doces e sal apresentaram prevalências de $37,2 \%, 23,4 \%, 21,7 \%$ e $14,2 \%$, respectivamente (IBGE, 2015d).

São observadas diferenças relacionadas a fatores sociodemográficos: o consumo de carnes com excesso de gordura, de leite integral e de refrigerantes foram mais frequentes na Região Centro-Oeste e Sul (somente carnes com excesso de gordura), entre homens, jovens e pessoas com menor nível de instrução; o consumo de doces foi maior entre pessoas com maior escolaridade, residentes área urbana e na Região Sul (Claro et al, 2015); feijão foi mais consumido na Região Centro-Oeste e Sudeste, por homens, indivíduos com menor escolaridade, de cor preta/parda e residentes na área rural; o consumo de frutas e hortaliças foi maior nas Regiões Centro-Oeste e Sudeste, entre mulheres, pessoas acima de 60 anos, de cor branca e residentes na área urbana; já os peixes foram mais consumidos na Região Norte, por indivíduos mais velhos, de maior escolaridade e residentes em áreas rurais (Jaime et al, 2015). Em relação ao consumo autorreferido de sal foi verificada maior prevalência na Região Sul, entre homens, sujeitos de 18 a 29 anos, com Ensino Superior completo e residentes na área urbana (Oliveira et al, 2015).

Apesar do alto consumo de alimentos não saudáveis considerados fatores de risco para doenças crônicas não-transmissíveis (DCNT) e de a média nacional de consumo de frutas, hortaliças e peixes ser baixa, ainda é grande a presença de alimentos marcadores de alimentação saudável na dieta da população brasileira (Jaime et al, 2015; Claro et al, 2015). Este perfil alimentar, aliado aos fatores culturais e simbólicos e à biodiversidade brasileira, pode ser considerado cenário ainda 
favorável para o fortalecimento e resgate dos hábitos alimentares e da dimensão cultural da alimentação (Consea, 2015).

As práticas alimentares da população brasileira também indicam comportamentos relacionados ao estilo de vida. Quando observados os dados da POF 2008-2009, verifica-se que quase um quinto das calorias consumidas provinha da alimentação fora do domicílio (IBGE, 2011a), composta majoritariamente por alimentos ultraprocessados e de alta densidade energética (Bezerra et al, 2013). O consumo de alimentos fora de casa era realizado por $40 \%$ da população, variando de acordo com variáveis socioeconômicas e demográficas: era maior entre a população mais jovem, com maior renda, entre homens e residentes na área urbana (Bezerra et al, 2013).

Quando observadas informações obtidas pelo Sisvan de 41.449 adolescentes de 10 a 19 anos (65,3\% mulheres), 102.501 adultos (79,3\% mulheres) e 29.360 idosos (60,4\% mulheres) acompanhados pela atenção básica em 2015, verifica-se padrão alimentar semelhante ao identificado em inquéritos nacionais, porém, tanto as prevalências dos marcadores da alimentação saudável, quanto dos marcadores não saudáveis, são maiores do que as encontradas nesses inquéritos em todas as faixas etárias. Verifica-se ainda importante redução no consumo de alimentos marcadores de alimentação não-saudável com aumento da idade (Figura 1) (Sisvan, 2016).

Figura 1 - Consumo alimentar de adolescentes, adultos e idosos no Brasil - 2016.

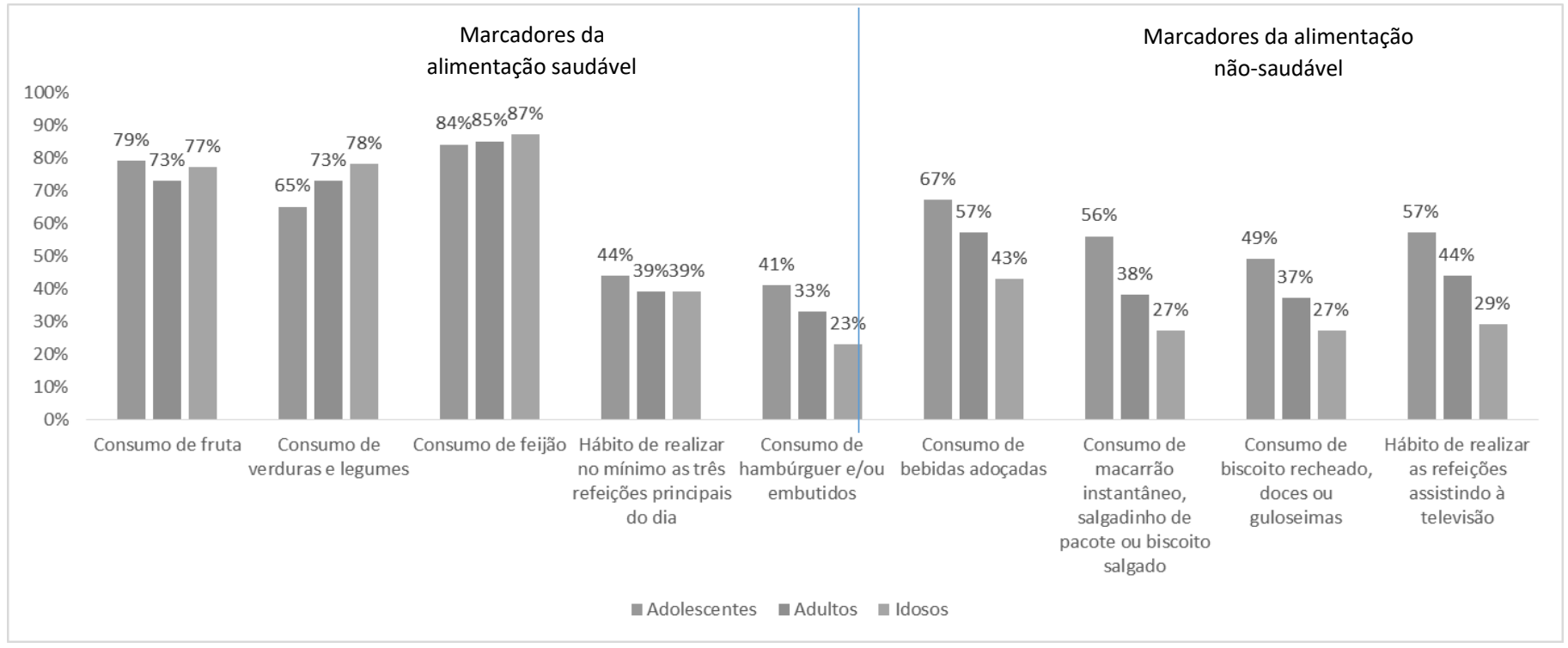

Fonte: Ministério da Saúde. Sistema de Vigilância Alimentar e Nutricional. Dados de 2015. 
Os dados do Sisvan sugerem que, apesar dessa população também ser vulnerável ao consumo de alimentos ultraprocessados, a preservação da alimentação tradicional, com prevalência do consumo de frutas, verduras e legumes e feijão muito acima do encontrado na população geral, podem estar mais presentes em seu cotidiano, devendo isso ser reforçado pelas equipes de saúde.

O cenário alimentar da população brasileira pode responder pelo perfil nutricional, que vem apresentando alta taxa de crescimento do excesso de peso nos últimos anos. Entre os adultos, em inquérito nacional realizado entre 1974-1975, a prevalência de excesso de peso era de 18,5\% entre homens e 28,7\% entre mulheres. A PNS 2013 mostrou que o excesso de peso já alcança mais da metade da população (55,6\% entre homens e 58,2\% entre mulheres), sendo que a média de prevalência aumenta à medida que a população envelhece, dos 18 aos 64 anos a prevalência passa de 32,8\% a 68,3\%, diminuindo a partir desta idade. Em relação à obesidade, a prevalência aumentou de cerca de 2,0\% em 1974-1975 para 20,8\% da população em 2013, com a mesma tendência de aumento conforme idade (IBGE, 2015). Além da idade, foi demonstrada tendência de crescimento entre adultos em todas as regiões, sexo e escolaridade (Malta et al, 2016).

Além dos dados de excesso de peso e obesidade, mais de um terço da população acima de 18 anos (37,7\%) possuía a medida de circunferência de cintura aumentada, sendo esse percentual muito maior entre as mulheres $(52,1 \%)$ em comparação aos homens (21,8\%), e 36,9\% referiam ter, pelo menos, uma doença crônica em 2013 (IBGE, 2015).

Destaca-se que as principais DCNT, muitas delas relacionadas à alimentação e ao sedentarismo, são responsáveis por grande parte das mortes até os 70 anos, pelo desenvolvimento de incapacidades que reduzem a qualidade de vida e impactar no sistema de saúde (Schmidt et al, 2011). O excesso de peso responde por 70,6\% do diabetes mellitus entre as mulheres e por 60,3\%, entre os homens (Flor et al, 2015), além de aumentar o custo individual (Canella, Novaes e Levy, 2015) e ter elevado custo para o SUS (Oliveira, 2013).

Entre adolescentes, o aumento de excesso de peso e obesidade é ainda mais expressivo, com grande crescimento da prevalência entre 1975 e 2008-2009 em todos sexos, faixas etárias, regiões brasileiras e quintis de renda. $O$ excesso de peso aumentou de $3,7 \%$ para $21,7 \%$ no sexo masculino e de $7,6 \%$ para $19,4 \%$ no sexo feminino e a obesidade cresceu de $0,4 \%$ para $5,9 \%$ no sexo masculino e de $0,7 \%$ para 
4,0\% no sexo feminino (IBGE, 2010). Contudo, destaca-se que houve redução da desnutrição (IBGE, 2010) e aumento da estatura em ambos os sexos, sendo verificado que a taxa de incremento de altura desempenha papel protetor contra o excesso de peso (Conde, Rinaldi e Enes, 2016).

O ERICA, realizado em 2013-2014, apresentou prevalências de 17,1\% de sobrepeso e $8,4 \%$ de obesidade entre adolescentes de 12 a 17 anos (Bloch et al, 2016). Neste estudo também foi encontrada prevalência de $20,1 \%$ dos adolescentes com hipercolesterolemia (Faria Neto et al, 2016), 9,6\%, com hipertensão arterial (Bloch et al, 2016), 7,8\%, com hipertrigliceridemia, 3,5\%, com LDL-colesterol elevado (Faria Neto et al, 2016) e 2,6\%, com síndrome metabólica (Kuschnir et al, 2016). Além disso, verificou-se que $17,8 \%$ da prevalência de hipertensão podia ser atribuída à obesidade (Bloch et al, 2016).

No caso de crianças, é observada a mesma tendência de crescimento das prevalências de excesso de peso e obesidade. De 1974-1975 a 2008-2009, as prevalências aumentaram em cerca de três e seis vezes, respectivamente, entre crianças de cinco a nove anos, sendo que, em 2008/2009, o excesso de peso atingia cerca de um terço das crianças (IBGE, 2010). Quando observadas crianças até cinco anos, a prevalência de excesso de peso para altura foi estável entre 1996 (7,2\%) e 2006 (7,3\%), porém, com aumento não estatisticamente significativo nas Regiões Sul e Centro Oeste, onde o excesso de peso passou de $6,9 \%$ para $9,0 \%$ e de $5,3 \%$ para 7,5\%, respectivamente (Ministério da Saúde, 2009a).

É importante destacar que, entre as crianças, houve importante queda da desnutrição crônica e da desnutrição aguda em todas as regiões do país. Entre as crianças menores de cinco a nove anos, entre 1974-1975 e 2008-2009, houve declínio da prevalência de déficit de peso para altura de $29,3 \%$ para $7,2 \%$ no sexo masculino e de $26,7 \%$ para $6,3 \%$, no sexo feminino, enquanto que o déficit de peso para idade reduziu de $5,7 \%$ para $4,3 \%$ no sexo masculino e de $5,4 \%$ para $3,9 \%$ no sexo feminino (IBGE, 2010).

No tocante à desnutrição infantil (menores de 5 anos), quando comparados dados das PNDS 1996 e 2006, verifica-se redução de 13,4\% para 6,7\% do déficit de altura para idade e de $4,2 \%$ para $1,8 \%$ do déficit de peso para idade. A redução da desnutrição crônica foi mais expressiva nas regiões Norte (de $20,7 \%$ para $14,5 \%$ ), Nordeste (de $22,1 \%$ para $5,1 \%$ ) e Centro-Oeste (de $10,7 \%$ para $5,5 \%$ ) e entre a população de menor renda - entre os $20 \%$ mais pobres, verificou-se redução de 
$30,1 \%$ para $9,9 \%$ no déficit de altura para idade, enquanto que o estrato de maior renda passou de 5,3\% para 3,9\% neste período (Ministério da Saúde, 2009). Dois terços deste declínio tiveram como causas o aumento da escolaridade materna (25,7\%), a melhoria do poder aquisitivo $(21,7 \%)$, a expansão dos serviços de saúde $(11,6 \%)$ e a melhoria do saneamento básico (4,3\%) (Monteiro et al, 2009).

No entanto, a desnutrição é ainda apresenta altas prevalências quando observados dados regionais e populações vulneráveis. Na Região Norte, em 2006, a prevalência de déficit de estatura por idade $(14,8 \%)$ era o dobro da média nacional (6,7\%); no mesmo ano, $15,0 \%$ crianças quilombolas apresentavam desnutrição crônica; e, em 2009, a prevalência de déficit de altura por idade era de $26,0 \%$ entre crianças indígenas (MDS, 2007; Ministério da Saúde, 2009a); e em 2012, 8,5\% das crianças beneficiárias do Programa Bolsa Família estavam com desnutrição (Jaime et al, 2014).

Contudo, apesar de a prevalência de desnutrição entre as crianças atendidas pelo Programa Bolsa Família ser maior do que a média nacional, a redução da desnutrição crônica entre 2008 e 2012 foi de 51,4\%, passando de 17,5\%, em 2008, para $8,5 \%$, em 2012. Tais dados sugerem que o acompanhamento contínuo pelas equipes da Atenção Básica tem efeito protetor para a desnutrição infantil. Destaca-se que o mesmo efeito foi encontrado em relação ao excesso de peso, com redução de cerca de $10 \%$ na chance de desenvolvimento da doença (Jaime et al, 2014).

Quando observada a população, de todas as faixas etárias, acompanhada pela atenção básica em 2015, verifica-se que a prevalência de desnutrição crônica e aguda entre menores de cinco anos é maior do que a observada nos inquéritos nacionais. Contudo, a prevalência de excesso de peso é menor em todas as faixas etárias, exceto em adolescentes. Destaca-se ainda a alta prevalência de desnutrição entre idosos (Sisvan, 2015) (Figura 2). 
Figura 2 - Prevalência de desnutrição e excesso de peso na população brasileira acompanhada pela atenção básica, por faixa etária - 2015 .

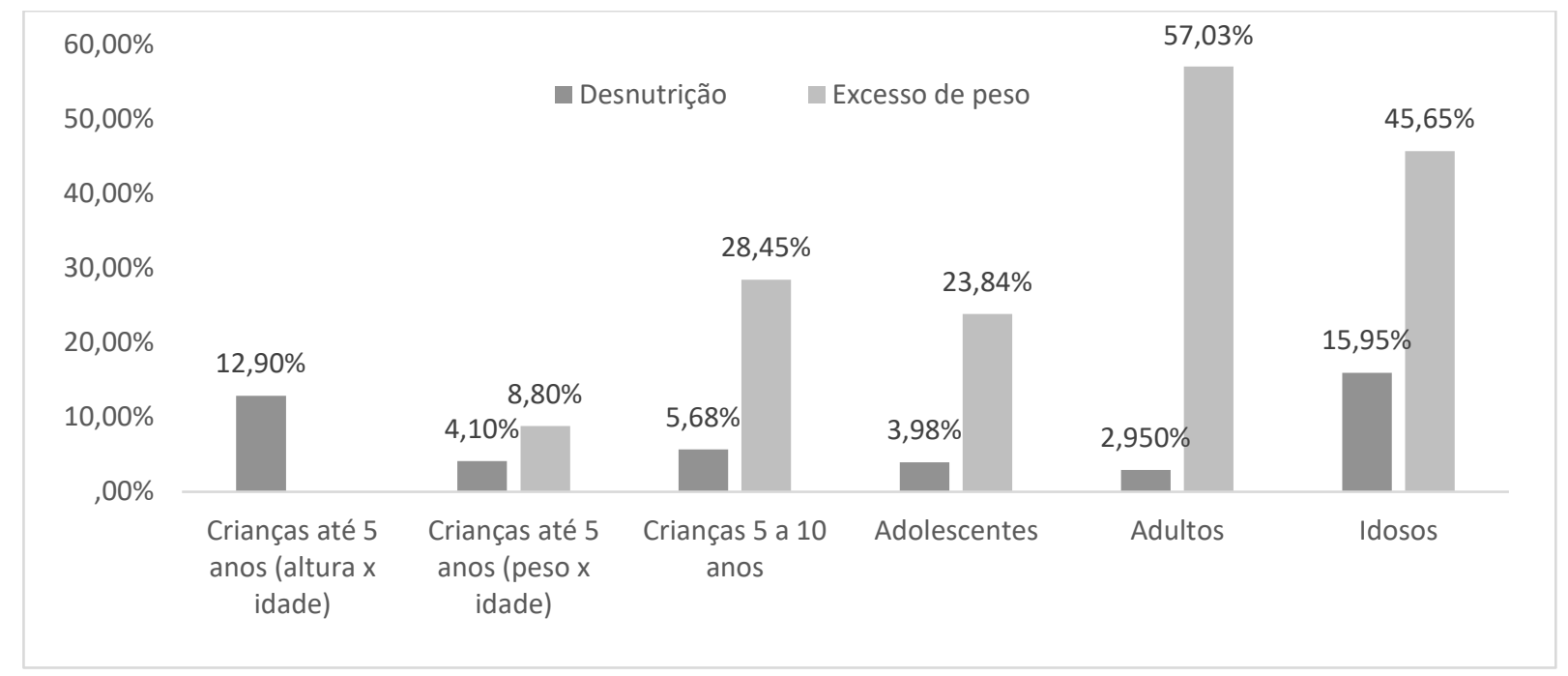

Nota: Dados referentes a 4.100.232 crianças menores de cinco anos, 5.450 .566 crianças entre cinco e dez anos, 3.924.718 adolescentes, 9.241.298 adultos e 474.050 idosos.

Fonte: SISVAN, 2015

De forma paralela à redução da desnutrição e aumento do excesso de peso, também são verificadas altas prevalências de carências nutricionais na população brasileira, especialmente entre crianças e mulheres em idade fértil, podendo estas também estar relacionadas ao padrão alimentar descrito anteriormente, visto que o aumento na participação de alimentos ultraprocessados está associado inversamente ao teor de onze micronutrientes, de 17 estudados, na dieta (vitaminas B12, D, E, niacina e piridoxina, cobre, ferro, fósforo, magnésio, selênio e zinco) (Louzada et al, 2015).

Dados da PNDS mostraram que a anemia estava presente em $20,9 \%$ das crianças menores de 5 anos e em 24,1\% na faixa etária de 6 a 23 meses. Em mulheres em idade fértil a prevalência de anemia observada foi de $29,4 \%$ (Ministério da Saúde, 2009a). Metanálise mostrou que, entre crianças menores de cinco anos, a anemia aparece de forma mais expressiva quando verificados locais e populações mais vulneráveis: em creches e escolas, a média de anemia foi de $52 \%$; entre as acompanhadas por serviços de saúde, de 60,2\%; e em áreas de iniquidades, de $66,5 \%$ (Vieira e Ferreira, 2010). Em crianças indígenas, a prevalência de anemia chega a $51,3 \%$ (FUNASA, 2010). 
Outra carência nutricional considerada problema de saúde pública no Brasil é a deficiência de vitamina A. Em 2006, 17,4\% das crianças menores de cinco anos e $12,3 \%$ das mulheres apresentam esta deficiência, sendo tais prevalências maiores na Região Sudeste (21,6\% e 14,0\%, respectivamente) (Ministério da Saúde, 2009a).

Além dessas duas deficiências, no Brasil, desde 2006 têm sido identificados casos de beribéri (deficiência de tiamina) nos estados do Maranhão, Tocantins e Roraima. Entre 2006 e 2015, foram registrados 2.201 casos, sendo que 48 foram a óbito (Ministério da Saúde, 2016b). Avaliação realizada entre 2011 e 2014 mostrou que a carência acometia majoritariamente adultos do sexo masculino $(70,3 \%)$ e povos indígenas (91,9\%), que realizavam atividades físicas extenuantes $(75,7 \%)$, consumiam bebidas alcóolicas $(70,3 \%)$ e possuíam hábito de fumar $(39,2 \%)$ (Ministério da Saúde, 2016a).

Este perfil nutricional apresentado no Brasil representa uma dupla manifestação da insegurança alimentar e nutricional e um grande desafio para o sistema de saúde do país. 


\subsection{ALIMENTAÇÃO E NUTRIÇÃO NA ATENÇÃO BÁSICA E MELHORIA DO PERFIL ALIMENTAR E NUTRICIONAL}

Com base no complexo cenário alimentar e nutricional brasileiro apresentado no capítulo anterior, é possível reafirmar a necessidade de implementação de ações, estratégias e políticas articuladas voltadas ao seu enfrentamento e identificar potencialidades e desafios para a atuação, especialmente, do sistema de saúde. Destaca-se que a PNAN, publicada em 2011, já reconhece a prevenção e tratamento da obesidade, a desnutrição, as carências nutricionais específicas e as doenças crônicas não transmissíveis relacionadas à alimentação e nutrição como prioridades para a organização da atenção nutricional no SUS, acrescentando ainda as necessidades alimentares especiais, que, apesar de não haver dados de inquéritos nacionais, são identificadas como problemas crescentes que também demandam de organização de cuidado (Ministério da Saúde, 2012a; Pereira et al, 2014).

Para a reversão do quadro, é necessária a realização de diversas estratégias e ações voltadas à promoção da saúde e da alimentação adequada e saudável e à prevenção, ao controle e ao tratamento das doenças e agravos relacionados à alimentação e nutrição, especialmente o excesso de peso, as necessidades alimentares especiais, as carências nutricionais e a desnutrição, esses três últimos, direcionadas a públicos específicos.

Contudo, é importante reconhecer que a saúde é determinada por fatores relacionados às características individuais, ao estilo de vida, às redes sociais e comunitárias, às condições de trabalho e de vida e às condições socioeconômicas, culturais e ambientais, dentre os quais se encontram e também determinam a alimentação e a nutrição (Buss e Pellegrini Filho, 2007; CNDSS, 2008). A adoção de uma alimentação adequada e saudável, por exemplo, depende de diversos fatores que influenciam positiva ou negativamente sobre o padrão alimentar da população, como condições socioeconômicas, divisão desigual entre gêneros e gerações no trabalho doméstico, políticas agrícolas e modos de produção, preço e disponibilidade de alimentos, acesso a informações confiáveis, tempo disponível para a alimentação, existência de ações e estratégias abusivas de marketing e publicidade de alimentos ultraprocessados, cultura alimentar, além de fatores relacionados à comensalidade $\mathrm{e}$ ao ato de comer (Ministério da Saúde, 2014b). 
Assim, agir sobre todos esses fatores implica aliar ações em nível macro, que tenham repercussões sobre os ambientes físico, econômico e sociocultural para desestimular comportamentos não saudáveis e facilitar a adoção de comportamentos saudáveis, a ações em nível micro, ou seja, relacionadas à motivação, informação adequada e educação alimentar e nutricional, para empoderar os indivíduos, aumentando seu poder de escolha consciente e reduzir vulnerabilidades ao ambiente. Além disso, é fundamental a oferta da atenção integral à saúde aos sujeitos com doenças relacionadas à alimentação e nutrição, com vistas ao seu tratamento e controle (Egger e Swinburn, 1997; Roberto et al, 2015).

Nesse contexto, tomadas de decisão em políticas públicas de diferentes setores têm impacto e devem levar em conta as consequências para a saúde e nutrição, atuar no enfrentamento de iniquidades e estabelecer intervenções que favoreçam mudanças de comportamento e contribuam para a melhoria das condições de saúde, nutrição e bem-estar da população (Buss e Pellegrini Filho, 2007; Declaração de Helsinque..., 2013).

Sabe-se que o setor saúde não dá conta de resolver os problemas relacionados à alimentação e nutrição sem articulação com os demais setores (Alves e Jaime, 2014), porém, possui papel fundamental para a promoção da saúde e da alimentação adequada e saudável e a oferta de serviços voltados à prevenção, tratamento e reabilitação de doenças e agravos relacionados à alimentação e nutrição, que, em seu conjunto, compõem a organização da atenção nutricional no SUS (Ministério da Saúde, 2012a), sendo a base para implementação das diretrizes da PNAN, que representam a contribuição do setor saúde para a garantia da segurança alimentar e nutricional.

Uma das etapas da organização da atenção nutricional corresponde à promoção da alimentação adequada e saudável, a qual deve ter suas ações ancoradas nos campos de atuação e princípios da promoção da saúde, tendo em vista que a PAAS é uma de suas vertentes e a nutrição e a alimentação são determinantes da saúde.

A promoção da saúde é o processo que apoia indivíduos a tornarem-se capazes de melhorar a sua saúde e terem maior participação no controle sobre ela, possuindo como campos de ação a elaboração e implementação de políticas públicas saudáveis, a criação de ambientes favoráveis à saúde, o reforço da ação comunitária, o desenvolvimento de habilidades pessoas e a reorientação dos sistemas de saúde. 
Suas ações são norteadas pelos princípios da equidade, participação social, empoderamento, concepção holística, intersetorialidade, ações multiestratégicas e sustentabilidade (Buss, 2003). Garantia de paz e de direitos humanos também constituem-se como base para a viabilização da promoção da saúde, a qual ainda sofre influência direta e indireta de diferentes visões políticas e ideologias (Declaração de Curitiba, 2016).

De acordo com a PNAN, a PAAS, definida como "conjunto de estratégias que proporcionem aos indivíduos e coletividades a realização de práticas alimentares apropriadas aos seus aspectos biológicos e socioculturais, bem como ao uso sustentável do meio ambiente", deve ter ações fundamentadas em três dimensões: incentivo (informações para empoderamento e adoção dessas práticas no cotidiano dos sujeitos ou grupos populacionais), apoio (facilitação da adoção dessas práticas) e proteção (implementação de medidas regulatórias) (Ministério da Saúde, 2012a; Castro, Castro e Gugelmin, 2012). O setor saúde tem potencial de atuação em todas elas, a partir da indução e implantação de ações que vão desde a vigilância sanitária e da regulação da publicidade e rotulagem de alimentos à realização de ações de educação alimentar e nutricional e de apoio, com a garantia da existência de bancos de leite humano e da oferta de alimentação adequada e saudável em ambientes institucionais, como hospitais, por exemplo.

Destaca-se a importância da realização de ações de promoção da saúde e da alimentação adequada e saudável em todas as etapas do cuidado, tendo em vista que uma alimentação adequada e saudável, além de poder contribuir para uma melhor qualidade de vida, também previne uma série de doenças (Ministério da Saúde, 2012a; WHO, 2003; WCRF/AICR, 2007; Hartley et al, 2013).

A prevenção de doenças objetiva evitar o surgimento de doenças ou agravos ou minimizar suas consequências (Ministério da Saúde, 2009b). Assim como a PAAS, a prevenção e o tratamento de doenças e agravos relacionados à alimentação e nutrição devem ser considerados para a organização da atenção nutricional no SUS como parte do cuidado integral na RAS (Ministério da Saúde, 2012a).

No caso da desnutrição e das carências nutricionais, a prevenção está relacionada, principalmente, à garantia de condições socioeconômicas que permitam acesso à alimentação adequada e saudável. Contudo, já foi demonstrado também que outros fatores influenciam a redução da desnutrição infantil, como a garantia de saneamento básico e a maior escolaridade materna. No tocante aos sistemas de 
saúde, no Brasil, a garantia de maior acesso a serviços de saúde correspondeu a 11,6\% da redução da desnutrição infantil entre 1996 e 2007 (Monteiro et al, 2009)

As carências nutricionais mais prevalentes no Brasil (vitamina A e ferro) podem ocorrer simultaneamente, trazendo consequências negativas para a saúde, produtividade e crescimento econômico. Para sua prevenção e tratamento, é recomendado que sejam utilizadas, pelos sistemas de saúde, estratégias de promoção do aleitamento materno exclusivo até o sexto mês, promoção da alimentação adequada e saudável, atenção aos casos de infecção parasitária, suplementação com micronutrientes e fortificação caseira com micronutrientes em pó; ainda, a prevenção pode ser realizada com fortificação de alimentos altamente consumidos pela população (OMS, 2013).

Especificamente no caso da deficiência de tiamina, apesar da natureza multicausal também relacionada à pobreza e à fome, há especificidades em sua origem relacionadas à alimentação monótona baseada em arroz polido e elevado teor de carboidrato simples, além de atingir grupos específicos, como alcoolistas, gestantes, crianças e pessoas que exercem atividade física extenuante, devendo os profissionais de saúde estarem mais atentos a esses grupos populacionais. A prevenção é realizada por meio de enfrentamento intersetorial de fatores determinantes, além da promoção da alimentação adequada e saudável e suplementação profilática de tiamina, que podem ser realizados nos sistemas de saúde, assim como o tratamento, que se baseia na suplementação com este micronutriente (Ministério da Saúde, 2012b).

O excesso de peso e as doenças crônicas não-transmissíveis relacionadas à alimentação e nutrição estão relacionadas, além de outros fatores, ao consumo alimentar e à prática de atividade física, necessitando de uma série de ações intersetoriais, com vistas à sua prevenção e controle. Tais ações envolvem regulação de publicidade e propaganda, rotulagem, medidas fiscais, melhoria nutricional de alimentos ultraprocessados, limitação do tamanho das porções, taxação de bebidas açucaradas e a outras estratégias de promoção da alimentação adequada e saudável, destacando-se o aleitamento materno exclusivo, nos macroambientes e microambientes (Yan et al, 2014; Hawkes et al, 2015; Hollands et al, 2015; Roberto et al, 2015; WHO, 2016).

As ações preventivas e de controle dessas doenças são majoritariamente intersetoriais, contando com importante papel do setor saúde. No tocante à 
assistência, ao tratamento e à reabilitação, a responsabilidade incide, principalmente, sobre esse setor.

Nesse sentido, no caso do excesso de peso, atual revisão da literatura mostrou que existem diversas modalidades terapêuticas que podem ser utilizadas no tratamento de adultos com sobrepeso e obesidade, ressaltando-se a necessidade de alinhamento entre a intensidade deste ao grau de obesidade e a integração entre abordagem clínica e ações na comunidade para a implementação dessas estratégias. Contudo, os autores verificaram que profissionais de saúde não são formados para atuarem no tratamento da obesidade e há poucas opções terapêuticas voltadas à obesidade infantil. Foram identificadas como estratégias promissoras para o cuidado o uso de novas tecnologias e a oferta de cuidados multidisciplinares, especialmente para indivíduos com sobrepeso e obesidade leve a moderada (Dietz et al, 2015). Outros estudos mostram que intervenções multidisciplinares desenvolvidas em longo prazo são mais eficientes no controle da obesidade do que intervenções tradicionais, tanto para adultos, quanto para crianças e adolescentes (Snethen, Broome e Cashin, 2006; Donini et al, 2009).

Destacam-se ainda doenças associadas à alimentação e à nutrição, como diabetes, hipertensão, outras doenças cardiovasculares, entre outras doenças e suas consequências, que também implicam necessidade de outras estratégias de controle e tratamento e alto custo para os sistemas de saúde (Schmidt et al, 2011; Oliveira, 2013).

Nesse contexto complexo e amplo de atuação e de ações diversas voltadas à reversão do quadro alimentar e nutricional, a atenção básica pode desempenhar papel estratégico por sua capilaridade, inserção e conhecimento de território e do perfil do demográfico e epidemiológico e proximidade e criação de vínculo com a população (Jaime et al, 2011).

No Brasil, a atenção básica é caracterizada pelo conjunto de ações de saúde, no âmbito individual e coletivo, que abrangem a promoção e a proteção da saúde, a prevenção de agravos, o diagnóstico, o tratamento, a reabilitação, a redução de danos e a manutenção da saúde, tendo por objetivo o desenvolvimento de uma atenção integral que tenha impacto na situação, determinantes e condicionantes de saúde e gere autonomia dos indivíduos. É norteada pela Política Nacional de Atenção Básica (PNAB), publicada em 2006 e revisada em 2011, sendo pautada nos princípios universalidade, da acessibilidade e coordenação do cuidado, do vínculo e 
continuidade, da integralidade, da responsabilização, da humanização, da equidade e da participação social (Ministério da Saúde, 2011b).

$A$ atenção básica possui diversos modelos de equipes adaptadas às diferentes populações e realidades brasileiras, tendo como modelo prioritário as equipes da Estratégia Saúde da Família (ESF), que podem contar com apoio de profissionais de diversas áreas de conhecimento do Núcleo de Apoio à Saúde da Família (NASF), incluindo o profissional nutricionista. A atuação conjunta das equipes contribui para a ampliação de ofertas de ações, sua resolutividade e abrangência (Ministério da Saúde, 2011b; 2012c).

Destaca-se que, entre 2010 e 2014, houve reposicionamento do papel e da importância da atenção básica no Governo Federal e no SUS, tendo essa maior prioridade, com a instituição de marcos legais, entre eles a revisão da própria PNAB que havia sido publicada em 2006, ampliação de aporte financeiro repassado aos municípios para a implementação das ações e estruturação das Unidades Básicas de Saúde (UBS) e criação de programas que se propunham a ampliar e qualificar o acesso da população à atenção básica, como o Programa de Melhoria do Acesso e da Qualidade na Atenção Básica (PMAQ-AB) ${ }^{\mathrm{a}}$ e o Programa Mais Médicos ${ }^{\mathrm{b}}$, mesmo havendo estabilização do orçamento geral da saúde no período (Magalhães Junior e Pinto, 2014; Vieira e Bevenides, 2016).

Tal cenário resultou em uma atenção básica implementada em todos os municípios e ampliação de sua cobertura de $66,2 \%$, em 2010 , para $70,2 \%$, em junho de 2016. Além disso, a ESF que cobria $51,7 \%$ da população em 5.272 municípios passou a cobrir $64,3 \%$ da população em 5.481 municípios. Os NASF, que correspondiam a somente 1.250 implantados em 2010, passaram a ser $4.326 \mathrm{em}$ junho de 2016 (Portal do DAB, 2016).

Destaca-se neste contexto o crescimento da incorporação de nutricionistas tanto nas equipes de atenção básica (eAB) tradicionais e equipes de Saúde da Família

\footnotetext{
a O Programa de Melhoria do Acesso e da Qualidade da Atenção Básica (PMAQ-AB) foi instituído em 2011, com o objetivo de induzir a ampliação do acesso e a melhoria da qualidade da atenção básica, a partir de um conjunto de estratégias de qualificação, acompanhamento e avaliação do trabalho das equipes de saúde, gerando aumento do repasse de recursos federais para os municípios que atingem melhora no padrão de qualidade. (Brasil, 2011 - Portaria)

b O Programa Mais Médicos foi instituído em 2013 para proporcionar acesso e melhoria do atendimento aos usuários da atenção básica, levando mais médicos para regiões onde há escassez ou ausência desses profissionais. No escopo do programa também estão incluídos investimentos para construção, reforma e ampliação de Unidades Básicas de Saúde, além de novas vagas de graduação, e residência médica para qualificar a formação desses profissionais. (Brasil, 2013 - Lei e Decreto)
} 
(eSF), quanto nos NASF (Vasconcelos, Sousa e Santos, 2015). Apesar de se reconhecer que esse não é o único profissional responsável pela realização de ações de alimentação e nutrição, a inserção de nutricionistas na atenção básica pode potencializá-las, pelos seus conhecimentos técnicos e possibilidade de compartilhamento de saberes, práticas e responsabilidades com os demais profissionais da AB (Jaime et al, 2011; Jaime et al, 2011; Brasil, 2012a; Boreli et al, 2015; Ministério da Saúde, 2016d).

Além do aumento numérico, diversas outras melhorias são observadas no período, como alta aprovação pelos usuários, crescente informatização, maior participação de profissionais de diversas áreas, resolutividade e facilidade no acesso ao serviço, a medicamentos, a exames e a ações de imunização, de saúde da mulher, da criança, da gestante e do adulto, além de menor tempo de espera. Contudo, apesar de a coordenação do cuidado, do vínculo e continuidade e da integralidade constituírem-se como alguns dos princípios da $A B$, ainda são observadas falhas na oferta de procedimentos comuns e deficiências na coordenação do cuidado e na gestão clínica de casos que necessitam de cuidado continuado (Magalhães Junior e Pinto, 2014).

Mesmo com as falhas identificadas na AB, foi possível observar até 2014, como mencionado nos parágrafos anteriores, um período de crescente investimento e melhorias na atenção básica. Contudo, é importante ressaltar que, a partir de 2015, houve contingenciamento orçamentário em diversas políticas sociais, incluindo a saúde, em função da crise político-econômica existente no país e no mundo, que impediu habilitações de serviços, expansão de atividades e lançamento de novas políticas. No âmbito da atenção básica, a indisponibilidade financeira impactou no não credenciamento de novas equipes de NASF e atrasos em transferências de recursos de custeio de equipes e programas, como o Programa Saúde na Escola e Academia da Saúde (Ministério da Saúde, 2016e).

O fortalecimento da atenção básica pode resultar na melhoria das condições de saúde e de nutrição da população brasileira, visto que impactos positivos já foram encontrados em função da expansão da ESF e do acompanhamento contínuo da população pela atenção básica, comprovando sua importância e necessidade de garantia de financiamento. São conhecidas melhorias relacionadas à redução da mortalidade infantil (Aquino, Oliveira e Barreto, 2009; Rasella, Aquino e Barreto, 2010; Rasella et al, 2013; Hone et al, 2017), da mortalidade cardio e cerebrovascular 
(Rasella et al, 2014), de internações por condições sensíveis à atenção primária (Macinko et al, 2010; Macincko et al, 2011), de desnutrição (Monteiro et al, 2009; Jaime et al, 2014) e obesidade (Ministério da Saúde, 2014e).

Tais dados levam a supor que a atenção básica tem papel estratégico para a realização de ações de alimentação e nutrição, sendo seu fortalecimento um investimento também para a organização da atenção nutricional no SUS que, além de representar importante contribuição setorial para a garantia da segurança alimentar e nutricional da população brasileira, pode contribuir para a reversão do quadro nutricional apresentado no capítulo anterior.

Por estar mais próxima à população, os profissionais de saúde da atenção básica podem realizar diagnóstico do território e sobre a população local e ter olhar ampliado sobre todos os aspectos envolvidos na determinação das escolhas alimentares dos indivíduos, famílias e comunidades. É possível que a realização de aconselhamento nutricional individual e coletivo tenha base na cultura, oferta e custo de alimentos no território, nas condições econômicas das famílias, na existência de equipamentos públicos de alimentação e de espaços livres que permitam a implantação de hortas, na alimentação realizada no ambiente escolar, no conhecimento acerca de acesso à água tratada, entre outros fatores que podem ser identificados pelas equipes (Ferreira e Magalhães, 2007). Além disso, as equipes podem ter algum nível de intervenção para modificar o microambiente da comunidade, além de atuarem sobre determinantes individuais, sendo, para isso, necessária a realização de articulações intersetoriais e parcerias no território.

As ações de alimentação e nutrição na atenção básica passam também pela realização de diagnóstico, controle e tratamento de carências nutricionais, desnutrição, obesidade e de doenças associadas à alimentação e nutrição, o que exige aliar ações de promoção da saúde à prática clínica, assistência ambulatorial e articulação com os demais pontos da RAS, com vistas à garantia do cuidado integral, e implica prévia organização de fluxos de encaminhamento entre os pontos da rede e boa estruturação dos serviços. Para tanto, é fundamental a garantia de financiamento e uso adequado e transparente dos recursos públicos, infraestrutura e recursos humanos e materiais suficientes, contratações não precárias, oferta de qualificação e apoio pela gestão, indução da atenção equânime e com participação e controle social (Gervas, 2011; Ministério da Saúde, 2011b; 2012a). 
Nesse sentido, em âmbito federal, uma série de programas, ações e iniciativas específicos de alimentação e nutrição na atenção básica têm sido realizadas, sendo que os cuidados em alimentação e nutrição relacionam-se à vigilância alimentar e nutricional, à promoção da saúde e da alimentação adequada e saudável e ao controle e prevenção de doenças e agravos relacionados à alimentação e nutrição, especialmente obesidade e carências nutricionais, além de ações intersetoriais transversais que visam o enfrentamento de determinantes e condicionantes de alimentação e nutrição e a qualificação local da atenção nutricional (Jaime et al, 2011; Jaime e Santos, 2014).

Apesar das ações, em âmbito nacionais, serem conhecidas, por serem mais publicizadas, não só por meio dos instrumentos de gestão, como os Planos Plurianuais e relatórios de gestão, mas também em publicações científicas, não se conhece o que as equipes têm implementado na atenção básica em relação à alimentação e nutrição e como tem sido realizada sua gestão local, municipal e estadual. Igualmente, não se tem descrito de forma consolidada como este tema tem sido incorporado à agenda de pesquisas das universidades e divulgado no meio científico.

Atualmente, há duas revisões que abordam o tema, trazendo importantes dados relacionados à produção científica e aos grupos de pesquisa existentes, porém, correspondem a revisões até 2011 e 2013, respectivamente, categorizam os temas encontrados nas publicações sem aprofundar sua descrição e não discriminam o que é produzido pelas equipes de atenção básica e gestão ou pelos pesquisadores (Canella, Silva e Jaime, 2013; Vasconcelos e Santos, 2014).

Nesse contexto, observa-se a necessidade de atualizar a revisão da literatura científica sobre a temática, procurando identificar os aspectos não encontrados nas duas revisões mencionadas acima e descrever, de forma mais detalhada, as ações realizadas pelo serviço, pela gestão e pela academia na atenção básica relacionadas à alimentação e nutrição.

Além disso, apesar de não existir um retrato nacional descrito na literatura científica sobre as ações desenvolvidas no serviço, há algumas fontes de dados que podem ser utilizadas para sua obtenção, como a IV Mostra Nacional de Experiências em Atenção Básica/Saúde da Família.

A IV Mostra de Experiências em Atenção Básica/Saúde da Família, realizada em 2013, tinha como principal foco a inscrição de experiências provenientes de 
trabalhadores e gestores da $A B$ e contou com a aprovação de mais de mil relatos sobre diversos temas, incluindo alimentação e nutrição, e ações desenvolvidas na $A B$ ou em articulação com essa (Ministério da Saúde, 2016c), sendo que os relatos estão disponíveis para acesso público e podem constituir-se fonte a ser explorada para conhecer as ações de alimentação e nutrição na $A B$.

Reconhecendo-se que o monitoramento e a avaliação são essenciais para implementação efetiva das políticas públicas e devem ser realizados de forma sistemática, sendo fundamentais para reorganizar sistemas e serviços de saúde e subsidiar a tomada de decisão dos gestores públicos quanto à definição de problemas, avaliação do impacto das intervenções sobre a saúde da população e orientação das estratégias desenvolvidas, sendo a descrição uma etapa essencial para sua realização (Aquino, Medina e Abdon, 2014), esta dissertação se propõe a analisar as ações de alimentação e nutrição no âmbito da atenção básica, a partir da literatura científica atual e das experiências aprovadas na IV Mostra de Experiências em Atenção Básica/Saúde da Família. 


\section{OBJETIVOS}

\subsection{OBJETIVO GERAL}

Analisar as ações de alimentação e nutrição no âmbito da Atenção Básica no Brasil.

\subsection{OBJETIVOS ESPECÍFICOS}

- Conhecer a produção científica sobre alimentação e nutrição na atenção básica.

- Descrever as experiências relacionadas à alimentação e nutrição na atenção básica aprovadas na IV Mostra Nacional de Experiências em Atenção Básica/Saúde da Família. 


\section{MÉTODOS}

Para atingir os objetivos descritos no capítulo anterior empregaram-se duas diferentes metodologias. No primeiro caso foi realizada uma revisão sistemática da literatura científica com síntese narrativa dos resultados encontrados. No segundo, foram descritos, quantitativamente, os relatos da IV Mostra de Experiências em Atenção Básica/Saúde da Família de 2014.

\subsection{REVISÃO SISTEMÁTICA}

De acordo com o Preferred Reporting Items for Systematic Review and MetaAnalysis Protocols (PRISMA-P) (Shamseer et al, 2015), revisões sistemáticas reúnem evidências relevantes que se encaixam critérios de elegibilidade pré-especificados para responder a uma pergunta de pesquisa específica, em que são utilizados métodos explícitos e sistemáticos para minimizar os vieses na identificação, seleção, síntese e resumo dos estudos. As principais características de revisões sistemáticas são: (a) conjunto definido de objetivos com uma metodologia explícita e reprodutível; (b) pesquisa sistemática que busque identificar todos os estudos que preencham os critérios de elegibilidade; (c) avaliação da validade dos resultados dos estudos incluídos; e (d) apresentação sistemática e síntese das características e achados dos estudos incluídos.

Com base nas etapas do PRISMA (Moher et al, 2009), foi realizada uma revisão sistemática para responder à pergunta "O que tem sido desenvolvido em relação à $A \& N$ no âmbito da $A B$, de acordo com a literatura científica?", de forma a retratar o que as equipes têm implementado na atenção básica e o que a gestão e as universidades têm produzido sobre a atenção básica referente à alimentação e nutrição. Seguindo as orientações da metodologia escolhida, a revisão foi registrada no Registro Prospectivo Internacional de Revisões Sistemáticas (PROSPERO) em 11 de Maio de 2016 (número de registro CRD42016038973).

A revisão foi conduzida entre agosto e novembro de 2015, sendo definido o ano da publicação da primeira versão da PNAB como marco para seleção dos artigos. A 
PNAB regulamentou a implantação e operacionalização das ações na $A B$, estabelecendo fundamentos e definindo áreas estratégicas relacionadas à $A \& N$, como a eliminação da desnutrição infantil, o controle do diabetes mellitus e da hipertensão arterial, a saúde da mulher e da criança e a promoção da saúde (Ministério da Saúde, 2006), o que pode ter influenciado o desenvolvimento das ações.

Pelo reconhecimento de que existem intervalos não definidos entre a publicação de diretrizes nacionais e a adequação destas aos serviços, quando necessária, e entre a elaboração dos artigos e sua publicação em periódicos científicos, foram incluídos estudos desenvolvidos a partir de 2007.

Quando o estudo foi realizado durante mais de um ano, foi considerado seu ano de início para caracterização. Artigos de discussão e opinião, foram incluídos por serem relevantes, especialmente, para descrição do que vem sendo realizado pelo governo federal, não sendo seu ano de desenvolvimento considerado.

O público-alvo dos artigos foi definido com vistas a somente identificar artigos que trouxessem dados de ações realizadas com a população acompanhada ou que residiam em território de abrangência de UBS, bem como profissionais envolvidos na atenção básica, como gestores das três esferas e profissionais de saúde atuantes na atenção básica. Assim, foram incluídos: população coberta pelas UBS/equipes de atenção básica, ESF ou NASF, usuários, profissionais e gestores da atenção básica.

O tipo de ação desenvolvida ou abordada nos artigos também foram definidos para haver maior possibilidade de inclusão de todos os tipos de ações relacionadas à alimentação e nutrição. Para tanto, foram identificadas ações na PNAN (Ministério da Saúde, 2012a) e na Matriz de Matriz de Ações de Alimentação e Nutrição na Atenção Básica à Saúde (Ministério da Saúde, 2009b). Assim, foram incluídos estudos que abordavam/desenvolveram ações de VAN, PAAS, prevenção, controle, diagnóstico, tratamento e reabilitação de doenças e agravos relacionados à $A \& N$ ou que tratavam da organização (local, municipal, estadual e federal) ou oferta de ações e serviços relacionados à $A \& N$ na $A B$.

Foram excluídos artigos não conduzidos no Brasil; que não mencionavam ano de desenvolvimento ou iniciaram seu desenvolvimento antes de 2007; que não tinham a $A \& N$ como objeto ou não eram relacionados à atenção básica; e com dados de inquéritos nacionais não realizados na atenção básica.

Uma vez que o artigo objetivava a descrição das ações realizadas e não dos resultados dessas ações e não propunha a realização de análise quantitativa de tais 
resultados, as autoras optaram pela não avaliação da qualidade do artigo, como preconizado no protocolo de revisão sistemática utilizado, para possibilitar maior inclusão de artigos à análise. Ressalta-se que modificações de etapas em circunstâncias específicas é prevista pelos autores do protocolo adotado (Moher et al, 2009).

Estratégia de busca e corpus de análise

Utilizaram-se as bases de dados Lilacs, PUBMED, SCOPUS e Web of Science, tendo como limites artigos originais publicados entre 2007 e 2015.

Para a base de dados Lilacs, foram definidos os seguintes descritores combinados com operadores booleanos: ("primary health care" OR "health center" OR "basic health service" OR "family health" OR "family health strategy") AND ("Food and Nutrition Security" OR "Nutritional Surveillance" OR "Nutritional Status" OR "anthropometry" OR "nutritional assessment" OR "Food and Nutrition Education" OR "food habits" OR "food consumption" OR "diet" OR "feeding" OR "nutrition" OR "nutrition policy"). Nas demais bases, foram utilizados os MeSH: ("primary health care" OR "community health services" OR "family health") AND ("Nutritional Status" OR "nutrition assessment" OR "anthropometry" OR "food habits" OR "food intake" OR "diet" OR "feeding behavior" OR "food security" OR "nutrition policy") AND "Brazil".

Instrumento de síntese dos estudos

Para gerenciamento das informações obtidas, foi elaborada planilha com as seguintes variáveis: tipo de publicação (artigo original, de revisão, discussão/opinião/especial e relato de experiência), ano de publicação do artigo e ano de desenvolvimento do estudo, instituições envolvidas (gestão e serviço - Ministério da Saúde e suas autarquias, Secretarias Estaduais e Municipais de Saúde e rede vinculada; universidades e faculdades brasileiras - públicas e privadas; e instituições de outros países), tema do estudo, participantes da pesquisa e envolvimento de profissionais da gestão/serviço no estudo.

Para gerenciamento de dados de caracterização das ações desenvolvidas, foram identificadas informações sobre: diretrizes da PNAN relacionadas; tipo de ação realizada; sujeito da ação; e se a ação já era desenvolvida pelas equipes/gestores ou 
foi pontualmente realizada para o estudo. Destaca-se que foram consideradas ações: intervenções realizadas pelos pesquisadores nos serviços de $A B$ ou com seus usuários (em geral, metodologia empregada no estudo, como avaliação da alimentação e do estado nutricional e propostas de intervenção) e ações/estratégias desenvolvidas na $A B$ ou pela gestão (em geral, avaliadas pelos pesquisadores e descritas nos resultados). Destaca-se que a classificação do tipo de ação foi realizada com base na ação principal, e não em suas ações complementares, a exemplo da realização de diagnóstico no início e no fim do estudo para avaliação a intervenção.

Em relação às diretrizes da PNAN, considerando que a atenção nutricional "compreende os cuidados relativos à alimentação e nutrição voltados à promoção e proteção da saúde, prevenção, diagnóstico e tratamento de agravos, devendo estar associados às demais ações de atenção à saúde do SUS, para indivíduos, famílias e comunidades" (Ministério da Saúde, 2012a), sendo que ações desenvolvidas tanto na assistência, quanto na gestão correspondem ou possuem impacto direto ou indireto para a organização da atenção nutricional, esta diretriz foi entendida como transversal a todas as ações, não entrando na classificação.

Com o mesmo entendimento de transversalidade, a diretriz Articulação e Cooperação para Segurança Alimentar e Nutricional não entrou entre as diretrizes relacionadas à ação, visto que a realização das ações relacionadas a todas as diretrizes corresponde à concretização da contribuição setorial para a promoção da garantia da segurança alimentar e nutricional (Alves e Jaime, 2014). Já a diretriz "Pesquisa, Inovação e Conhecimento" não foi considerada, por todas as análises estarem, de alguma forma, relacionadas à geração de evidências.

No tocante ao tipo de ação realizada, as ações foram agrupadas em categorias baseadas na Matriz de Ações de Alimentação e Nutrição na Atenção Básica à Saúde (Ministério da Saúde, 2009b), complementadas por categorias identificadas na PNAN (Ministério da Saúde, 2012a), sendo elas: diagnóstico, promoção da saúde e de práticas alimentares adequadas e saudáveis, controle e prevenção de doenças e agravos relacionados à $A \& N$, assistência/tratamento, descrição abrangente das ações e gestão das ações de $A \& N$.

Foram consideradas diagnóstico as ações relacionadas à identificação ou avaliação do estado nutricional e das doenças relacionadas alimentação e nutrição e fatores relacionados (Brasil, 2009b), sendo este item subdivido em (1) nutricional (parâmetros antropométricos, dietéticos - consumo, hábitos alimentares e 
amamentação - , clínicos e bioquímicos); (2) socioeconômico e demográfico (incluindo uso da Escala Brasileira de Insegurança Alimentar, por esta ter o aspecto acesso à alimentação como principal determinante (Segal-Correa e Marin-Leon, 2009); (3) aspectos subjetivos e culturais; (4) hábitos de vida, condições de saúde/histórico de saúde e familiar/doenças associadas e acesso a serviços de saúde; e (5) outros. Nesta categoria também foram incluídos artigos que tratavam de ações de apoio ao diagnóstico nutricional, relacionadas à operacionalização e uso de sistemas de informação em saúde, uso de medidas antropométricas como preditivas de doenças e discussão ou teste de novas ferramentas para diagnóstico em alimentação e nutrição na atenção básica.

As ações foram classificadas como promoção da saúde e de práticas alimentares adequadas e saudáveis quando se tratavam de ações ou atividades fundamentadas nas dimensões de incentivo, visando à difusão de informações para empoderamento e adoção dessas práticas no cotidiano dos sujeitos ou grupos populacionais, ou de apoio, que facilitavam a adoção dessas práticas (Ministério da Saúde, 2012a; Castro, Castro e Gugelmin, 2012).

Em relação às ações de prevenção de doenças e agravos relacionados à alimentação e nutrição, estas foram assim definidas quando objetivavam evitar o surgimento de doenças ou agravos ou minimizar suas consequências (Brasil, 2009b), sendo subdividas em ações de educação alimentar e nutricional (EAN) e suplementação. Como a EAN também compõe a PAAS, a ação foi classificada de acordo com o objetivo (promoção ou prevenção) descrito pelos autores dos artigos.

Foram consideradas ações de assistência/tratamento aquelas relacionadas à orientação dietética individual ou coletiva voltada ao tratamento e à reabilitação de doenças e agravos associados à alimentação e nutrição (Ministério da Saúde, 2009b).

$\mathrm{Na}$ classificação em descrição abrangente das ações foram incluídos artigos que não focaram em ações pontuais, mas trouxeram dados amplos sobre a organização da atenção integral à saúde, como estrutura, processo de trabalho e resultados das ações desenvolvidas.

Apesar de a gestão das ações de alimentação e nutrição corresponder a diversas atividades, como planejamento, monitoramento, avaliação, entre outras, esta categoria abrangeu somente discussões e divulgação das ações desenvolvidas pela gestão federal e força de trabalho (educação permanente, organização de cargos e 
identificação de atividades profissionais) (Ministério da Saúde, 2009b; 2012a), classificações definidas a partir dos achados da revisão.

Cabe ressaltar ainda que o sujeito da ação foi considerado o público-alvo da ação identificada, não sendo este necessariamente o mesmo da pesquisa realizada, estes denominados nesta análise como Participantes da Pesquisa. Algumas ações foram classificadas em mais de uma categoria. No caso de artigos realizados com maiores de uma idade específica, foi identificado no método ou nos resultados se a ação incluía idosos (maiores de 60 anos) para uma classificação mais fidedigna.

\subsection{DESCRIÇÃO DOS RELATOS DA IV MOSTRA NACIONAL DE EXPERIÊNCIAS EM ATENÇÃO BÁSICA/SAÚDE DA FAMÍLIA}

Trata-se de estudo descritivo, realizado por meio de identificação e análise das experiências relacionadas à A\&N aprovadas na IV Mostra Nacional de Experiências em Atenção Básica/Saúde da Família.

A IV Mostra foi um evento realizado em março de 2014 com o objetivo de promover a apresentação e o compartilhamento de experiências entre gestores, trabalhadores e usuários da $A B$ ou que possuem interface com esta. $A$ inscrição dos relatos foi realizada em um dos 20 eixos $^{c}$, por meio da plataforma eletrônica "Comunidade de Práticas", um espaço online criado em 2012 para promover a interação e a troca de experiências e informações entre gestores e trabalhadores da saúde. Na CdP estão disponíveis espaços para a inserção de relatos de experiências,

\footnotetext{
c O Programa de Melhoria do Acesso e da Qualidade na Atenção Básica (PMAQ-AB) e a Mobilização pela Melhoria do Cuidado na Atenção Básica; Ambiência e Estrutura: Acesso, Qualidade e Resolutividade; Ampliação e Qualificação da Saúde Bucal na Atenção Básica; Arte, Saúde e Cuidado; As Práticas de Vigilância em Saúde no Território da Atenção Básica; Controle Social e Participação Política; Educação em Saúde e Educação Popular em Saúde; Educação Permanente em Saúde e a Interface Ensino-Serviço na Atenção Básica; Gestão do Cuidado e Processo de Trabalho; Gestão do Trabalho: Provimento, Vínculo, Fixação, Carreira e Remuneração por Desempenho; Humanização na Atenção Básica; Monitoramento e Avaliação em Atenção Básica; Atenção Nutricional na Atenção Básica; Práticas Integrativas e Complementares na Atenção Básica; Promoção da Saúde e Intersetorialidade; Telessaúde, Núcleo de Apoio à Saúde da Família e Atenção Domiciliar como dispositivos de qualificação da Atenção Básica; Redes de Atenção à Saúde; Processo de implantação do e-SUS AB e Tecnologias/Sistemas de informação na Atenção Básica; Trabalho das equipes de Atenção Básica junto a Populações Específicas e Povos Indígenas; e Eixo Livre
} 
criação de comunidades sobre temas diversos e realização de cursos (Comunidade de Práticas, 2016).

O formulário de inscrição dos relatos colocava a experiência como foco, sendo que os autores puderam expressá-las em diferentes formatos (arte, fotografia, vídeo, relatos de experiências, poesia, entre outros), não estando, portanto, restritos ao tradicional modelo técnico-científico (Ministério da Saúde, 2016c). As seguintes perguntas norteadoras, que não eram obrigatórias, compunham o formulário, que também solicitava o local de realização da experiência e o âmbito da experiência (local, municipal e estadual):

- Sobre qual experiência você quer contar?

- O que você e sua equipe aprenderam com a experiência?

- Que desafios foram encontrados para seu desenvolvimento?

- O que você mais gostou e o que não gostou?

- Pensando no que você descreveu sobre sua experiência, o que mais ainda pode ser feito?

- Para fechar, deixamos um campo aberto onde você pode escrever o que quiser e no formato que quiser.

Dos 4.612 relatos de experiência inscritos, cerca de 2.000 tiveram a opção de receber curadoria, ou seja, contribuições de atores com diversas inserções na $A B$, cuja atribuição era dialogar com a experiência, colaborando assim para qualificação e aprofundamento de sua descrição, caso o autor aceitasse a curadoria e julgasse as contribuições pertinentes. Os relatos, por ficarem disponíveis na CdP e visíveis a qualquer participante da comunidade, também puderam receber comentários de outros autores ou pessoas externas, ampliando as possibilidades de trocas entre autores e autoras, curadores e curadoras e demais participantes da CdP (Ministério da Saúde, 2013a; 2016c).

Após a finalização da etapa de curadoria e do prazo para edição dos relatos, iniciou-se a avaliação entre pares, em que autores deveriam avaliar cinco relatos de outras regiões do país, para cada relato inscrito, não sendo, portanto, concorrentes. Este processo visou promover uma avaliação menos científica e mais horizontal e baseada em conhecimentos adquiridos com a experiência prática (Ministério da Saúde, 2013a; 2016c). 
A partir da avaliação, os relatos poderiam ser classificados para apresentação em Cirandas de Experiência, Dedos de Prosa ou Pontos de Encontro. Nos dois primeiros espaços, havia data e horário para apresentação oral, com tempo prédeterminado (20 e 10 minutos, respectivamente). No caso dos Pontos de Encontro, os relatos poderiam ser apresentados livremente sem prévia definição de dia e horário (Ministério da Saúde, 2013a; 2016c).

Foram selecionados 1.380 relatos de experiência para as modalidades Ciranda de Experiência e Dedos de Prosa, dentre todos os relatos inscritos, considerando pontuação obtida na avaliação de pares e respeitando distribuição por região do país, pré-definida de acordo com a população e cobertura de atenção básica. Os 900 relatos melhor classificados na avaliação entre pares foram apresentados nas Cirandas de Experiência e os 480 relatos seguintes foram apresentados nos Dedos de Prosa, seguindo a distribuição de $37,0 \%$ relatos da Região Nordeste, $32,0 \%$ da Região Sudeste, $13,0 \%$ da Região Sul, 10,0\% da Região Norte e 8,0\% relatos da Região Centro-Oeste (Ministério da Saúde, 2016c).

Destaca-se que, ao submeter os relatos na CdP, os autores concordavam em ceder os direitos autorais e patrimoniais relativos ao material submetido para o Ministério da Saúde sob o regime Creative Commons, conforme Termos de Uso da Comunidade de Práticas, podendo os relatos serem utilizados para a divulgação, exceto em caso de veículos de mídia que possuem fins comerciais (Ministério da Saúde, 2013a; Comunidade de Práticas, 2016).

A identificação dos relatos que descreviam ações de $A \& N$ foi realizada por meio de busca pelo título, dentre a lista dos aprovados nas categorias Ciranda de Experiência e Dedos de Prosa, por serem as modalidades que tiveram melhor classificação. Após a busca pelo título, foi avaliado relato completo na CdP. A avaliação buscou encontrar ações relacionadas à organização da atenção nutricional, à VAN, à promoção da alimentação adequada e saudável, à prevenção e controle de excesso de peso, desnutrição e carências nutricionais e à gestão das ações de alimentação e nutrição.

Para a caracterização geral das ações, os dados foram agrupados nas variáveis: região do país, âmbito de realização (local, municipal ou estadual), tema da ação e público-alvo. O detalhamento da ação se deu a partir da consolidação de informações sobre o tipo de ação, existência de mais de uma categoria profissional atuando na ação, realização de parcerias e articulações intersetoriais e com outros 
pontos da RAS e sobre a forma do público-alvo conhecer/participar da ação desenvolvida.

Assim como a revisão sistemática, a classificação do tipo de ação teve como base a Matriz de Ações de Alimentação e Nutrição na Atenção Básica à Saúde (Ministério da Saúde, 2009b) e a PNAN (Ministério da Saúde, 2012a) e foram consideradas as mesmas definições para a classificação.

Contudo, as ações de promoção da saúde e de práticas alimentares adequadas e saudáveis prevenção e controle e tratamento de obesidade, desnutrição e carências nutricionais foram ainda subdividas em ações individuais e atividade em grupo no caso de ações de PAAS e acompanhamento nutricional integral para prevenção controle e tratamento, considerada como ações que incluíam mais de um tipo de atividade (avaliação nutricional, atendimento individual, atividade em grupo, encaminhamento a outros profissionais/pontos da rede, organização de fluxos de atenção, por exemplo). Destaca-se também que nas ações de gestão o escopo foi maior, abrangendo a educação permanente, organização de ações, descrição de atividades desenvolvidas por profissionais específicos e sensibilização de profissionais e apoio. Além disso, foram criadas outras duas categorias: atenção integral à saúde da comunidade, que incluiu relatos que tratavam sobre atividades abertas diversas, realizadas em locais públicos; e pesquisa, que abrangeu atividades realizadas por iniciativa ou encomenda de pesquisadores, profissionais da atenção básica ou gestores.

Quando realizadas atividades em grupo, foram identificados os temas abordados e a metodologia utilizada, e, em casos de acompanhamento nutricional integral, as ações desenvolvidas também foram categorizadas.

Em relação às equipes, foram reunidas informações sobre o tipo de equipe responsável pela ação, área de atuação dos profissionais de referência, qual a motivação e os desafios para o desenvolvimento e quais os aprendizados com a realização da ação.

As análises dos dados foram realizadas por meio do software $E x c e^{\circledR}$ versão 2013.

\section{RESULTADOS E DISCUSSÃO}


Os resultados e a discussão desta dissertação serão apresentados a seguir em formato de dois artigos. 


\title{
5.1 ALIMENTAÇÃO E NUTRIÇÃO NA ATENÇÃO PRIMÁRIA À SAÚDE NO BRASIL: UMA REVISÃO SISTEMÁTICA DA PRODUÇÃO CIENTÍFICAd
}

\author{
Tatiane Nunes Pereira \\ Renata Alves Monteiro \\ Leonor Maria Pacheco dos Santos
}

\section{Resumo}

Introdução: A organização e a oferta de ações de alimentação e nutrição no Sistema Único de Saúde são norteadas pela Política Nacional de Alimentação e Nutrição, devendo ter a atenção básica como principal lócus de atuação. Objetivo: revisar a literatura científica e descrever o que tem sido desenvolvido em relação à alimentação e nutrição no âmbito da atenção básica. Métodos: Revisão sistemática, conduzida em 2015, por meio das bases de dados Lilacs, PUBMED, SCOPUS e Web of Science. Resultados: Foram incluídos 88 artigos, sendo a maior parte publicada entre $2012 \mathrm{e}$ 2015; os estudos foram desenvolvidos, principalmente, na região Sudeste. O tema mais prevalente foi hábitos/consumo alimentar e estado nutricional e público-alvo, população acompanhada pelas equipes. A maioria das ações foi iniciativa de universidades, voltada ao diagnóstico e às mulheres. Considerações Finais: Observou-se aumento no interesse nacional pelo tema, porém, com necessidade de realização pesquisas que descrevam, proponham ou avaliem ações e programas desenvolvidos pela gestão.

Palavras-chave: Atenção Primária à Saúde; Nutrição em Saúde Pública; Saúde Pública; Alimentação; Programas e Políticas de Nutrição e Alimentação

\section{INTRODUÇÃO}

Desnutrição, carências nutricionais, obesidade e doenças crônicas relacionadas à alimentação são desafios globais e coexistem na maioria dos países 
do mundo, tornando essencial a implementação de políticas intersetoriais de alimentação e nutrição (A\&N) com vistas ao seu enfrentamento. No setor saúde, é necessária a oferta de ações de $A \& N$ nos serviços, de forma a proporcionar cuidado integral e contínuo aos cidadãos e a contribuir para redução de iniquidades. ${ }^{1}$

No Brasil, a Constituição Federal reconhece a A\&N entre os fatores determinantes e condicionantes da saúde, sendo a organização e a oferta de ações no Sistema Único de Saúde (SUS) norteadas pela Política Nacional de Alimentação e Nutrição (PNAN). 2,3 Tais ações devem ser transversais a todos os pontos da Rede de Atenção à Saúde (RAS), tendo a atenção básica ( $A B$ ) como principal lócus de atuação, por ser um espaço privilegiado para a promoção da saúde e prevenção de agravos e realização de diagnóstico, tratamento, reabilitação e redução de danos. 2,4

O cenário epidemiológico deve ser base para a organização do cuidado nutricional na $A B$, sendo a transição nutricional grande desafio, cujo enfrentamento exige priorização de ações de $A \& N$ nas três esferas de gestão do SUS. ${ }^{5,6}$ Nesse sentido, o governo brasileiro tem organizado essas ações em quatro grandes eixos: vigilância alimentar e nutricional (VAN); promoção de práticas alimentares adequadas e saudáveis (PAAS); prevenção e cuidado integral de agravos; e, de forma transversal, desenvolvimento de ações intersetoriais. ${ }^{7}$

Em 2011, tanto a PNAN, lançada em 1999, quanto a Política Nacional de Atenção Básica (PNAB), lançada em 2006, foram revisadas e houve reposicionamento do papel e da importância da nutrição e da atenção básica no Governo Federal e no SUS, tendo essas maior prioridade, inclusive com ampliação de aporte financeiro. ${ }^{2,4,8}$

Apesar de se conhecer as ações estimuladas pelo Governo Federal, não há descrito na literatura, de forma consolidada, as ações de $A \& N$ no âmbito da $A B$. Atualmente, há duas revisões da literatura científica publicadas, porém, seus dados correspondem a artigos publicados até $2011^{9}$ e $2013^{10}$, sendo que uma classifica as ações desenvolvidas em categorias sem aprofundar sua descrição e diferenciar o que foi desenvolvido pelo serviço e gestão e academia ${ }^{9}$, por não ser seu objetivo, e a outra traça o perfil de grupos de pesquisa e publicações sobre ações em A\&N na ESF ${ }^{10}$. Deste modo, o objetivo deste artigo é descrever o que tem sido desenvolvido em relação à $A \& N$ no âmbito da $A B$, de acordo com a literatura científica. 


\section{METODOLOGIA}

Realizou-se revisão sistemática, seguindo as etapas do PRISMA ${ }^{11}$ e com registro no Registro Prospectivo Internacional de Revisões Sistemáticas (PROSPERO) (número de registro CRD42016038973).

A revisão foi conduzida entre agosto e novembro de 2015, baseada na pergunta "O que tem sido desenvolvido em relação à $A \& N$ no âmbito da $A B$, de acordo com a literatura científica?".

Uma vez que o artigo objetivava a descrição das ações realizadas e não dos resultados dessas ações e não propunha a realização de análise quantitativa de tais resultados, as autoras optaram pela não avaliação da qualidade do artigo, como preconizado no protocolo de revisão sistemática utilizado, para possibilitar maior inclusão de artigos à análise. Porém, modificações de etapas em circunstâncias específicas é prevista pelos autores do protocolo ${ }^{11}$.

Foi definido o ano da publicação da primeira versão da PNAB como marco para seleção dos artigos, visto que a PNAB regulamentou a implantação e operacionalização das ações já realizadas na $A B$, estabelecendo fundamentos e definindo áreas estratégicas relacionadas à $A \& N$, como a eliminação da desnutrição infantil, o controle do diabetes mellitus e da hipertensão arterial, a saúde da mulher e da criança e a promoção da saúde ${ }^{12}$, o que pode ter influenciado o desenvolvimento das ações já existentes.

Considerando que existem intervalos entre a publicação de diretrizes nacionais e a adequação destas aos serviços, quando necessária, e entre a elaboração dos artigos e sua publicação em periódicos científicos, foram incluídos estudos desenvolvidos a partir de 2007.

Como critérios de inclusão, consideraram-se estudos que tinham como público população adstrita/ coberta pelas UBS/ equipes de atenção básica(eAB), Estratégia Saúde da Família(ESF)/ equipes de Saúde da Família(eSF)/ Núcleos de Apoio à Saúde da Família(NASF) e/ou usuários, profissionais e gestores da $A B$; que abordavam/ desenvolveram ações de VAN, PAAS, prevenção, controle, diagnóstico, tratamento e reabilitação de doenças e agravos relacionados à $A \& N$ ou que tratavam da organização ou oferta de ações e serviços relacionados à $A \& N$ na $A B$. 
Foram excluídos artigos não conduzidos no Brasil; que não mencionavam ano de desenvolvimento ou iniciaram seu desenvolvimento antes de 2007; que não tinham a $A \& N$ como objeto; não relacionados à $A B$; e com dados de inquéritos nacionais não realizados na $A B$.

Estratégia de busca e corpus de análise

Utilizaram-se as bases de dados Lilacs, PUBMED, SCOPUS e Web of Science, tendo como limites artigos originais publicados entre 2007 e 2015.

Para a base de dados Lilacs, foram definidos os seguintes descritores: ("primary health care" OR "health center" OR "basic health service" OR "family health" OR "family health strategy") AND ("Food and Nutrition Security" OR "Nutritional Surveillance" OR "Nutritional Status" OR "anthropometry" OR "nutritional assessment" OR "Food and Nutrition Education" OR "food habits" OR "food consumption" OR "diet" OR "feeding" OR "nutrition" OR "nutrition policy"). Nas demais bases, foram utilizados os MeSH: ("primary health care" OR "community health services" OR "family health") AND ("Nutritional Status" OR "nutrition assessment" OR "anthropometry" OR "food habits" OR "food intake" OR "diet" OR "feeding behavior" OR "food security" OR "nutrition policy") AND "Brazil".

A análise dos artigos ocorreu inicialmente pelo título e resumo e, em caso de dúvidas, foi avaliada a metodologia para seleção. Foram identificados 222 artigos não duplicados, dos quais 88 foram incluídos; os principais motivos para exclusão foram o desenvolvimento do estudo antes de 2007 ( $n=59)$ e não atender aos demais critérios de inclusão de público-alvo ou não ter a $A \& N$ como objeto do estudo ( $n=48$ ) (Figura 1). 
Figura 1 - Fluxograma de seleção dos estudos. Brasil, 2015.

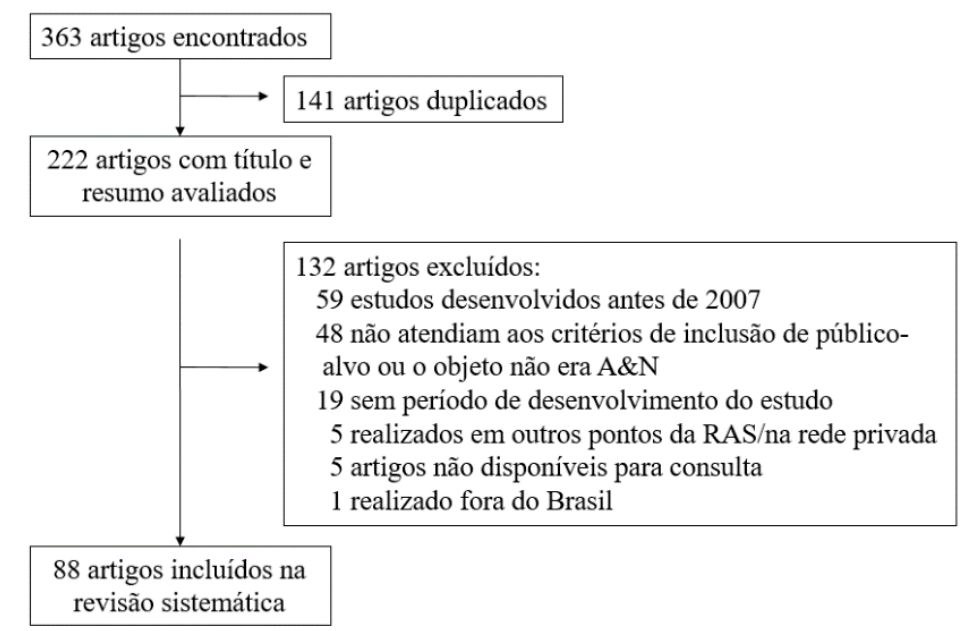

Instrumento de síntese dos estudos

Para gerenciamento das informações obtidas, os dados foram consolidados nas seguintes variáveis: ano e tipo de publicação, tema e ano de desenvolvimento do estudo, instituições envolvidas, participantes da pesquisa, envolvimento de profissionais da gestão ou do serviço no estudo e reconhecimento da aplicabilidade da pesquisa.

Para a caracterização das ações desenvolvidas, foram consolidados dados sobre: diretrizes da PNAN relacionadas (exceto "Organização da Atenção Nutricional" e "Cooperação e Articulação para Segurança Alimentar e Nutricional", por serem transversais às ações); tipo e sujeito de ação; e se já era desenvolvida pelas equipes/gestores ou foi pontualmente realizada para o estudo.

Para agrupamento e descrição, o tipo de ação realizada categorizado com base na Matriz de Ações de Alimentação e Nutrição na Atenção Básica à Saúde ${ }^{13}$, complementadas por categorias identificadas na $\mathrm{PNAN}^{2}$, sendo elas: diagnóstico, promoção da saúde e de práticas alimentares adequadas e saudáveis, controle e prevenção de doenças e agravos relacionados à $\mathrm{A} \& \mathrm{~N}$, assistência/tratamento, descrição abrangente das ações e gestão das ações de A\&N. 


\section{RESULTADOS}

Dentre os 88 artigos incluídos na revisão, a maioria correspondia a artigos originais (93,2\%), publicados entre 2012 e 2015 (72,7\%) e desenvolvidos na região Sudeste (48,9\%), Nordeste (18,2\%) e Sul (18,2\%) entre 2007 e 2011 (85,2\%). A média de intervalo entre desenvolvimento da pesquisa e publicação do artigo foi de 2,7 anos (0-6 anos). Os temas mais frequentes foram Hábito/Consumo Alimentar e Estado Nutricional (36,4\%) e Doenças Crônicas Não-Transmissíveis (DCNT) (32,9\%) e o público participante, a população acompanhada pelas eAB (68,2\%) (Quadro 1).

Mais da metade dos artigos foi publicado exclusivamente por pesquisadores de universidades brasileiras (64,8\%) (Quadro 2). Contudo, 25,0\% dos artigos tiveram parceria do serviço/gestão na elaboração do artigo e 47,7\% contaram com a participação de profissionais atuantes na gestão e/ou serviço em, pelo menos, uma etapa do estudo (Quadro 1).

Quadro 1 - Características dos artigos. Brasil, 2015.

\begin{tabular}{|c|c|c|c|c|}
\hline \multicolumn{2}{|c|}{ Categorias Analíticas } & $\mathbf{N}$ & $\%$ & Referências \\
\hline \multicolumn{5}{|l|}{ Tipo de estudo } \\
\hline \multirow{3}{*}{ Original } & Quantitativo & 68 & 77,3 & $\begin{array}{l}31-43,45-54,56-63,66-70,72-74,76,77,79-83,86,87 \\
91,93,95,97-106,109-112,114-116\end{array}$ \\
\hline & Qualitativo & 10 & 11,4 & $5,44,75,78,84,85,90,94,96,113$ \\
\hline & Quanti-Quali & 4 & 4,5 & $55,65,92,107$ \\
\hline \multirow{2}{*}{\multicolumn{2}{|c|}{$\begin{array}{l}\text { Artigo de Discussão/ Opinião/ Especial } \\
\text { Relato de Experiência }\end{array}$}} & 4 & 4,5 & $7,64,71,108$ \\
\hline & & 2 & 2,3 & 88,89 \\
\hline \multicolumn{5}{|c|}{ Ano de Publicação } \\
\hline \multicolumn{2}{|l|}{$2007-2011$} & 25 & 28,4 & $\begin{array}{l}5,7,31,32,34,37,38,42,49,53,61,72,75,79,81-84 \\
92,94,95,98,99,101,115\end{array}$ \\
\hline \multicolumn{2}{|l|}{ 2012-2015 } & 64 & 72,7 & $\begin{array}{l}33,35,36,39-41,43,44-48,50-52,54-60,62-71,73 \\
74,76,77,78,80,85-91,93,96,97,100,102-114,116\end{array}$ \\
\hline \multicolumn{5}{|c|}{ Ano de Desenvolvimento do Estudo } \\
\hline \multicolumn{2}{|l|}{ 2007-2011 } & 75 & 85,2 & $\begin{array}{l}31-39,41-63,65-69,72-75,78-84,86-102,104-107 \\
109-111,113,115,116\end{array}$ \\
\hline \multicolumn{2}{|l|}{ 2012-2015 } & 8 & 9,1 & $40,70,76,77,85,103,112,114$ \\
\hline \multicolumn{2}{|l|}{ Não se aplica } & 5 & 5,7 & $5,7,64,71,108$ \\
\hline
\end{tabular}


Quadro 1 - Características dos artigos. Brasil, 2015.

Continuação.

\begin{tabular}{|c|c|c|c|}
\hline Categorias Analíticas & $\mathbf{N}$ & $\%$ & Referências \\
\hline \multicolumn{4}{|l|}{ Local de realização } \\
\hline Sudeste & 43 & 48,9 & $\begin{array}{l}33,35-38,42-45,50,52-56,62,63,65,69,70,75-83 \\
85,86,88,91-95,99,100,110,111,113,114\end{array}$ \\
\hline Nordeste & 16 & 18,2 & $\begin{array}{l}31,46,57,59,68,73,74,84,89,97,101,102,104 \\
106-08\end{array}$ \\
\hline Sul & 16 & 18,2 & $\begin{array}{l}39-41,47,49,51,60,61,66,67,72,98,105,109,115 \\
116\end{array}$ \\
\hline Centro-Oeste & 12 & 13,6 & $5,7,32,34,48,64,71,87,90,96,103,112$ \\
\hline Norte & 1 & 1,1 & 58 \\
\hline \multicolumn{4}{|l|}{ Instituições Envolvidas } \\
\hline Universidades/Faculdades Brasileiras & 59 & 67 & $\begin{array}{l}31-39,41,42,44,45,48,50-54,59-63,65,68,70,72- \\
78,81-85,87,90-92,94-97,101,102,104-108,110 \\
112,114-116\end{array}$ \\
\hline $\begin{array}{l}\text { Gestão e serviço e Universidades/ } \\
\text { Faculdades brasileiras }\end{array}$ & 22 & 25 & $\begin{array}{l}5,40,43,46,49,58,64,67,69,79,80,86,88,89,93 \\
98-100,103,109,111,113\end{array}$ \\
\hline Gestão e serviço & 3 & 3,4 & $7,66,71$ \\
\hline $\begin{array}{l}\text { Gestão e serviço e Universidades/ } \\
\text { Faculdades brasileiras e de outros } \\
\text { países }\end{array}$ & 2 & 2,3 & 56,57 \\
\hline $\begin{array}{l}\text { Universidades/ Faculdades Brasileiras e } \\
\text { de outros países }\end{array}$ & 2 & 2,3 & 47,55 \\
\hline \multicolumn{4}{|l|}{ Tema do estudo* } \\
\hline $\begin{array}{l}\text { Hábito/consumo alimentar e estado } \\
\text { nutricional }\end{array}$ & 32 & 36,4 & $\begin{array}{l}32,34,36,37,45-50,53,54,56,60-63,67,70,76,81 \\
82,85,97,98,100,101,104,106,107,108\end{array}$ \\
\hline DCNT & 29 & 32,9 & $\begin{array}{l}34,36,37,42,45,52,55,57,58,60,61,63,64,67-69 \\
71,73,74,76,78,93-95,98,101,110,114,116\end{array}$ \\
\hline $\begin{array}{l}\text { Aleitamento materno/ Alimentação } \\
\text { complementar/ Atenção ao pré-natal }\end{array}$ & 16 & 18,2 & $\begin{array}{l}33,40,41,43,59,75,79,80,86,88,91,92,99,102 \\
109,113\end{array}$ \\
\hline Promoção da saúde/PAAS & 6 & 6,8 & $35,39,77,83,105,115$ \\
\hline Carências nutricionais & 4 & 4,5 & $38,72,84,103$ \\
\hline $\begin{array}{l}\text { Ações de alimentação e nutrição na } \\
\text { atenção básica }\end{array}$ & 2 & 2,3 & 7,90 \\
\hline SAN & 3 & 3,4 & $31,51,87$ \\
\hline Sisvan/sistemas de informação & 3 & 3,4 & $65,66,89$ \\
\hline Atuação do nutricionista & 2 & 2,3 & 44,112 \\
\hline Condicionalidade de saúde - PBF & 1 & 1,4 & 111 \\
\hline Educação permanente & 1 & 1,4 & 96 \\
\hline Transição nutricional & 1 & 1,4 & 5 \\
\hline
\end{tabular}


Quadro 1 - Características dos artigos. Brasil, 2015.

Continuação

\begin{tabular}{|c|c|c|c|}
\hline Categorias Analíticas & $\mathbf{N}$ & $\%$ & Referências \\
\hline \multicolumn{4}{|l|}{ Participantes da pesquisa } \\
\hline $\begin{array}{l}\text { Acompanhados pelas equipes das UBS, } \\
\text { ESF ou NASF }\end{array}$ & 60 & 68,2 & $\begin{array}{l}31-38,41-43,45-50,52,54,57,58-63,67-70,72-74 \\
76-82,85,86,88,92-95,98-101,103-105,107,109 \\
110,114-116\end{array}$ \\
\hline $\begin{array}{l}\text { População adstrita às UBS, ESF ou } \\
\text { NASF }\end{array}$ & 6 & 6,8 & $39,51,87,91,97,106$ \\
\hline Profissionais da $A B$ & 5 & 5,7 & $56,83,84,89,90$ \\
\hline $\begin{array}{l}\text { População adstrita /acompanhada e } \\
\text { profissionais da } A B\end{array}$ & 4 & 4,5 & $53,55,75,102$ \\
\hline Gestores & 3 & 3,4 & $65,33,111$ \\
\hline Profissionais da $A B$ e gestores & 2 & 2,3 & 24,96 \\
\hline $\begin{array}{l}\text { População adstrita /acompanhada, } \\
\text { profissionais da AB e gestores }\end{array}$ & 2 & 2,3 & 40,113 \\
\hline Não se aplica & 6 & 6,8 & $5,7,64,71,108,112$ \\
\hline \multicolumn{4}{|c|}{ Envolvimento de profissionais da gestão ou serviço } \\
\hline Sujeitos da pesquisa & 15 & 17 & $\begin{array}{l}40,47,53,55,56,65,75,83,84,89,90,97,102,111 \\
113\end{array}$ \\
\hline $\begin{array}{l}\text { Identificação/seleção/convite aos } \\
\text { participantes do estudo/Apresentação } \\
\text { ao entrevistador }\end{array}$ & 8 & 9,1 & $34,38,48,87,95,97,99,116$ \\
\hline $\begin{array}{l}\text { Supervisão/acompanhamento/realização } \\
\text { da coleta de dados }\end{array}$ & 7 & 7,9 & $32,35,39,46,69,88,91$ \\
\hline Condução do estudo/Todas as etapas & 6 & 6,8 & $5,7,64,66,71,77$ \\
\hline Planejamento & 3 & 3,4 & $38,70,110$ \\
\hline Fornecimento de dados & 3 & 3,4 & $97,112,116$ \\
\hline Não foi mencionado envolvimento & 48 & 54,5 & $\begin{array}{l}31,33,36,37,41-43,45,49-52,54,57-63,67,68,72- \\
74,76,78-82,85,92-94,96,98,100,101,103-109 \\
114,115\end{array}$ \\
\hline
\end{tabular}

Nota:

* Em alguns artigos, foi identificado mais de um tema principal do estudo.

No tocante às ações, verificou-se que $64,8 \%$ foram iniciativas de universidades, $78,4 \%$ estavam relacionadas principalmente à diretriz de VAN, $52,3 \%$ eram voltadas ao diagnóstico e $28,4 \%$ tinham como público-alvo mulheres, sendo que, dessas, 80,8\% eram gestantes/puérperas/nutrizes. As ações de promoção da saúde/PAAS corresponderam a $17,0 \%$ e as ações de assistência/tratamento, cuidado integral, prevenção de doenças e distúrbios relacionados à $A \& N$ gestão juntas somaram menos $30 \%$, sendo que nenhuma dessas categorias alcançou $10 \%$ das ações (Quadro 2). 
Quadro 2 - Características das Ações. Brasil, 2015.

\begin{tabular}{|c|c|c|c|}
\hline \multicolumn{4}{|c|}{ Principais Diretrizes da PNAN relacionadas } \\
\hline Vigilância Alimentar e Nutricional & 67 & 78,4 & $\begin{array}{l}5,7,31,32,34-38,41-43,45,46,48,49,51-54,56-65 \\
67,68,70-74,76-78,80-83,85,87,89,91-93,95,97 \\
104,106-109,111,114-116\end{array}$ \\
\hline $\begin{array}{l}\text { Gestão das ações de alimentação e } \\
\text { nutrição }\end{array}$ & 31 & 35,2 & $\begin{array}{l}5,7,35,40,41,44,47,52,53,56,59,64-66,71,75,80 \\
83,84,86,89,90,96,97,101,102,105,108,111,112 \\
113\end{array}$ \\
\hline $\begin{array}{l}\text { Promoção da Alimentação Adequada } \\
\text { e Saudável }\end{array}$ & 26 & 29,5 & $\begin{array}{l}5,7,35,39,40,47,50,64,68-71,75,77,79,83,86,88 \\
92,94,95,105,110,113-115\end{array}$ \\
\hline Qualificação da força de trabalho & 11 & 12,5 & $5,7,40,47,64,71,86,88,96,112,113$ \\
\hline \multicolumn{4}{|l|}{ Tipo de Ação } \\
\hline Diagnóstico alimentar e nutricional & 46 & 52,3 & $\begin{array}{l}31-34,36,37,42,43,45,46,48,49,51,53,54,57-63 \\
65-67,72-74,76,78,81,82,85,87,91,98- \\
101,103,104,106-109,116\end{array}$ \\
\hline Socioeconômico/demográfico/EBIA & 40 & 45,5 & $\begin{array}{l}31-34,36,37,41-43,45,48,49,51,54,57-63,67,72-74 \\
78,81,85,87,91,98-101,103,104,106,107,109,116\end{array}$ \\
\hline Nutricional & 38 & 43,2 & $\begin{array}{l}32-34,36,37,41-43,45,46,48,49,53,54,57-63,67 \\
72-74,76,81,91,98-101,103,104,106,107,109,116\end{array}$ \\
\hline $\begin{array}{l}\text { Hábitos de vida/condições de } \\
\text { saúde/acesso a serviços de saúde }\end{array}$ & 22 & 25,0 & $\begin{array}{l}32-34,36,43,45,48,49,58-62,73,74,91,99,100,103 \\
106,109,116\end{array}$ \\
\hline Apoio ao diagnóstico & 6 & 6,8 & $65,66,76,82,89,108$ \\
\hline Aspectos subjetivos/culturais & 4 & 4,5 & $59,78,85,107$ \\
\hline Outros & 2 & 2,3 & 100,104 \\
\hline Promoção da saúde/PAAS & 15 & 17,0 & $35,40,41,56,69,70,75,77,79,83,86,88,92,105,113$ \\
\hline Incentivo & 14 & 15,9 & $35,40,41,56,69,70,75,77,79,83,86,92,105,113$ \\
\hline Apoio & 1 & 1,1 & 88 \\
\hline Assistência/Tratamento & 8 & 9,1 & $52,55,68,93-95,110,114$ \\
\hline Prevenção de doenças e agravos & 7 & 7,9 & $38,39,47,50,84,110,115$ \\
\hline Educação alimentar e nutricional & 5 & 5,7 & $39,47,50,110,115$ \\
\hline $\begin{array}{l}\text { Suplementação com } \\
\text { micronutrientes }\end{array}$ & 2 & 2,3 & 38,84 \\
\hline Gestão & 7 & 7,9 & $5,7,44,64,71,96,112$ \\
\hline Divulgação das ações & 4 & 4,5 & $5,7,64,71$ \\
\hline $\begin{array}{l}\text { Força de trabalho ( } \mathrm{RH} \text { e educação } \\
\text { permanente) }\end{array}$ & 3 & 3,4 & $44,96,112$ \\
\hline Análise abrangente das ações & 5 & 5,7 & $80,90,97,102,111$ \\
\hline
\end{tabular}


Quadro 2 - Características das Ações. Brasil, 2015.

Continuação.

\begin{tabular}{|c|c|c|c|}
\hline Categorias Analíticas & $\mathbf{N}$ & $\%$ & Referências \\
\hline \multicolumn{4}{|l|}{ Público-alvo da ação } \\
\hline Mulheres & 25 & 28,4 & $\begin{array}{l}40,41,43,45,50,59,62,63,77,79,80,82,85,86,88, \\
91,93,94,95,99,102,107,109,113,115\end{array}$ \\
\hline Indivíduos com DCNT & 23 & 26,1 & $\begin{array}{l}34,36,42,49,52,55,57,58,60,61,63,67,68,73,74, \\
78,93-95,98,110,114,116\end{array}$ \\
\hline Gestantes/puérperas/nutrizes & 21 & 23,9 & $\begin{array}{l}40,41,43,45,59,62,75,79,80,82,83,85,86,88,91, \\
92,99,102,107,109,115\end{array}$ \\
\hline Adultos & 21 & 23,9 & $\begin{array}{l}34,35,37,42,50,52,55,57,58,61,67-70,73,74,78, \\
105,110,114,116\end{array}$ \\
\hline Idosos & 20 & 22,7 & $\begin{array}{l}32,35-37,42,47,52,54,55,58,60,61,68,70,76,104, \\
106,110,114,116\end{array}$ \\
\hline Crianças & 13 & 14,8 & $33,38,39,46,47,48,72,81,83,97,98,101,103$ \\
\hline Gestores e profissionais da saúde & 15 & 17,1 & $40,44,53,56,65,66,84,86,88-90,96,108,112,113$ \\
\hline Famílias & 5 & 5,7 & $31,51,83,87,111$ \\
\hline Adolescentes & 5 & 5,7 & $49,72,83,100,107$ \\
\hline Todos & 4 & 4,5 & $5,7,64,71$ \\
\hline \multicolumn{4}{|c|}{ Responsabilidade da ação desenvolvida } \\
\hline Instituição de ensino e pesquisa & 57 & 64,8 & $\begin{array}{l}31-34,36,37,39,41-52,54,56-63,67,68,70,72-74,76- \\
78,81,82,85,87,93-95,98,99-101,103,104,106-110 \\
115,116\end{array}$ \\
\hline Serviço & 31 & 35,2 & $\begin{array}{l}5,7,35,38,40,53,55,64,65,66,69,71,75,79,80,83, \\
84,86,88-92,96,97,102,105,111,112,113,114\end{array}$ \\
\hline
\end{tabular}

No tocante ao detalhamento das ações, na categoria Gestão das Ações de Alimentação e Nutrição, foram identificados artigos referentes à discussão e à divulgação de ações desenvolvidas/impulsionadas pela gestão federal da PNAN $5,7,64,71$ e relacionados à força de trabalho, com foco na evolução da incorporação do profissional nutricionista na $A B$ e nas representações sociais sobre o fazer teórico-prático do nutricionista ${ }^{44,112 ;}$ além de um que descrevia fatores facilitadores e dificultadores para realização de estratégias de educação permanente (EP) com eSF. ${ }^{96}$

Em cinco artigos foi possível identificar descrições ou avaliações mais amplas sobre um ou mais temas da área de $A \& N$ na $A B$, sendo assim, classificadas em Análise Abrangente das Ações. Foram verificadas descrições de dificuldades e potencialidades para a realização ações de A\&N por eSF ${ }^{90}$; relatos sobre assistência ao pré-natal, com avaliação de estrutura para sua realização ${ }^{80,102}$, ações de acompanhamento ${ }^{80,102}$ e resultado da implementação ${ }^{80}$; avaliação do acompanhamento do crescimento infantil, considerando a forma de realização e a 
existência de recursos humanos e de estrutura ${ }^{97}$; e descrição de atividades relacionadas do acompanhamento das condicionalidades de saúde do Programa Bolsa Família (PBF) ${ }^{111}$.

Mais da metade dos artigos apresentavam ações de Realização de Diagnóstico, sendo que todas, exceto duas ${ }^{53,91}$, foram desenvolvidas pontualmente para a realização do estudo. No caso das ações de Apoio ao Diagnóstico, que corresponderam àquelas relacionadas a sistemas de informação em saúde, uso de medidas antropométricas como preditivas de doenças e discussão ou teste de novas ferramentas para diagnóstico em $A \& N$ na $A B$, foram identificadas seis ações, sendo três desenvolvidas no serviço, relacionadas ao uso/operacionalização do Sisvan $66,66,89$.

Em relação à PAAS, foram identificadas ações de Incentivo à PAAS em 14 artigos, sendo que sete abordavam características gerais relacionadas ao aconselhamento nutricional para adultos ${ }^{35,56,69,102} \mathrm{e}$ gestantes/nutrizes/puérperas ${ }^{75,79,92}$ realizado em UBS; três estavam relacionados à implantação da Rede Amamenta Brasil ${ }^{40,86,113}$, duas testaram o impacto ou efetividade de ações, realizadas por universidades, para mulheres ${ }^{77}$ ou adultos/idosos ${ }^{70}$ acompanhados na $A B ;$ e um descreveu ações de educação em saúde desenvolvidas por UBS para adolescentes ${ }^{83}$. Além disso, foi encontrado um artigo com descrição da estruturação para doação de aleitamento materno em uma unidade de saúde, classificada em Apoio à $P A A S^{88}$.

No tocante à Prevenção de Agravos Relacionados à $A \& N$, foram identificados seis artigos: quatro com ações de EAN relacionadas à prevenção do ganho de preso em gestantes acompanhadas na atenção básica ${ }^{115}$, de obesidade/DCNT em mulheres adultas que frequentavam polos do Programa Academia da Saúde ${ }^{50}$ e de cáries em pré-escolares acompanhados por UBS ou residentes em área adstrita ${ }^{39,47}$; e duas de suplementação de micronutrientes, relacionadas à efetividade de esquemas diário e semanal de suplementação prevenção e controle da anemia ${ }^{38}$ e à implantação do Programa Nacional de Suplementação de Vitamina $A^{84}$.

Dentre os oito artigos classificados com ações de assistência e tratamento, quatro correspondiam a intervenções de educação em saúde para pessoas com diabetes $^{110,114}$ e hipertensão ${ }^{68,93,95}$ acompanhadas ou cobertas pela $A B$, mas de responsabilidade de universidades; dois avaliaram aspectos relacionados à adesão 
ao tratamento de diabetes ${ }^{52}$ e hipertensão ${ }^{94}$; e um identificou se havia concordância entre médicos e pacientes sobre as condutas do tratamento de diabetes ${ }^{55}$.

A descrição mais detalhada das ações encontradas nos artigos foi realizada a partir de sua consolidação no Quadro 3. 
Quadro 3 - Descrição das ações de alimentação e nutrição. Brasil, 2015.

\begin{tabular}{|c|c|c|c|}
\hline Tema & Subtema & \multicolumn{2}{|c|}{ Descrição das Ações } \\
\hline \multirow{4}{*}{$\begin{array}{l}\text { Gestão das } \\
\text { Ações de } \\
\text { A\&N }\end{array}$} & \multirow[b]{2}{*}{$\begin{array}{l}\text { Divulgaçã } \\
\text { o de } \\
\text { Ações - } \\
\text { Gestão } \\
\text { Federal }\end{array}$} & $\begin{array}{l}\text { Pré-revisão } \\
\text { da PNAN } \\
(2008)^{5}\end{array}$ & $\begin{array}{l}\text { Sugestão de agenda única de nutrição focada no curso da vida; possibilidade de ampliação de abrangência de ações e resolubilidade } \\
\text { da ESF pela recente instituição dos NASF. Ações descritas: } \\
\text { Avaliação e do monitoramento do estado nutricional: Caracterização do perfil epidemiológico e da situação de saúde, A\&N, a partir do } \\
\text { registro de dados no SISVAN, em todas as fases do curso da vida; utilização do Protocolo do SISVAN: orientações para o atendimento } \\
\text { nutricional em serviços de saúde da atenção básica; organização de protocolos de atendimento; pré-natal para as gestantes e } \\
\text { acompanhamento do crescimento e desenvolvimento de crianças até dois anos; acompanhamento prioritário na atenção básica às } \\
\text { famílias beneficiárias do Programa Bolsa Família (PBF). } \\
\text { Prevenção e controle de doenças e agravos relacionados à A\&N: suplementação de micronutrientes para grupos mais vulneráveis; } \\
\text { educação alimentar e nutricional no serviço de saúde, a partir das diretrizes de guias alimentares oficiais; ações intersetoriais. } \\
P A A S: \text { incentivo e apoio à adoção de hábitos alimentares saudáveis e à prática de atividade física; promoção do aleitamento materno } \\
\text { exclusivo até o sexto mês e complementar até o segundo ano de vida. }\end{array}$ \\
\hline & & $\begin{array}{l}\text { Pós-revisão } \\
\text { da PNAN } \\
(2011-2013) \\
7,64,71\end{array}$ & 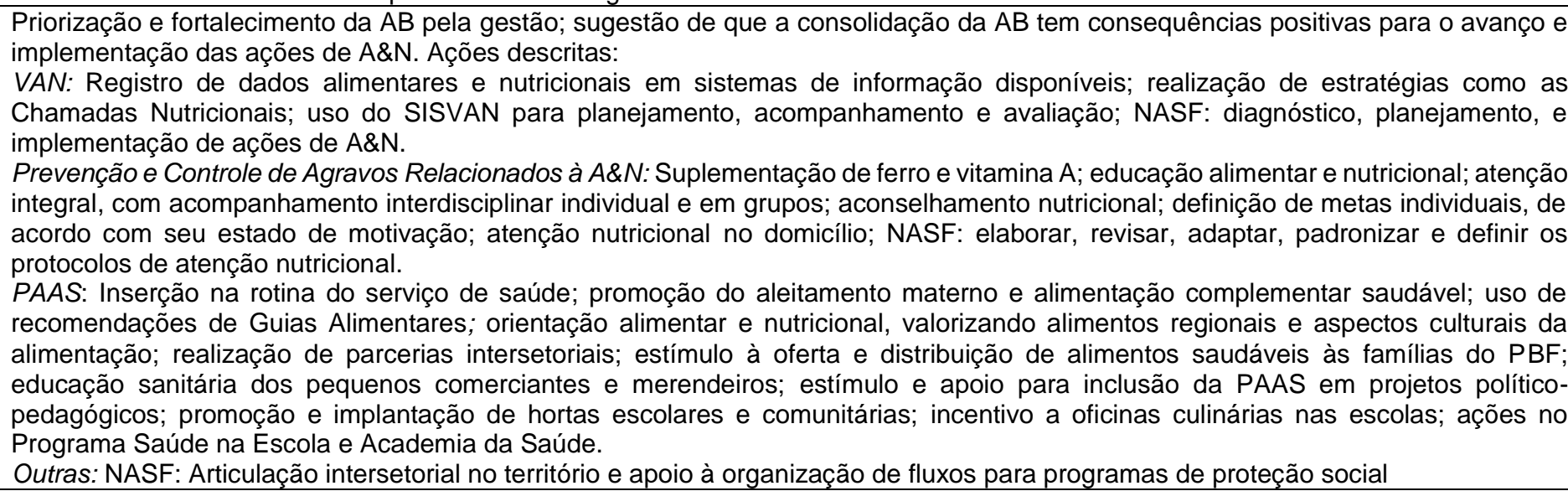 \\
\hline & & $\begin{array}{l}\text { Quantitativo } \\
\text { de } \\
\text { nutricionistas }\end{array}$ & $\begin{array}{l}\text { Crescimento de } 176 \% \text { nas eSF e de } 75 \% \text { nas UBS tradicionais entre } 2007 \text { e } 2013 \text { e de } 657 \% \text { nos NASF entre } 2008 \text { e } 2013 \text {, com } \\
\text { contratações principalmente em municípios de pequeno porte da região Nordeste e médio IDH. A média de profissionais por município } \\
\text { manteve-se a mesma e menos de } 15 \% \text { permaneceram no cargo por mais de cinco anos. (Dados do Cadastro Nacional de } \\
\text { Estabelecimentos de Saúde) }{ }^{112}\end{array}$ \\
\hline & $\begin{array}{l}\text { Força de } \\
\text { trabalho }\end{array}$ & $\begin{array}{l}\text { Atuação de } \\
\text { nutricionistas } \\
\text { e de } \\
\text { profissionais } \\
\text { da AB em } \\
\text { A\&N }\end{array}$ & $\begin{array}{l}\text { Atribuições do nutricionista: prevenção de doenças e promoção da saúde, prescrição dietética e realização de ações educativas. } \\
\text { Abordagem do tema pelas equipes: orientações impositivas e normativas e baseada em pouco conhecimento técnico. } \\
\text { Nutricionistas na equipe mínima da SF: sugestão de inclusão por alguns, sendo a ausência atribuída ao modelo médico-hegemônico, } \\
\text { à falta de reconhecimento e de recursos financeiros e ao desconhecimento sobre a profissão; outros profissionais consideraram a } \\
\text { presença para apoio e encaminhamento suficiente (entrevista com } 21 \text { profissionais de eSF, } 6 \text { residentes e } 1 \text { gestora; São Carlos/SP; } \\
\text { 2008-09).44 }\end{array}$ \\
\hline
\end{tabular}




\begin{tabular}{|c|c|c|c|}
\hline Tema & ubtema & \multicolumn{2}{|c|}{ crição das Ações } \\
\hline $\begin{array}{l}\text { Gestão } \\
\text { das Ações } \\
\text { de A\&N }\end{array}$ & $\begin{array}{l}\text { Força de } \\
\text { trabalho }\end{array}$ & $\begin{array}{l}\text { o } \\
\text { nte }\end{array}$ & $\begin{array}{l}\text { Facilitadores para realização nas eSF: realização de parcerias, adesão dos profissionais, formação de tutores da Rede Amamenta } \\
\text { Brasil e existência de recursos financeiros e de setor específico para EP. } \\
\text { Dificultadores: indisponibilidade de tempo dos profissionais, falta de priorização, de estratégias de EP estruturadas, de infraestrutura e } \\
\text { de recursos humanos, especialmente nutricionistas, rotatividade de profissionais, pouca adesão, especialmente de médicos, e } \\
\text { burocracia para uso dos recursos. } \\
\text { Principais estratégias: ações locais; planejamento e programação das atividades baseadas em necessidades; atividades em grupos; } \\
\text { avaliação e acompanhamento das ações; e subsídio teórico e técnico e feedback para os profissionais. } \\
\text { Pouca existência de EP contínua e organizada; realizadas principalmente ações pontuais com temas específicos (entrevista com } 44 \\
\text { coordenadores de A\&N; } 28 \text { municípios de grande porte; } 2008-11) .{ }^{96}\end{array}$ \\
\hline \multirow{4}{*}{$\begin{array}{l}\text { Descrição } \\
\text { Abrangent } \\
\text { e de Ações } \\
\text { Desenvolvi } \\
\text { das }\end{array}$} & & \multicolumn{2}{|r|}{$\begin{array}{l}\text { Dificuldades: resistência à mudança de hábitos alimentares e influência da mídia, falta de conhecimento técnico, de auxílio de nutricionista e articulação } \\
\text { entre a equipe e com a gestão e aspectos sócio-econômicos-culturais. } \\
\text { Potencialidades: inclusão do nutricionista na equipe, ações multidisciplinares de EAN desde a infância com famílias e em escolas; espaço físico } \\
\text { adequado, desburocratização, nomeação de gestores desvinculada da política, articulação entre profissionais, tempo para atendimento e planejamento } \\
\text { e pactuação da PNAN (grupos focais com } 60 \text { profissionais das eSF; cinco municípios;2009-10).90 }\end{array}$} \\
\hline & & \multicolumn{2}{|c|}{$\begin{array}{l}\text { João Pessoa/PB: UBS com equipamentos, materiais, medicamentos e suplementos necessários; baixa cobertura de mulheres em idade fértil e alta de } \\
\text { gestantes, com realização de pré-natal e uso de suplementos; baixa participação em atividades de educação em saúde (entrevistas com } 239 \text { usuárias; } \\
\text { avaliação de } 44 \text { UBS; 2008). }{ }^{102} \\
\text { Rio de Janeiro/RJ: aferição e registro da pressão arterial e do peso; prescrição de suplementos e realização de exames de sangue como rotina, porém, } \\
\text { com baixo registro de estatura, peso inicial, edema, IMC e resultados de exames; falta de orientações sobre alimentação, ganho de peso e uso de } \\
\text { sulfato ferroso (entrevistas com } 130 \text { gestantes e verificação dos cartões de pré-natal; sete UBS; 2008). }{ }^{80}\end{array}$} \\
\hline & & \multicolumn{2}{|r|}{$\begin{array}{l}\text { Queimadas/PB: } 20 \% \text { das UBS não tinham equipe completa; apenas } 6,2 \% \text { não contavam apoio de nutricionistas (NASF); todas possuíam equipamentos } \\
\text { antropométricos; mais de } 60 \% \text { dos enfermeiros afirmaram não ter recebido treinamento sobre o tema e } 75 \% \text { baseavam a conduta em protocolos; } \\
\text { registro de peso e de estatura contínuo observado em mais de } 60 \% \text { dos casos; } 82,4 \% \text { dos cartões tinham, pelo menos, duas marcações no gráfico de } \\
\text { peso por idade; crianças com baixo peso ao nascer sem atenção especial quando comparadas às com peso adequado. (entrevistas com mães de } 204 \\
\text { crianças e enfermeiros; } 16 \text { UBS; 2011). }{ }^{97}\end{array}$} \\
\hline & & \multicolumn{2}{|c|}{$\begin{array}{l}\text { Rio de Janeiro/RJ: maioria realizava pré-natal, aferia peso e estatura, realizava consultas individuais para crianças, acompanhava crescimento e } \\
\text { desenvolvimento e avaliava estado nutricional; } 65,6 \% \text { intervinham no risco nutricional; } 85,0 \% \text { realizavam ações de promoção do AM e } 48,4 \% \text {, grupos } \\
\text { educativos; } 73,4 \% \text { aferiam peso e estatura das mulheres; } 84,3 \% \text { realizavam ações de diabetes e hipertensão; } 73,8 \% \text {, consultas individuais para } \\
\text { adolescentes e } 57,8 \% \text { para outros membros da família; } 53,1 \% \text { promoviam articulação intersetorial; } 17,2 \% \text { participavam de fóruns de gestão (128 UBS; } \\
\text { 2008). }{ }^{111}\end{array}$} \\
\hline $\begin{array}{l}\text { Diagnósti } \\
\text { co } \\
\text { alimentar } \\
\text { e } \\
\text { nutricional }\end{array}$ & & \multicolumn{2}{|r|}{$\begin{array}{l}\text { 80\% dos artigos apresentavam avaliação do estado nutricional, por medidas antropométricas coletadas ou referidas, ou do consumo alimentar; } \\
\text { considerados aspectos clínicos e bioquímicos; identificados, a partir de entrevistas estruturadas ou semiestruturadas, fatores socioeconômicos e } \\
\text { demográficos, relacionados ou estratificados com uma ou mais variáveis referidas; três avaliaram aspectos subjetivos e culturais, além dos anteriores; } \\
\text { uso de variáveis relacionadas aos hábitos de vida; uso da EBIA para diagnóstico de insegurança alimentar e nutricional; diagnóstico exclusivo de } \\
\text { questões subjetivas relacionadas à A\&N. Um artigo descreveu a qualidade das medidas de peso em UBS. Somente um não foi desenvolvido } \\
\text { pontualmente para a realização do estudo. }\end{array}$} \\
\hline
\end{tabular}


Quadro 3 - Descrição das ações de alimentação e nutrição. Brasil, 2015.

\begin{tabular}{|c|c|c|c|}
\hline Tema & Subtema & \multicolumn{2}{|c|}{ escricão das Acões } \\
\hline \multirow[t]{2}{*}{$\begin{array}{l}\text { Diagnósti } \\
\text { co } \\
\text { alimentar } \\
\text { e } \\
\text { nutricional }\end{array}$} & \multirow[t]{2}{*}{$\begin{array}{l}\text { Apoio ao } \\
\text { Diagnós } \\
\text { tico }\end{array}$} & $\begin{array}{l}\text { Uso/ } \\
\text { operacionali } \\
\text { zação do } \\
\text { Sisvan }\end{array}$ & $\begin{array}{l}\text { Rio Grande do Sul: dez coordenadorias regionais de saúde (CRS) com percentual de uso do Sisvan entre } 60 \text { e } 80 \% \text {; } 17 \text { com cobertura } \\
\text { de até } 2,5 \% \text {; a maior ocorreu entre } 0 \text { e } 5 \text { anos e } 5 \text { e } 10 \text { anos, estando a maioria abaixo de } 10 \% \text {; entre adolescentes, adultos e idosos, } \\
\text { a cobertura foi menor de } 3 \% \text { para quase todas CRS e, entre os adultos, as mulheres representaram mais de } 80 \% \text { dos acompanhados } \\
\text { (Uso do Sisvan: municípios que inseriram dados de pelo menos um indivíduo; } 19 \text { CRS; 2010). }{ }^{66} \\
\text { Zona da Mata/MG: Informatização considerada aspecto facilitador; registro manual, lentidão da internet e sobrecarga de trabalho, } \\
\text { dificultadores do trabalho de digitadores; essencial a colaboração das equipes responsáveis pela consolidação dos dados nas UBS. } \\
\text { Reconhecida a importância das informações para a gestão e atenção ao usuário (entrevista com digitadores; } 37 \text { municípios; } 2010 \text { ). }{ }^{65} \text {. } \\
\text { Juazeiro do Norte/CE: operacionalização do Sisvan após contratação de nutricionista e leitura de materiais temáticos, que basearam } \\
\text { discussões com a eSF e pactuação com gestores; realizada sensibilização e capacitação de enfermeiros, técnicos de enfermagem, } \\
\text { agentes administrativos, ACS e digitadores sobre o Sisvan e ficha de marcadores de consumo; elaborados materiais de apoio; houve } \\
\text { aumento da motivação para desenvolvimento das ações e melhor divisão de tarefas (relato de experiência; } 2009-10)^{89}\end{array}$ \\
\hline & & $\begin{array}{l}\text { Outras } \\
\text { ações }\end{array}$ & $\begin{array}{l}\text { Avaliação do uso de indicadores antropométricos como preditores de risco cardiovascular para idosos. }{ }^{76} \\
\text { Desenvolvimento de Questionário de Frequência Alimentar para gestantes. }{ }^{82} \\
\text { Discussão de proposta de uma ficha antropométrica para uso de ACS e profissionais de educação física. }{ }^{108}\end{array}$ \\
\hline \multirow{3}{*}{ PAAS } & \multirow{3}{*}{ Incentivo } & $\begin{array}{l}\text { Aconselham } \\
\text { ento para } \\
\text { adultos }\end{array}$ & $\begin{array}{l}\text { Brasil: mais de } 30 \% \text { receberam orientações sobre o consumo de sal, açúcar e gordura em UBS - } 72,0 \% \text { por médicos; orientações } \\
\text { contribuíram para melhorar a alimentação para maioria (entrevista com } 12.402 \text { brasileiros; } 2008-09)^{105} \text {. Comportamentos saudáveis } \\
\text { foram associados a conhecimentos prévios e realização de aconselhamento por ACS, contudo, a maioria não conhece as } \\
\text { recomendações de alimentação e valores de corte de IMC (entrevista com } 269 \text { ACS) }{ }^{56} \\
\text { Belo Horizonte/MG: aconselhamento sobre modos de vida saudáveis/alimentação/atividade física para } 40,8 \%{ }^{35} \text { e } 51,1 \%{ }^{69} \text { dos usuários } \\
\text { - maioria realizada por médicos, }{ }^{35,69} \text { voltada para mulheres e adultos }{ }^{35} \text { e associado a DCNT, uso de medicamentos e Programa } \\
\text { Academia da Saúde. }{ }^{69} \text { (417 usuários; } 1 \text { UBS; } 2010^{35} \text { e } 1616 \text { usuários; } 4 \text { UBS; } 2009-10^{69} \text {, respectivamente). }\end{array}$ \\
\hline & & $\begin{array}{l}\text { Aconselham } \\
\text { ento para } \\
\text { gestantes/pu } \\
\text { érperas/nutri } \\
\text { zes }\end{array}$ & $\begin{array}{l}\text { Rio de Janeiro/RJ: } 47,0 \% \text { das mães de crianças menores de seis meses não receberam orientações sobre o AM na primeira consulta } \\
\text { pós-parto e } 38,8 \% \text { não receberam orientações após o parto (entrevista com } 1057 \text { mães; } 27 \text { UBS; } 2007)^{79} \\
\text { Viçosa/MG: somente cinco, de } 22 \text { mulheres, referiram ter recebido orientações de nutricionistas, médico, Pastoral da Criança ou } \\
\text { estagiárias da UBS sobre AM (2010). }{ }^{92} \\
\text { Viçosa/MG: a maior parte dos profissionais de saúde referiu não ter participado de capacitação e orientava com conhecimentos de sua } \\
\text { vivência; presença de mitos e crenças em discursos de profissionais e nutrizes; divergências entre os profissionais sobre uso de chupeta } \\
\text { e mamadeira e introdução de líquidos; orientações reduzidas a ações biologicistas e verticalizadas (entrevista com } 58 \text { nutrizes e } 32 \\
\text { profissionais da saúde; } 2 \text { UBS; 2007). }{ }^{75}\end{array}$ \\
\hline & & $\begin{array}{l}\text { Implantação } \\
\text { da Rede } \\
\text { Amamenta } \\
\text { Brasil }\end{array}$ & $\begin{array}{l}\text { Brasil: } 58 \text { oficinas que formaram } 1415 \text { tutores e } 22545 \text { profissionais em } 1034 \text { UBS até } 2010 \text {; quanto mais favorável o contexto, maior } 0 \\
\text { grau de implantação da Rede. Apoio da gestão, aporte financeiro, recursos humanos qualificados, autonomia do coordenador, } \\
\text { priorização nos planos de saúde, inexistência de açães concorrentes, articulação com outras áreas, município de menor porte e uso } \\
\text { do Sisvan-Web favoreceram a implantação (avaliação em } 36 \text { UBS, três municípios, seus respectivos estados e governo federal). }{ }^{113} \\
\text { Ribeirão Preto/SP: grau de implantação da Rede impacta significativamente a prevalência de AME, aumentando progressivamente em } \\
\text { UBS que não realizaram oficinas, com oficina realizada e certificada na Rede ( } 916 \text { crianças menores de seis anos usuárias da rede } \\
\text { privada e de } 40 \text { UBS; } 2011) .{ }^{86} \\
\text { Bento Gonçalves/RS: não encontrada diferença entre as prevalências de AM de crianças acompanhadas por UBS aderidas ou não à } \\
\text { Rede ( } 405 \text { crianças menores de um ano participantes de campanhas de vacinação; 2012). }{ }^{40}\end{array}$ \\
\hline
\end{tabular}




\begin{tabular}{|c|c|c|c|}
\hline Tema & Subtema & \multicolumn{2}{|c|}{ Descrição das Ações } \\
\hline \multirow[t]{3}{*}{ PAAS } & \multirow[t]{2}{*}{ Incentivo } & $\begin{array}{l}\text { Avaliação de } \\
\text { impacto ou } \\
\text { efetividade } \\
\text { de ações } \\
\text { realizadas } \\
\text { por } \\
\text { universida } \\
\text { des na } A B\end{array}$ & $\begin{array}{l}\text { Belo Horizonte/MG: acompanhamento ( } 6 \text { meses) de mulheres divididas nos grupos controle (rotina da AB - atividade física } 3 \text { vezes por } \\
\text { semana, grupos de EAN mensais e atendimento individual em casos de excesso de peso e DCNT estáveis) e intervenção (Modelo } \\
\text { Transteórico - subdivisão por estágio de mudança; atividades de rotina associadas a } 10 \text { oficinas conduzidas por equipe multidisciplinar). } \\
\text { Constataram-se melhoras antropométricas e nutricionais no grupo intervenção ( } 71 \text { mulheres do Programa Academia da Saúde; } 2013 \text { ). }{ }^{77} \\
\text { Belo Horizonte/MG: acompanhamento mensal ( } 6 \text { meses) por acadêmicos de Nutrição e equipes de educação física - orientações } \\
\text { nutricionais, baseadas em guias e manuais oficiais e atividade física } 3 \text { vezes por semana. Mudanças positivas na alimentação e em } \\
\text { medidas antropométricas ( } 20 \text { adultos e idosos do Programa Academia da Cidade; 2007). } .^{70}\end{array}$ \\
\hline & & $\begin{array}{l}\text { Educação } \\
\text { em Saúde } \\
\text { com Adoles } \\
\text { centes }\end{array}$ & $\begin{array}{l}\text { Vitória/ES: atividades coletivas sobre AM antes das consultas de puericultura - falta recursos didático-pedagógicos; atividades } \\
\text { mensais/quinzenais com temas variados escolhidos por beneficiários do PBF - uso de materiais de apoio (avaliação de } 6 \text { UBS; } \\
2007)^{83}\end{array}$ \\
\hline & Apoio & \multicolumn{2}{|r|}{$\begin{array}{l}\text { Doação de Leite Materno: capacitação dos profissionais motivou articulação com BLH e estruturação para coleta e ordenha de leite na UBS; } \\
\text { identificação contínua de doadoras, divulgação, realização de oficinas e apoio domiciliar. Ação baseada em necessidades e valorização de } \\
\text { conhecimentos de possíveis doadoras e nutrizes. }{ }^{88}\end{array}$} \\
\hline \multirow{3}{*}{$\begin{array}{l}\text { Prevenção } \\
\text { de } \\
\text { doenças e } \\
\text { agravos } \\
\text { relaciona } \\
\text { dos à } A \& N\end{array}$} & \multirow[t]{2}{*}{$\begin{array}{l}\text { Educação } \\
\text { alimentar e } \\
\text { nutricional }\end{array}$} & $\begin{array}{l}\text { Avaliação de } \\
\text { impacto ou } \\
\text { efetividade } \\
\text { de ações de } \\
\text { EAN para } \\
\text { prevenção } \\
\text { de } \\
\text { ganho/exces } \\
\text { so de peso/ } \\
\text { DCNT }\end{array}$ & $\begin{array}{l}\text { Porto Alegre/RS: acompanhamento de gestantes - grupo intervenção (orientaçães alimentares a partir do estado nutricional e } \\
\text { fornecimento de valores e medidas caseiras) e controle (estado nutricional avaliado e orientação para informarem resultado no pré- } \\
\text { natal - atendimento de rotina). Intervenção significativamente mais efetiva na redução do ganho de peso semanal e na prevalência de } \\
\text { intercorrências clínicas ( } 215 \text { gestantes; } 1 \text { UBS; } 2007-08) .{ }^{115} \\
\text { Belo Horizonte/MG: intervenção por } 11 \text { meses com mulheres classificadas em grupos de atividade física (3 vezes por semana) e } \\
\text { participação insatisfatória e satisfatória na intervenção nutricional (grupos mensais de educação nutricional, com uso de materiais } \\
\text { lúdicos e educativos, e baseados em conhecimentos prévios e dúvidas das participantes). Maiores melhorias no grupo de participação } \\
\text { satisfatória (124 mulheres; 2011).50 }\end{array}$ \\
\hline & & $\begin{array}{l}\text { Prevenção } \\
\text { de cáries em } \\
\text { pré- } \\
\text { escolares }\end{array}$ & $\begin{array}{l}\text { Porto Alegre/RS: capacitação de profissionais, exposição de banners e distribuição de panfletos para usuárias de nove UBS que } \\
\text { incluíam informações sobre alimentação saudável; efeito protetor para cárie precoce severa entre as que crianças permaneceram na } \\
\text { mesma UBS no período e quando a UBS era única fonte de informação sobre alimentação ( } 458 \text { crianças; } 20 \text { UBS; } 2008) .{ }^{47} \\
\text { Porto Alegre/RS: capacitação de profissionais, observação prévia dos hábitos das crianças, desenvolvimento de ações lúdicas, } \\
\text { incluindo sobre alimentação saudável, demonstração de higiene bucal e da placa bacteriana e supervisão da escovação em uma escola } \\
\text { do território, verificou-se melhoras na saúde bucal após a intervenção. ( } 41 \text { crianças; } 2010)^{39}\end{array}$ \\
\hline & $\begin{array}{l}\text { Suplemen } \\
\text { tação com } \\
\text { micronutrie } \\
\text { ntes }\end{array}$ & $\begin{array}{l}\text { Avaliação de } \\
\text { efetividade } \\
\text { de } \\
\text { suplementa } \\
\text { ção com } \\
\text { sulfato } \\
\text { ferroso }\end{array}$ & $\begin{array}{l}\text { Viçosa/MG: Crianças divididas em um grupo que recebia suplementação diária, recomendada pela Sociedade Brasileira de Pediatria, } \\
\text { e outro com dosagem semanal, preconizada pelo Ministério da Saúde. Houve maior redução nos níveis de hemoglobina entre as } \\
\text { crianças suplementadas diariamente (103 lactentes não anêmicos; 2007-08). }{ }^{38}\end{array}$ \\
\hline
\end{tabular}




\begin{tabular}{|c|c|c|c|}
\hline Tema & ubtema & \multicolumn{2}{|c|}{ Descrição das Ações } \\
\hline $\begin{array}{l}\text { Prevenção } \\
\text { de } \\
\text { doenças e } \\
\text { agravos } \\
\text { relaciona } \\
\text { dos à A\&N }\end{array}$ & $\begin{array}{l}\text { Suplemen } \\
\text { tação com } \\
\text { micronutrie } \\
\text { ntes }\end{array}$ & $\begin{array}{l}\text { Avaliação da } \\
\text { implantação } \\
\text { do Programa } \\
\text { Nacional de } \\
\text { Suplementa } \\
\text { ção de } \\
\text { Vitamina A }\end{array}$ & $\begin{array}{l}\text { Paraíba: adequado armazenamento dos insumos ( } 57,2 \%) \text {, conhecimento dos materiais do programa (74,4\%) e da regularidade } \\
\text { preconizada }(91,0 \%) \text {; suplementação semanal ou trimestral }(67,4 \%) \text {; boa adesão das famílias }(55,0 \%) \text {; identificação da população por } \\
\text { demanda espontânea, busca ativa e campanhas de vacinação; desenvolvimento de ações para a comunidade. Verificou-se falta de } \\
\text { materiais }(70,3 \%) \text { e de capacitação }(60,5 \%) \text { e irregularidades na aquisição }(23,4 \%) \text { e na aplicação do suplemento }(24,5 \%) .24,1 \% \text { das } \\
\text { crianças nunca haviam sido suplementadas e } 72,4 \% \text {, ao menos uma vez, porém, } 74,3 \% \text { há mais de seis meses, representando } \\
\text { descontinuidade na cobertura (entrevistas com responsáveis pelos programas ou aplicação do suplemento; análise de cadernetas de } \\
1.211 \text { crianças; } 47 \text { UBS; três municípios; } 2007) .{ }^{84}\end{array}$ \\
\hline \multirow{3}{*}{$\begin{array}{l}\text { Assistênci } \\
\text { a e } \\
\text { tratamento } \\
\text { de } \\
\text { doenças e } \\
\text { agravos } \\
\text { relaciona } \\
\text { dos à } A \& N\end{array}$} & \multirow{2}{*}{ Diabetes } & $\begin{array}{l}\text { Intervenções } \\
\text { desenvolvi } \\
\text { das por } \\
\text { universida } \\
\text { des }\end{array}$ & $\begin{array}{l}\text { Belo Horizonte/MG: grupos, a cada três meses, sobre a doença, alimentação, prática de atividade física e questões psicológicas; } \\
\text { monitoramento telefônico entre os encontros presenciais, reforçando informações e apoiando dificuldades e metas (115 usuários; } 4 \\
\text { UBS; 2010) }{ }^{110} \\
\text { Ribeirão Preto/SP: grupos educativos com } 12 \text { pacientes por } 12 \text { semanas, abordando corpo e diabetes, alimentação e atividade física, } \\
\text { tratamento medicamentoso, monitoração da glicose e alcance de metas; sem analisar o impacto da intervenção, verificou-se que a } \\
\text { alimentação, avaliação da glicose sanguínea, secagem dos pés e uso de medicamentos eram realizados nos padrões adequados, } \\
\text { porém, identificaram-se dificuldades para seguimento do plano alimentar ( } 72 \text { usuários; } 2 \text { UBS; 2012). }{ }^{114}\end{array}$ \\
\hline & & $\begin{array}{l}\text { Adesão e } \\
\text { Tratamento }\end{array}$ & $\begin{array}{l}\text { Passos/MG: apenas 1,4\% dos sujeitos aderiam ao tratamento completo (medicamentoso, alimentar e com prática de atividade física); } \\
1,7 \% \text {, ao medicamentoso e plano alimentar; e } 6,2 \% \text { seguiam as orientações dietéticas. Em mais da metade das UBS (52,9\%) não } \\
\text { houve adesão ao plano alimentar, sendo esse um dos maiores desafios para as equipes ( } 423 \text { usuários; } 17 \text { UBS; } 2010) .{ }^{52} \\
\text { Belo Horizonte/MG: médicos tendem a superestimar o risco de complicações e a subestimar a adesão dos usuários ao tratamento. } \\
\text { Todos os pacientes referiram ter recebido aconselhamento dietético e a concordância sobre a adesão foi de } 78,2 \% \text { (283 pares } \\
\text { pacientes-médicos; } 108 \text { UBS; 2011). }{ }^{55}\end{array}$ \\
\hline & $\begin{array}{l}\text { Hiperten } \\
\text { são }\end{array}$ & $\begin{array}{l}\text { Intervenções } \\
\text { desenvolvi } \\
\text { das por } \\
\text { universida } \\
\text { des }\end{array}$ & $\begin{array}{l}\text { São Luís/MA: Acompanhamento de adultos e idosos ( } 6 \text { meses), divididos nos grupos controle (rotina da UBS - orientações sobre dieta } \\
\text { com baixo teor de sódio e tratamento medicamentoso) e intervenção (orientações mensais por nutricionistas). Melhoras mais } \\
\text { significativas no grupo intervenção (156 sujeitos; } 2 \text { UBS; 2010-11). }{ }^{68} \\
\text { Porto Firme/MG: Acompanhamento de mulheres, subdivididas em um grupo que recebeu } 5 \text { oficinas mensais com palestras dialogadas } \\
\text { e utilização de recursos lúdicos, e outro, em que, além das oficinas, foram realizadas } 5 \text { visitas domiciliares (VD). As orientações com } \\
\text { VD resultaram em maior adesão às mudanças nos hábitos alimentares e melhora nos parâmetros dietéticos, antropométricos, } \\
\text { bioquímicos e clínicos ( } 28 \text { mulheres; } 2009)^{95} \text {. Estratégias como as utilizadas melhoram a autopercepção, conscientização e } \\
\text { compreensão sobre o tratamento dietético; mudanças nos hábitos alimentares influenciadas pela presença do nutricionista e } \\
\text { demonstrações práticas (entrevistas e grupos focais) }{ }^{93} ; \text { adesão teve influência negativa da falta de apoio familiar, hegemonia médica } \\
\text { e do caráter prescritivo das consultas, e positiva do acesso à informação, suporte social e estratégias educativas realizadas por equipes } \\
\text { multidisciplinares. }{ }^{94}\end{array}$ \\
\hline
\end{tabular}




\section{DISCUSSÃO}

O número de artigos publicados entre 2012 e 2015 (64) encontrados nesta revisão revela grande aumento na produção científica sobre o tema nos últimos anos, considerando que os critérios de seleção foram semelhantes aos de revisão sistemática de Canella, Silva e Jaime ${ }^{9}$, que encontrou 75 (64,1\% do total) publicados em maior intervalo de tempo (2002 a 2011) de forma crescente, sendo sugerido pelas autoras que o apoio financeiro realizado pelo Ministério da Saúde neste período para pesquisas relacionadas à $A \& N$ poderia explicar o crescimento das publicações.

Apesar de a maioria dos artigos encontrados terem sido publicados a partir de 2012, 85,6\% foram desenvolvidos entre 2007 e 2011, podendo também ser decorrentes do investimento mencionado. Além disso, possível aumento da relevância nacional do tema em função da publicação da PNAB em 2006, da priorização da $A B$ e do interesse de pesquisadores e agências de fomento à pesquisa na área também podem ter influenciado esse crescimento das publicações.

Em relação à região e ao tema de pesquisa, os resultados corroboram com os achados de revisões realizadas por Canella, Silva e Jaime ${ }^{9}$ e Vasconcellos e Santos ${ }^{10}$, as quais identificaram predomínio de grupos de pesquisa e artigos desenvolvidos na região Sudeste, metodologias quantitativas ${ }^{9,10}$ e avaliação do estado nutricional ${ }^{9}$.

Desconsiderando as mulheres que não eram gestantes/puérperas/nutrizes, os principais sujeitos das ações foram indivíduos com DCNT (26,4\%). Revisão anterior já tinha apontado pesquisas com esse público como crescentes $^{9}$, mas não a ponto de superar o volume de publicações com crianças e gestantes. Assim, esses resultados reafirmam o crescimento das publicações e mostram inversão do que historicamente foi considerado público prioritário de pesquisas nesta área. ${ }^{14}$

As principais DCNT, muitas delas relacionadas à alimentação e ao sedentarismo, são responsáveis por grande parte das mortes até 70 anos, pelo desenvolvimento de incapacidades que reduzem a qualidade de vida e impactar no sistema de saúde ${ }^{15}$. Em 2013, mais da metade da população estava acima do peso $(56,9 \%)^{16}$ e já foi demonstrada tendência de crescimento entre adultos em todas as regiões, faixas etárias, escolaridades e em ambos os $\operatorname{sexos}^{17}$, aumento do custo individua ${ }^{18}$ e elevado custo para o SUS ${ }^{19}$, o que mostra a necessidade de priorização e realização de pesquisas e desenvolvimento ações de prevenção e tratamento de pessoas com DCNT, especialmente excesso de peso, em todas as faixas etárias. 
Somente em $24,4 \%$ dos artigos houve colaboração de sujeitos atuantes no serviço, em $43,3 \%$ houve participação em alguma etapa da pesquisa e $65,9 \%$ das ações identificadas foram iniciativa de universidades, podendo não representar o desenvolvido pelo serviço, o que aponta para o distanciamento entre o meio acadêmico e a gestão e o serviço. A academia tem grande potencial na proposição de intervenções que tenham impacto na situação de saúde e avaliação de políticas e programas existentes para aprimorá-los, contudo, esses dados mostram que a academia tem somente absorvido dados do sistema de saúde para uma produção pouco inovadora e distante da realidade, contribuindo pouco para o funcionamento e efetividade do sistema nesta área, que necessita de evidências que tenham como foco estratégias efetivas para a reversão da má-nutrição e a promoção da saúde.

A articulação entre gestão, atenção, ensino e controle social é fundamental tanto para o SUS quanto para as instituições de ensino, por permitir realização conjunta de diagnóstico local, formulação de soluções baseadas em evidências, implementação de ações para enfrentamento de problemas e avaliação das intervenções. Ainda, o contato com a gestão e serviço é necessário às instituições para que a educação superior e profissional, a produção de conhecimentos e 0 desenvolvimento de pesquisas sejam pautados na realidade local e nas RAS e estejam alinhados às necessidades da população. ${ }^{20,21}$

Apesar de, de forma geral, as pesquisas serem pouco inovadoras e focarem no diagnóstico alimentar e nutricional, a maior parte utilizou características socioeconômicas, de hábitos de vida, histórico de saúde e acesso a serviços para descrição e compreensão das relações existentes entre esses fatores e variáveis antropométricas e de consumo. Conhecer a realidade, realizando diagnósticos que considerem a complexidade da alimentação e os determinantes da saúde, é fundamental para que sejam planejadas ações mais efetivas para os usuários.

Além disso, os achados correspondem a dados da população local e podem ser utilizados pelas equipes, sendo, para isso, importante que haja retorno de resultados aos participantes e aos gestores, equipes e controle social ${ }^{22}$. Ainda é possível que gestores e equipes utilizem questões validadas pelos pesquisadores e criem instrumentos para avaliação abrangente do território, caso os sistemas de informação existentes, que já possibilitam conhecer a situação de saúde da população quando alimentados sistematicamente, não sejam considerados suficientes. 
Entre os artigos que descreveram ações da gestão, somente foram encontradas publicações sobre a gestão federal, que possibilitaram verificar evolução das ações priorizadas nos períodos pré e pós-revisão da PNAN. Foi possível identificar, em âmbito nacional, maior consolidação da $A B$ e estruturação das ações de $A \& N$ neste ponto de atenção nos últimos anos. Além disso, no período pré-revisão tinha sido identificada a necessidade de organizar ações para todo o ciclo de vida, que apareceram de forma mais consistente para faixas-etárias além das crianças no segundo momento; assim como as ações de PAAS, que, apesar de reconhecidas como estratégicas anteriormente, foram pouco mencionadas entre as ações avaliadas como prioritárias para a $A B$, estando mais presentes nos artigos pós-revisão. Possivelmente, tais mudanças devam-se a novas prioridades de gestão, a maior consolidação da área na $A B$ e à necessidade de adequação ao cenário epidemiológico.

Por não terem sido encontrados artigos sobre gestões estaduais e municipais, não foi possível identificar se essas possuíam prioridades semelhantes ou diferentes da nacional, nem suas especificidades locais. Sabe-se que o trabalho na gestão das ações de $A \& N$ possui número reduzido de recursos humanos ${ }^{23}$, contudo, a divulgação das ações, além dos relatórios de prestação de contas, por meios diversos, como o científico, poderia possibilitar a ampliação do conhecimento da população do que a gestão tem feito, ser utilizado por outros gestores para identificação de experiências baseadas na realidade, além de representar importante contribuição para a meio acadêmico e tornar-se registro histórico da gestão. Além disso, trata-se de um campo a ser mais explorado pelas universidades.

Em relação à força de trabalho, o foco dos artigos encontrados foi sobre o profissional nutricionista. Foi verificada grande incorporação nas eAB tradicionais, eSF e NASF nos últimos anos e reconhecimento de sua importância e de suas atribuições pelas equipes.

O aumento de nutricionistas na $A B$ pode potencializar as ações de $A \& N$, especialmente, em função de seus conhecimentos técnicos, que podem ser compartilhados com os demais profissionais de saúde, para enfrentamento do atual cenário epidemiológico ${ }^{7}$. Contudo, é fundamental que essa incorporação seja qualificada e aliada à realização de matriciamento e estratégias de educação permanente e continuada voltada aos demais profissionais da equipe na temática. 
2,7,24 Além disso, ressalta-se que a gestão tem responsabilidade de avaliar quais os profissionais de saúde necessários a partir de análise da situação de saúde local. ${ }^{4}$

As ações de PAAS majoritariamente identificadas foram de incentivo à alimentação adequada e saudável, a partir de aconselhamento, implantação da Rede Amamenta Brasil ou realização de grupos para a população. Tendo em vista que as ações de incentivo visam à difusão de informações para empoderamento e adoção dessas práticas no cotidiano dos sujeitos ou grupos populacionais e as de apoio facilitam a adoção dessas práticas ${ }^{25}$ e considerando as atribuições das eAB, era esperada maior prevalência dessas ações.

A realização de aconselhamento individual e em grupo, especialmente quando utilizadas metodologias ativas baseadas em comportamentos e necessidades do indivíduo, são fundamentais para ampliar conhecimento e apoiar sujeitos na realização de escolhas mais saudáveis ${ }^{26-28}$, como pode ser verificado nas ações de PAAS, EAN para prevenção e de assistencia e tratamento nutricional desta revisão. ${ }^{39,50,68,70,77,80,95,110,115}$

Destaca-se que, apesar de o cenário epidemiológico mostrar o crescimento da obesidade em todas as faixas etárias, foram poucas as pesquisas relacionadas ao cuidado nutricional relacionado a sujeitos com obesidade, sendo que nenhuma correspondia à obesidade na infância e adolescência. Da mesma forma, não foram encontrados artigos com ações relacionadas ao tratamento de sujeitos com necessidades alimentares especiais, como as decorrentes dos erros inatos do metabolismo e intolerâncias e alergias alimentares, e em uso de terapia nutricional enteral. Apesar de não haver dados de inquéritos nacionais para esses últimos, são identificados como problemas crescentes e alvo de alta judicialização para o SUS, demandando organização do cuidado e desenvolvimento de ações efetivas no âmbito da atenção básica. ${ }^{2,29}$

Em relação às pesquisas que trouxeram ações de $A \& N$ realizadas na $E S F$, no PBF ou que avaliaram a implantação de ações e programas de $A \& N$ de forma mais abrangente, estas permitiram visão mais completa das ações desenvolvidas pelas equipes ou municípios. ${ }^{80,84,88,90,96,97,102,111,113}$

A formulação e implementação de programas e ações é influenciada por diversos aspectos relacionados à prioridade dos gestores, à disponibilidade de recursos financeiros, humanos e de materiais e insumos, à existência de estrutura física adequada, às demandas dos usuários e outros grupos de interesses, à 
capacidade técnica e operacional, entre outros. ${ }^{30}$ Nesse sentido, conhecer os diversos fatores sobre o desenvolvimento das ações e que impactam sobre essas auxilia a definição de estratégias prioritárias que ajam sobre esses fatores e possam levar ao aprimoramento das ações desenvolvidas.

Esse estudo apresenta como limitação o uso de descritores pré-definidos, que podem ter restringido os artigos encontrados sobre o tema, tanto pelo fato de pesquisadores do tema poderem não ter escolhido descritores relacionados que permitissem ser encontrados nesta pesquisa, quanto pelos autores deste artigo poderem ter deixado algum descritor importante de fora da pesquisa.

\section{CONSIDERAÇÕES FINAIS}

O crescimento da produção sobre ações de $A \& N$ no âmbito da $A B$ mostra aumento no interesse e relevância nacional do tema. Contudo, a produção acadêmica ainda está distante das necessidades reais de geração de evidências que impactem positivamente sobre a situação de saúde da população.

Assim, a partir da revisão, podem ser identificados alguns temas que ainda precisam ser explorados pela academia, como pesquisas que proponham intervenções inovadoras, viáveis e efetivas ou avaliem ações e programas existentes, especialmente relacionados à prevenção, controle e tratamento da obesidade em todas as faixas etárias. Não foram identificadas pesquisas que abordassem articulação da $A B$ com outros pontos da RAS e da $A B$ com outros setores, além da educação. Também há lacunas na produção de pesquisas que abordem as necessidades alimentares especiais e a terapia nutricional neste ponto de atenção. No âmbito da gestão da $A B$ na área, há ausência de pesquisas que identifiquem suas lacunas e desenvolvam ferramentas que a auxiliem a superá-las, proponham métodos inovadores para a educação permanente, discutam sobre recursos humanos para além de nutricionistas, explorem as potencialidades dos NASF e desenvolvam avaliações de impacto das ações e análises econômicas sobre o tema.

Nesse sentido, é fundamental maior aproximação entre academia e gestão/serviço para alinhamento de interesses e maior produção de pesquisas que respondam às necessidades da área de $A \& N$ na atenção básica do SUS e possam contribuir para planejamento e aperfeiçoamento do que vem sendo realizado. Para tanto, além da necessidade de pesquisadores estarem atentos às necessidades do 
sistema, também é essencial que haja priorização e financiamento para esse tipo de pesquisas por agências de fomento e gestores das três esferas de governo.

\section{REFERÊNCIAS BIBLIOGRÁFICAS}

1. Food and Agriculture Organization of the United Nations. World Health Organization. Rome Declaration on Nutrition: Second International Conference on Nutrition. Rome: FAO/WHO, 2014.

2. Ministério da Saúde (BR). Secretaria de Atenção à Saúde. Departamento de Atenção Básica. Política Nacional de Alimentação e Nutrição. Brasília, DF: 2012.

3. Brasil. Constituição (1988). Emenda Constitucional no90, de 15 de setembro de 2015. Dá nova redação ao art. 6º da Constituição Federal, para introduzir o transporte como direito social. DOU. 16/9/2015. 2015.

4. Ministério da Saúde (BR). Secretaria de Atenção à Saúde. Departamento de Atenção Básica. Política Nacional de Atenção Básica. Brasília: Ministério da Saúde, 2012b.

5. Coutinho JG, Gentil PC, Toral N. A desnutrição e obesidade no Brasil: o enfrentamento com base na agenda única da nutrição. Cad Saúde Pública. 2008; 24 (Sup 2):332-340

6. Jaime PC, Santos LMP. Transição nutricional e a organização do cuidado em alimentação e nutrição na Atenção Básica em saúde. Divulgação em Saúde para Debate. 2014; 51:72-85.

7. Jaime PC, Silva ACS, Lima AMC, Bortolini GA. Ações de alimentação e nutrição na atenção básica: a experiência de organização no Governo Brasileiro. Rev. Nutr. 2011; 24(6):809-824.

8. Magalhães Junior HM, Pinto HA. Atenção Básica enquanto ordenadora da rede e coordenadora do cuidado: ainda uma utopia? Divulgação Saúde para Debate. 2014; 51: 14-29. http://cebes.org.br/site/wpcontent/uploads/2014/12/Divulgacao-51.pdf

9. Canella DS, Silva ACFS, Jaime PC. Produção científica sobre nutrição no âmbito da atenção primária à saúde no Brasil: uma revisão da literatura. Cien Saude Coletiva. 2013; 18(2):297-308.

10. Vasconcelos IAL, Santos LMP. Research potential of food and nutrition in the Family Health Strategy: A structured review. Rev. Nutr.2014;27(1):107-126 
11. Moher D, Liberati A, Tetzlaff J, Altman DG, The PRISMA Group (2009). Preferred Reporting Items for Systematic Reviews and Meta-Analyses: The PRISMA Statement. PLoS Med 6(7): e1000097. doi:10.1371/journal.pmed1000097

12. Ministério da Saúde (BR). Secretaria de Atenção à Saúde. Departamento de Atenção Básica. Política Nacional de Atenção Básica. Brasília: Ministério da Saúde, 2006.

13. Ministério da Saúde (BR). Secretaria de Atenção à Saúde. Departamento de Atenção Básica. Matriz de Ações de Alimentação e Nutrição na Atenção Básica à Saúde. Brasília, DF: 2009.

14. Ministério da Saúde (BR). Secretaria de Atenção à Saúde. Departamento de Atenção Básica. Coordenação-Geral da Política de Alimentação e Nutrição. Política Nacional de Alimentação e Nutrição. Brasília, DF: 2012.

15. Schmidt $\mathrm{Ml}$ et al. Doenças crônicas não transmissíveis no Brasil: carga e desafios atuais. Lancet.2011: 61-74

16. Instituto Brasileiro de Geografia e Estatística. Pesquisa Nacional de Saúde 2013. Rio de Janeiro: IBGE; 2015

17. Malta, et al. Tendência temporal dos indicadores de excesso de peso em adultos nas capitais brasileiras, 2006-2013. Cien Saúde Coletiva.2016;21(4):1061-1069.

18. Canella DS, Novaes HMD, Levy RB. Influência do excesso de peso e da obesidade nos gastos em saúde nos domicílios brasileiros. Cad. Saúde Pública.2015;31(11):2331-2341

19. Oliveira ML. Estimativa dos custos da obesidade para o Sistema Único de Saúde do Brasil. 2013. Tese (Doutorado em Nutrição Humana) - Universidade de Brasília. Brasília, 2013.

20. Ceccin RB, Feuerwerker LCM. O quadrilátero da formação para a área da saúde: ensino, gestão, atenção e controle social. Physis.2004;14(1):41-65.

21. Barata RB. Epidemiologia e políticas públicas. Rev. bras. epidemiol. 2013;16(1):3-17

22. Ministério da Saúde (BR). Conselho Nacional de Saúde. Resolução no466, de 12 de dezembro de 2012. DOU. 13jun2013; Seção1:59.

23. Ministério da Saúde (BR). Secretaria de Atenção à Saúde. Departamento de Atenção Básica. Coordenação-Geral de Alimentação e Nutrição. Relatório de Gestão 2011-2014. Brasília: Ministério da Saúde,2016 [no prelo]. 


\section{ARTIGOS INCLUÍDOS NA REVISÃO}

5. Coutinho JG, Gentil PC, Toral N. A desnutrição e obesidade no Brasil: o enfrentamento com base na agenda única da nutrição. Cad Saúde Pública. 2008; 24 (Sup 2):332-340

7. Jaime PC, Silva ACS, Lima AMC, Bortolini GA. Ações de alimentação e nutrição na atenção básica: a experiência de organização no Governo Brasileiro. Rev. Nutr. 2011; 24(6):809-824.

24. Boreli et al $A$ inserção do nutricionista na Atenção Básica: uma proposta para o matriciamento da atenção nutricional. Ciên Saúde Coletiva.2015;20(9):27652778.

25. Castro IRRC, Castro LMC, Gugelmin SA. Ações educativas, programas e políticas envolvidos nas mudanças alimentares. In: Diez-Garcia RW, CervatoMacuso AM (coord). Rio de Janeiro: Guanabara-Koogan; 2012.

26. McKevith B1, Stanner S, Butriss J. Food choices in primary care: a summary of the evidence.Nurs Times.2005;101(40):38-42.

27. Anderson P. Reducing overweight and obesity: closing the gap between primary care and public health. Fam Pract. 2008; 25 Suppl 1:i10-6.

28. Rollins NC, et al. Lancet Breastfeeding Series: Why invest, and what it will take to improve breastfeeding practices in less than a generation. Lancet. 2016;387:491-504.

29. Pereira TN, Silva KC, Pires ACL, Alves KPS, Lemos ASP, Jaime PC. Perfil das demandas judiciais para fornecimento de fórmulas nutricionais encaminhadas ao ministério da saúde do Brasil. DEMETRA. 2014; 9: 199-214.

30. Capella AC. Perspectivas teóricas sobre o processo de formulação de políticas públicas. BIB. 2006; 61:20-40.

31. Aires JS, et al. (In) segurança alimentar em familias de pré-escolares de uma zona rural do Ceará. Acta Paul Enferm. 2012;25(1):102-108.

32. Alvarenga MRM, et al. Evaluation of the nutritional risk in elderly assisted by family health teams. Rev Esc Enferm.2010;44(4): 1046-1051.

33. Alves CRL, et al. Alimentação complementar em crianças no segundo ano de vida. Rev Paul Pediatr.201230(4):499-506.

34. Amer NM, Marcon SS, Santana RG. Body mass index and hypertension in adult subjects in Brazil's midwest. Arq Bras Cardiol.2011;96(1):47-53. 
35. Andrade KA, et al. Counseling regarding healthy lifestyles in primary healthcare and the dietary practices of clients. Rev Esc Enferm.2012;46(5):1117-1124.

36. Anunciação PC et al. Different measurements of waist circumference and sagittal abdominal diameter and their relationship with cardiometabolic risk factors in elderly men. J Human Nutr Dietetics.2014;27(2):162-167.

37. Arimura ST et al. Waist circumference is better associated with high density lipoprotein (HDL-c) than with body mass index (BMI) in adults with metabolic syndrome. Nutr Hosp.2011;26(6):1328-32.

38. Azeredo CM, et al. Efetividade superior do esquema diário de suplementação de ferro em lactentes. Rev Saude Publica. 2010;44(2):230-239.

39. Badalotti TS, Weigert KL, Bos ÂJG. Efeito de um programa de educação em saúde no perfil de saúde bucal de pré- escolares: uma experiência na rede pública de Porto Alegre, Brasil. Rev. Bras Promoç. Saúde. 2013;26(1):102-109.

40. Brandão DS, Venancio SI, Giugliani ERJ. Association between the Brazilian Breastfeeding Network implementation and breastfeeding indicators. J Pediatr.2015; $91(2): 143-151$.

41. Broilo MC, et al. Maternal perception and attitudes regarding healthcare professionals' guidelines on feeding practices in the child's first year of life. $\mathrm{J}$ Pediatr.2013;89(5):485-91.

42. Bubach S, Oliveira ERA. Associação entre o controle da pressão arterial e o estado nutricional em hipertensos. Rev. enferm. UERJ. 2013;19(3):415-419.

43. Buccini GS, Benício MHD, Venancio SI. Determinants of using pacifier and bottle feeding. Rev Saude Publica. 2014; 48(4), 571-582.

44. Camossa ACA, Telarolli Jr R, Machado MLT. O fazer teórico-prático do nutricionista na estratégia saúde da família: representações sociais dos profissionais das equipes. Rev. Nutr.2012;25(1):89-106.

45. Carvalhaes MABL, et al. Prepregnancy overweight is associated with excessive weight gain during pregnancy. Rev Bras Ginecol Obstet. 2013;35(11):523-529.

46. Carvalho AT et al. Situação nutricional de crianças menores de cinco anos em municípios do Nordeste Brasileiro. J Human Growth Develop. 2014;24(2).

47. Chaffee BW, Feldens CA, Vítolo MR. Cluster-randomized trial of infant nutrition training for caries prevention. J Dent Research. 2013;92(7 Suppl):29S-36S. 
48. Costa LR, Daher A, Queiroz MG. Early Childhood Caries and Body Mass Index in Young Children from Low Income Families. Int $\mathrm{J}$ Environ Res Public Health.2013; 10(3):867-878.

49. Dalla-Costa MC, et al. Estado nutricional de adolescentes atendidos em uma unidade de referência para adolescentes no município de Cascavel, estado do Paraná, Brasil. Epidemiol Serv Saúde. 2011;20(3):355-361.

50. Deus RM, et al. Impacto de intervenção nutricional sobre o perfil alimentar e antropométrico de usuárias do Programa academia da saúde. Cienc saúde coletiva. 2015; 20(6):1937-1946.

51. Facchini LA et al. Insegurança alimentar no Nordeste e Sul do Brasil: magnitude, fatores associados e padrões de renda per capita para redução das iniquidades. Cad Saúde Pública. 2014;30(1):161-174.

52. Faria HTG et al. Adesão ao tratamento em diabetes mellitus em unidades da Estratégia Saúde da Família. Rev. Esc Enferm. 2014; 48(2):257-63.

53. Ferreira MCS, Detregiachi CRP, Oliveira MRM. Qualidade das medidas de peso produzidas em unidades de atenção básica à saúde da região de Botucatu-SP, Brasil. Rev. Soc. Bras. Aliment. Nutr. 2011;36(3):27-36.

54. Ferreira PM, Papini SJ, Corrente JE. Diversity of eating patterns in older adults: A new scenario? Rev Nutr.2014;27(1):67-79.

55. Figueiredo RCD, et al. Do patients and physicians agree on diabetes management? A study conducted in Public Healthcare Centres in Brazil. Patient Educ Couns.2013;92(1):107-113.

56. Florindo AA et al. Association of knowledge, preventive counseling and personal health behaviors on physical activity and consumption of fruits or vegetables in community health workers Health behavior, health promotion and society. BMC Public Health. 2015;15(1):1-8.

57. Fontbonne A, et al. Risk factor control in hypertensive and diabetic subjects attended by the Family Health Strategy in the State of Pernambuco, Brazil: the SERVIDIAH study. Cad Saúde Pública.2013;29(6):1195-204.

58. Freitas LC et al. Perfil dos hipertensos da Unidade de Saúde da Família Cidade Nova 8, município de Ananindeua-PA. RBMFC.2012;7(22): 13-19.

59. Freitas LJQ, et al. Amamentação ineficaz entre nutrizes atendidas em unidades básicas de saúde. Rev enferm UERJ. 2014.22(1):103-110. 
60. Gadenz SD, Benvegnú LA. Eating habits in the prevention of cardiovascular diseases and associated factors in elderly hypertensive individuals. Cien Saude Coletiva.2013;18(12):3523-3533.

61. Girotto E, Andrade SM, Cabrera MAS. Prevalência de obesidade abdominal em hipertensos cadastrados em uma Unidade de Saúde da Família. Arq Bras Cardiol. 2010; 94(6):754-762.

62. Gomes $\mathrm{CB}$, et al. Práticas alimentares de gestantes e mulheres não grávidas: há diferenças? Rev Bras Ginecol Obstetr. 2015;37(7):325-332.

63. Horta PM, et al. Dietary quality maintained among overweight Brazilian women enrolled in a primary healthcare service. J Health Popul Nutr. 2014;32(4):60814.

64. Jaime PC, et al. Brazilian obesity prevention and control initiatives. Obes Rev. 2013;14(S2):88-95.

65. Jesus MCP, et al. Atualização dos dados nos sistemas de informação em saúde. Rev. enferm. UERJ. 2013;20(2):795-801.

66. Jung NM, Bairros FS, Neutzling MB. Utilização e cobertura do Sistema de Vigilância Alimentar e Nutricional no Estado do Rio Grande do Sul, Brasil. Ciên Saúde Coletiva. 2014;19(5):1379-1388.

67. Lima LA et al. Food habits of hypertensive and diabetics cared for in a primary health care service in the South of Brazil. Rev Nutr. 2015;28(2):197-206.

68. Lima STRM, et al. Reductions in glycemic and lipid profiles in hypertensive patients undergoing the Brazilian Dietary Approach to Break Hypertension: a randomized clinical trial. Nutrition Research.2014;34(8):682-687.

69. Lopes ACS, et al. Condições de saúde e aconselhamento sobre alimentação e atividade física na atenção primária à saúde de Belo Horizonte-MG. Epidemiol Serv Saúde.2014;23(3):305-316.

70. Machado $\mathrm{CH}$, et al. Efetividade de uma intervenção nutricional associada à prática de atividade física. Cad Saúde Coletiva.2013;21(2):148-153.

71. Malta DC, et al. Balanço do primeiro ano da implantação do Plano de Ações Estratégicas para o Enfrentamento das Doenças Crônicas Não Transmissíveis no Brasil, 2011 a 2022. Epidemio. serv saúde. 2013;22(1):171-178.

72. Mariath $A B$, et al. Estado de ferro e retinol sérico entre crianças e adolescentes atendidos por equipe da Estratégia de Saúde da Família de Itajaí, Santa Catarina. Ciênc. saúde coletiva,2010;15(2):509-516. 
73. Marinho NBP, et al. Risk for type 2 diabetes mellitus and associated factors. ACTA Paul Enferm.2013;26(6):569-574.

74. Marinho NBP, et al. Diabetes mellitus: fatores associados entre usuários da estratégia saúde da família. Acta paul. enferm. 2012;25(4):595-600.

75. Marques ES, et al. Práticas e percepções acerca do aleitamento materno: consensos e dissensos no cotidiano de cuidado numa unidade de saúde da família. Physis.2009;19(2):439-455.

76. Martins MV et al. Anthropometric indicators of obesity as predictors of cardiovascular risk in the elderly. Nutr Hosp. 2015;31(6):2583-2589

77. Menezes MC, et al. Intervention based on Transtheoretical Model promotes anthropometric and nutritional improvements - A randomized controlled trial. Eat Behav. 2015;17:37-44.

78. Moraes AL, Almeida EC, Souza LB. Perceptions of depressed obese people about the factors associated with the maintenance of their obesity: An investigation in a family health program in Rio de Janeiro city. Physis. 2013;23(2):553-572.

79. Niquini RP, et al. User embracement and maternal characteristics associated with liquid offer to infants. Rev Saude Publica. 2010;44(4):677-685.

80. Niquini RP, et al. Avaliação do processo da assistência nutricional no pré-natal em sete unidades de saúde da família do Município do Rio de Janeiro. Ciên Saúde Coletiva. 2012;17(10):2805-2816.

81. Oliveira FCC, et al. Programa Bolsa Família e estado nutricional infantil: desafios estratégicos. Cien Saude Coletiva.2011;16(7):3307-3316.

82. Oliveira $\mathrm{T}$, et al. Desenvolvimento de um Questionário Quantitativo de Freqüência Alimentar (QQFA) para gestantes usuárias de Unidades Básicas de Saúde de Ribeirão Preto, São Paulo, Brasil. Cad Saude Publica.2010;26(12):2296-2306.

83. Oliveira $\mathrm{CB}$, et al. As ações de educação em saúde para crianças e adolescentes nas unidades básicas da região de Maruípe no município de Vitória. Ciênc saúde coletiva.2009;14(2):635-644.

84. Paiva AA, et al. Programa Nacional de Suplementação de Vitamina A no estado da Paraíba: uma análise a partir do relato de profissionais da Equipe de Saúde da Família. Epidemiol serv saúde.2011;20(3):373-383. 
85. Palombarini AF, et al. Nutritional practices of expectant mothers supported by a family health unit: An exploratory study. Online Brazilian Journal of Nursing. 2014;13(2), 186-197.

86. Passanha A, et al. Implantacao da Rede Amamenta Brasil e prevalencia de aleitamento materno exclusivo. Rev Saude Publica.2013;47(6):1141-1148.

87. Peixoto MRG, et al. Insegurança alimentar na área de abrangência do Núcleo de Apoio à Saúde da Família em Itumbiara, Goiás. Epidemiol serv saúde.2014;23(2):327-336.

88. Pellegrine JB, et al. Educação Popular em Saúde: doação de leite humano em comunidade do Rio de Janeiro, Brasil. Interface comun. saúde educ.2014;18(supl.2):1499-1506.

89. Pereira SMPD, et al. Operacionalização do sistema de vigilância alimentar e nutricional em Juazeiro do Norte, Ceará. Rev. baiana saúde pública. 2013;36(2):577-586.

90. Pimentel VRM, et al. Alimentação e nutrição na Estratégia Saúde da Família em cinco municípios brasileiros. Ciênc. saúde coletiva.2014;19(1):49-58.

91. Queluz MC, et al. Prevalência e determinantes do aleitamento materno exclusivo no município de Serrana, São Paulo, Brasil. Rev Esc Enferm USP.2012;46(3):537-543.

92. Reis RS, et al. Perfil sociossanitário, gestacional e de aleitamento materno das gestantes cadastradas nas unidades de atenção primária à saúde de ViçosaMG. Rev méd Minas Gerais.2011;21(3).

93. Ribeiro AG. Hypertension and educational home visits: The strategic role of family healthcare. Rev Nutr.2012;25(2):271-282.

94. Ribeiro AG, et al. Representações sociais de mulheres portadoras de hipertensão arterial sobre sua enfermidade: desatando os nós da lacuna da adesão ao tratamento na agenda da Saúde da Família. Physis (Rio J.).2011;21(1):87-112.

95. Ribeiro AG, et al. Non-pharmacological treatment of hypertension in primary health care: A comparative clinical trial of two education strategies in health and nutrition. BMC Public Health.2011;11(1):637.

96. Ricardi LM, Sousa MF. Educação permanente em alimentação e nutrição na Estratégia Saúde da Família: encontros e desencontros em municípios brasileiros de grande porte. Ciênc saúde coletiva.2015;20(1):209-218. 
97. Rocha ACD, Pedraza DF. Acompanhamento do crescimento infantil em unidades básicas de saúde da família do município de Queimadas, Paraíba, Brasil. Texto \& contexto enferm.2013;22(4):1169-1178.

98. Romagna ES, Silva MCA, Ballardin PAZ. Prevalência de sobrepeso e obesidade em crianças e adolescentes de uma unidade básica de saúde em Canoas, Rio Grande do Sul, e comparação do diagnóstico nutricional entre os gráficos do CDC 2000 e da OMS 2006. Sci med. 2010;20(3):228-231.

99. Sanches MTC, et al. Fatores associados à interrupção do aleitamento materno exclusivo de lactentes nascidos com baixo peso assistidos na atenção básica. Cad Saude Publica.2011;27(5):953-965.

100. Silva AMLV, Taquette SR, Hasselmann MH. Family violence and body mass index among adolescents enrolled in the Bolsa Família Program and treated at a primary care clinic. Cad Saude Publica. 2014;30(3):645-655.

101. Silva DAS. Overweight and obesity in five- to ten-year-old children benefited from Bolsa Família Program in the State of Sergipe, Brazil. Rev Paul Pediatr 2011;29(4):529-535.

102. Silva EP, Lima RT, Ferreira NLS, Costa MJC. Pré-natal na atenção primária do município de João Pessoa-PB: caracterização de serviços e usuárias. Rev bras saúde matern infant.2013;13(1):29-37.

103. Silva LLS, et al. Estado nutricional de vitamina $A$ e fatores associados em lactentes atendidos em Unidades Básicas de Saúde de Goiânia, Goiás, Brasil. Rev Bras Epidemiol.2015; 18(2): 490-502

104. Silva NA, Menezes TN, Melo RLP, Pedraza DF. Handgrip strength and flexibility and their association with anthropometric variables in the elderly. Rev Assoc Med Bras. 2013;59(2):128-135.

105. Silva SM et al. Recebimento de orientação sobre consumo de sal, açúcar e gorduras em adultos: um estudo de base nacional. Rev bras epidemiol. 2013; 16(4):995-1004.

106. Soares LDA et al. Análise do desempenho motor associado ao estado nutricional de idosos cadastrados no Programa Saúde da Família, no município de Vitória de Santo Antão-PE. Ciên Saúde Coletiva.2012;17(5):1297-1304.

107. Sousa EL, et al. Eating habits: knowledge of pregnant teenagers assisted in primary care. Rev. Pesqui. Cuid. Fundam. (Online).2013;5(4):661-670. 
108. Squarcini CFR, Jesus GM, Petroski EL. Ficha antropométrica nos Núcleos de Apoio à Saúde da Família: Potencialidades e obstáculos. Rev Bras Cineantropom Desempenho Hum.2015;17(2):248-255.

109. Stephan AMS, Cavada MN, Vilela CZ. Prevalência de aleitamento materno exclusivo até a idade de seis meses e características maternas associadas, em área de abrangência de unidade de Saúde da Família no município de Pelotas, estado do Rio Grande do Sul, Brasil, 2010. Epidemiol Serv Saúde. 2012; 21(3): 431-438.

110. Torres HC, Reis IA, Roque C, Faria P. Monitoramento telefônico como estrategia educativa para o autocuidado das pessoas com diabetes na atenção primária. Cienc. Enferm.2013;19(1):95-105.

111. Trevisani JJD, Jaime PC. Acompanhamento das condicionalidades da saúde do Programa Bolsa Família: estudo de caso no Município do Rio de Janeiro-RJ, Brasil, em 2008. Epidemiol Serv Saúde.2012;21(3):385-394.

112. Vasconcelos IAL, Sousa MF, Santos LMP. Evolução do quantitativo de nutricionistas na Atenção Básica do Brasil: a contribuição dos Núcleos de Apoio à Saúde da Família e da Estratégia Saúde da Família de 2007 a 2013. Rev Nutr.2015;28(4):431-450.

113. Venâncio SI, et al. Análise de implantação da Rede Amamenta Brasil: desafios e perspectivas da promoção do aleitamento materno na atenção básica. Cad Saude Publica.2013;29(11):2261-2274.

114. Veras VS, et al. Autocuidado de pacientes inseridos em um programa de automonitorização da glicemia capilar no domicílio. Rev Gaúcha Enferm.2014;35(4):42-8.

115. Vítolo MR, Bueno MSF, Gama CM. Impacto de um programa de orientação dietética sobre a velocidade de ganho de peso de gestantes atendidas em unidades de saúde. Rev Bras Ginecol Obstet.2011;33(1):13-9.

116. Winkelmann ER, Fontela PC. Condições de saúde de pacientes com diabetes mellitus tipo 2 cadastrados na Estratégia Saúde da Família, em ljuí, Rio Grande do Sul, 2010-2013. Epidemiol serv saúde. 2014;23(4):665-674. 
5.2 AÇÕES DE NUTRIÇÃO NO BRASIL: DESCRIÇÃO A PARTIR DA IV MOSTRA NACIONAL DE EXPERIÊNCIAS DA ATENÇÃO BÁSICA/SAÚDE DA FAMÍLIA e

Tatiane Nunes Pereira

Leonor Maria Pacheco dos Santos

RESUMO

Introdução: Alimentação e nutrição são requisitos para a promoção da saúde e prevenção e tratamento de doenças, sendo essenciais no contexto da atenção básica. Conhecer as ações desenvolvidas na atenção básica na área de alimentação e nutrição é fundamental para identificar lacunas e potencialidades. Objetivo: Descrever as experiências relacionadas à alimentação e nutrição na atenção básica aprovadas na IV Mostra de Experiências em Atenção Básica/Saúde da Família. Métodos: Foram identificadas e analisadas as experiências, a partir do título dos relatos aprovados para Dedo de Prosa e Ciranda de Experiência, e da análise dos relatos. Resultados: Foram encontrados 81 relatos, predominantemente das regiões Sudeste e Nordeste, realizadas em âmbito local, tendo como temas principais o excesso de peso e alimentação adequada e saudável. A maioria das ações ocorreu de forma multidisciplinar e com articulação intersetorial, porém com baixa articulação com a rede de atenção à saúde. Considerações Finais: As experiências analisadas permitiram obter retrato nacional do que equipes têm desenvolvido na atenção básica na área, possibilitando reflexões sobre suas práticas, necessidades e dificuldades para a realização das ações.

Palavras-chave: Atenção Primária à Saúde; Nutrição em Saúde Pública; Saúde Pública; Alimentação; Programas e Políticas de Nutrição e Alimentação

\footnotetext{
e Artigo submetido à Revista Ciência \& Saúde Coletiva
} 


\section{INTRODUÇÃO}

A oferta de ações de alimentação e nutrição $(A \& N)$ que proporcionem cuidado integral e contínuo à população e contribua para a redução de iniquidades nos serviços de saúde é essencial para a promoção da saúde e prevenção doenças e agravos relacionados à $A \& N .{ }^{1}$

No Brasil, A\&N são direitos constitucionais, que devem ser garantidos por meio de políticas públicas. Nesse contexto, a Política Nacional de Alimentação e Nutrição (PNAN) norteia a organização das ações de A\&N no Sistema Único de Saúde, orientando que estas devem permear todos os pontos da Rede de Atenção à Saúde (RAS), tendo a Atenção Básica ( $A B)$ como principal lócus de atuação. ${ }^{2,3}$

Contudo, descrições de ações de $A \& N$ neste ponto de atenção ainda são escassas. Assim, os relatos da IV Mostra Nacional de Experiências em Atenção Básica/Saúde da Família constituem-se como fonte a ser explorada para conhecer as ações de $A \& N$ na $A B$. Assim, este artigo tem o objetivo de descrever as experiências relacionadas à $A \& N$ na $A B$ aprovadas na IV Mostra de Experiências em Atenção Básica/Saúde da Família.

\section{MÉTODOS}

Trata-se de estudo descritivo, realizado por meio da identificação e análise das experiências relacionadas à $A \& N$ aprovadas na IV Mostra de Experiências em AB/SF.

A IV Mostra foi um evento realizado em 2014 com o objetivo de promover o compartilhamento de experiências entre gestores, trabalhadores e usuários da $A B$ ou que possuíam interface com esta. A inscrição dos relatos foi realizada no sítio eletrônico "Comunidade de Práticas". ${ }^{4}$

Dos 4.612 relatos inscritos, cerca de 2.000 tiveram a opção de receber contribuições de curadores, cuja atribuição era colaborar para qualificação do relato. Por meio de avaliação de pares (os próprios autores avaliaram relatos de autores de outras regiões) e cotas regionais (CO 8\%, S 13\%, SE 32\%, N 10\% e NE 37\%), foram selecionados 1.380 relatos para as modalidades Ciranda de Experiência e Dedos de Prosa. $^{4}$

Para este artigo, a identificação dos relatos que descreviam ações de $A \& N$ foi realizada após o final do período de inscrições por avaliação do título, dentre a lista 
dos aprovados em todos os eixos temáticos das modalidades mencionadas acima, e do relato completo.

Para a caracterização das ações, os dados foram agrupados em região, âmbito de realização, tema da ação, público-alvo, tipo de ação, existência de mais de uma categoria profissional atuando na ação, realização de parcerias e articulações intersetoriais e com outros pontos da RAS e sobre a forma do público-alvo conhecer/participar da ação desenvolvida. Quando realizadas atividades em grupo, foram identificados os temas abordados e a metodologia utilizada, e, em casos de acompanhamento nutricional integral, as ações desenvolvidas foram categorizadas.

Em relação às equipes, foram reunidas informações sobre o tipo de equipe responsável pela ação, área de atuação dos profissionais de referência, motivação, desafios e aprendizados.

A classificação do tipo de ação teve como base a Matriz de Ações de Alimentação e Nutrição na Atenção Básica à Saúde 5 e a PNAN².

\section{RESULTADOS}

Foram encontrados 81 relatos de experiência, predominantemente das regiões Sudeste $(29,6 \%)$, Nordeste $(28,4 \%)$ e Sul $(24,7 \%)$. Mais da metade foi realizada em âmbito local $(53,1 \%)$, tendo como temas principais o excesso de peso/obesidade $(27,2 \%)$ e alimentação adequada e saudável $(25,9 \%)$ e público-alvo, indivíduos com excesso de peso $(23,5 \%)$ e comunidade (16,0\%) (Tabela 1$)$. 
Tabela 1 - Caracterização geral das ações de alimentação e nutrição na atenção básica aprovadas na IV Mostra de Experiências em Atenção Básica/Saúde da Família. Brasil, 2014.

\begin{tabular}{|c|c|c|c|}
\hline Categorias & $\mathbf{N}$ & $\%$ & Referência \\
\hline \multicolumn{4}{|l|}{ Região } \\
\hline Sudeste & 24 & 29,6 & $\begin{array}{l}36,38,45-48,61,62,64,68,73,74,76,80,83 \\
86,88,91,92,93,97,98,105,114\end{array}$ \\
\hline Nordeste & 23 & 28,4 & $\begin{array}{l}35,41,42,51,52,56,58,60,65-67,72,78,79 \\
89,94,101-104,107,110,112\end{array}$ \\
\hline Sul & 20 & 24,7 & $\begin{array}{l}43,49,50,54,55,57,59,69,70,71,75,81,95 \\
96,99,106,108,109,111,115\end{array}$ \\
\hline Centro-Oeste & 8 & 9,9 & $39,40,77,84,85,87,90,100$ \\
\hline Norte & 6 & 7,4 & $37,44,53,63,82,113$ \\
\hline \multicolumn{4}{|l|}{ Âmbito } \\
\hline Local & 43 & 53,1 & $\begin{array}{l}38,40-42,44,47,49,52,53,55,58,59,61,63-68 \\
71-73,77,80,81,83,85,86,89,91,93-97,99 \\
101,104,105,108,109,110,113\end{array}$ \\
\hline Municipal & 36 & 44,4 & $\begin{array}{l}35-37,39,43,45,46,48,50,51,54,56,57,60 \\
62,69,70,74,75,76,78,79,84,87,88,92,98 \\
100,102,103,106,107,111,112,114,115\end{array}$ \\
\hline Estadual & 2 & 2,5 & 82,90 \\
\hline \multicolumn{4}{|l|}{ Tema } \\
\hline Excesso de peso & 22 & 27,2 & $\begin{array}{l}40,43,45,49,54-56,64,68,71,73,76,77,81 \\
83,87,92,100,106,108,110,115\end{array}$ \\
\hline Alimentação Saudável & 22 & 27,2 & $\begin{array}{l}36,38,41,47,48,52,53,57,69,72,74,75,79 \\
80,82,89,93,94,96,99,104,111\end{array}$ \\
\hline Aleitamento materno/ACS & 13 & 16,0 & $37,39,44,46,59,63,67,88,95,97,105,112,113$ \\
\hline Avaliação nutricional & 6 & 7,4 & $58,65,84,90,102,109$ \\
\hline Organização de ações de A\&N & 5 & 6,2 & $42,86,101,103,107$ \\
\hline Desnutrição e carências nutricionais & 4 & 4,9 & $61,62,70,91$ \\
\hline Atuação do nutricionista & 4 & 4,9 & $42,50,51,60$ \\
\hline Saúde da comunidade & 3 & 3,7 & $35,66,78$ \\
\hline Condicionalidades do PBF & 2 & 2,5 & 85,98 \\
\hline \multicolumn{4}{|l|}{ Público-alvo } \\
\hline Indivíduos com excesso de peso & 20 & 24,7 & $\begin{array}{l}40,43,45,54,55,63,71,73,76,77,80,81,83 \\
87,92,100,106,108,110,115\end{array}$ \\
\hline Comunidade $^{a}$ & 16 & 19,8 & $\begin{array}{l}35,36,41,46,57,69,72,74,77,78,82,84,89 \\
93,96,112\end{array}$ \\
\hline Crianças & 12 & 14,8 & $61,63,65,76,87,90,91,101,102,108,111,115$ \\
\hline Mulheres & 11 & 13,6 & $39,44,63,70,88,91,97,104,105,112,113$ \\
\hline Gestantes/puérperas/nutrizes & 10 & 12,3 & $39,44,63,70,88,91,97,105,112,113$ \\
\hline Adolescentes & 9 & 11,1 & $43,54,63,65,83,87,101,102,111$ \\
\hline Profissionais da saúde & 9 & 11,1 & $39,59,82,86,95,98,103,112,114$ \\
\hline Responsáveis dos estudantes & 4 & 4,9 & $47,56,63,99$ \\
\hline Adultos & 3 & 3,7 & $43,68,83$ \\
\hline Idosos & 2 & 2,5 & 68,82 \\
\hline Atendido pelo PBF & 2 & 2,5 & 85,104 \\
\hline Outros ${ }^{b}$ & 2 & 2,5 & 36,69 \\
\hline Não se aplica & 1 & 1,2 & 60 \\
\hline Não especificado & 3 & 3,7 & $42,48,50$ \\
\hline
\end{tabular}

Notas: ${ }^{a}$ Qualquer pessoa interessada no tema da atividade

b Pessoas com transtornos mentais e acamados 
Os principais tipos de ação relatados foram de promoção da saúde/PAAS $(40,7 \%)$ e controle e tratamento de doenças $(32,1 \%)$ (Tabela 2). Destaca-se que a maior parte das ações de diagnóstico estavam incluídas como parte de outras atividades $(66,7 \%)$ - dados não apresentados.

A maioria das ações ocorreu de forma multidisciplinar $(86,4 \%)$ e menos de um terço $(27,2 \%)$ referiu articulação com outros pontos da RAS, porém, mais da metade mencionou ter articulado com outros setores $(50,6 \%)$, principalmente com educação (75,6\%). Também foi relatado o desenvolvimento de parcerias (58,0\%), especialmente com instituições de ensino e pesquisa $(36,2 \%)$ e escolas ou creches $(31,9 \%)$ (Tabela 2).

A forma de identificação dos sujeitos e como esses conheceram as atividades foi descrita em $69,1 \%$ dos relatos, sendo a maioria $(78,6 \%)$ a partir de discussão de caso em equipe ou encaminhamento de profissionais de saúde, em atividades escolares (aulas, reuniões de responsáveis e atividades específicas relacionadas à A\&N na escola) ou por convites de profissionais de saúde (Tabela 2).

Tabela 2 - Detalhamento das ações de alimentação e nutrição na atenção básica aprovadas na IV Mostra de Experiências em Atenção Básica/Saúde da Família. Brasil, 2014.

\begin{tabular}{|c|c|c|c|}
\hline Categorias & $\mathbf{N}$ & $\%$ & Referência \\
\hline \multicolumn{4}{|l|}{ Tipo de Ação } \\
\hline $\begin{array}{l}\text { Promoção da saúde e de práticas alimentares } \\
\text { adequadas e saudáveis }\end{array}$ & 33 & 40,7 & $\begin{array}{l}36,38,39,41,44,46-49,52,53,57,63, \\
66,69,72,74,75,79,88,89,93-97,99, \\
101,104,105,111-113 \\
36,38,39,41,44,46-49,52,57,69,72,\end{array}$ \\
\hline Incentivo - Atividades em grupo & 28 & 34,6 & $\begin{array}{l}74,75,79,88,89,93-96,99,101,104, \\
111-113\end{array}$ \\
\hline Apoio - Ações individuais ${ }^{a}$ & 4 & 4,9 & $63,97,101,105$ \\
\hline Apoio - Atividades em grupo ${ }^{b}$ & 3 & 3,7 & $36,38,53$ \\
\hline $\begin{array}{l}\text { Incentivo - Acompanhamento nutricional } \\
\text { integral }\end{array}$ & 2 & 2,5 & 66,101 \\
\hline $\begin{array}{l}\text { Controle e tratamento de excesso de peso, } \\
\text { desnutrição e carências nutricionais }\end{array}$ & 26 & 32,1 & $\begin{array}{l}40,43,45,51,54-56,61,64,68,71,73, \\
76,77,80,81,83,86,87,91,92,100, \\
106,108,110,115 \\
40,43,45,54-56,64,68,71,73,76,77,\end{array}$ \\
\hline Atividades em grupo & 22 & 27,2 & $\begin{array}{l}80,81,83,91,92,100,106,108,110, \\
115\end{array}$ \\
\hline Acompanhamento nutricional integral & 11 & 13,6 & $\begin{array}{l}40,51,55,61,71,76,86,87,91,100 \text {, } \\
115\end{array}$ \\
\hline Diagnóstico nutricional & 18 & 22,2 & $\begin{array}{l}37,38,43,49,58,62,65,66,67,68 \\
77,80,83,84,90,94,102,109\end{array}$ \\
\hline Estado Nutricional & 16 & 19,8 & $\begin{array}{l}37,38,43,49,58,62,65,66,68,77 \\
80,83,84,94,102,109\end{array}$ \\
\hline Consumo alimentar & 4 & 4,9 & $62,67,70,94$ \\
\hline Elaboração de material de apoio & 1 & 1,2 & 90 \\
\hline
\end{tabular}


Tabela 2 - Detalhamento das ações de alimentação e nutrição na atenção básica aprovadas na IV Mostra de Experiências em Atenção Básica/Saúde da Família. Brasil, 2014.

Continuação

\begin{tabular}{|c|c|c|c|}
\hline Categorias & $\mathbf{N}$ & $\%$ & Referência \\
\hline \multicolumn{4}{|l|}{ Tipo de Ação } \\
\hline Gestão & 9 & 11,1 & $39,50,59,83,94,103,107,112,114$ \\
\hline Educação permanente & 4 & 4,9 & $39,59,83,112$ \\
\hline Sensibilização e apoio a profissionais da $A B$ & 2 & 2,5 & 103,107 \\
\hline Descrição de atividades do nutricionista & 2 & 2,5 & 50,94 \\
\hline Organização de ações & 1 & 1,2 & 114 \\
\hline $\begin{array}{l}\text { Prevenção de excesso de peso, desnutrição e } \\
\text { carências nutricionais }\end{array}$ & 4 & 4,9 & $49,62,70,101$ \\
\hline Acompanhamento nutricional integral & 4 & 4,9 & $49,62,70,101$ \\
\hline Atividades em grupo & 1 & 1,2 & 62 \\
\hline $\begin{array}{l}\text { Atenção à saúde da comunidade (atividades } \\
\text { abertas à comunidade) }\end{array}$ & 3 & 3,7 & $35,78,85$ \\
\hline Feiras de saúde & 2 & 2,5 & 35,78 \\
\hline $\begin{array}{l}\text { Acompanhamento das condicionalidades do } \\
\text { PBF }\end{array}$ & 1 & 1,2 & 85 \\
\hline Pesquisa (iniciativa de pesquisadores) & 4 & 4,9 & $60,82,94,98$ \\
\hline Intervenção de PAAS & 2 & 2,5 & 82,94 \\
\hline Descrição de atividades do nutricionista & 1 & 1,2 & 60 \\
\hline Diagnóstico de conhecimento sobre o PBF & 1 & 1,2 & 98 \\
\hline Ação multidisciplinar & 71 & 87,7 & $\begin{array}{l}35,36,38,40-45,47-49,51,53-65,67- \\
70,73-89,91-93,95-115\end{array}$ \\
\hline Articulação com a RAS & 22 & 27,2 & $\begin{array}{l}39,43,46,63,70,72,76,78,79,85, \\
86,88,95,97,100,101,103,105,107, \\
112,114,115\end{array}$ \\
\hline Gestão (SMS, SES) & 10 & 45,4 & $43,46,72,78,79,85,88,103,105,107$ \\
\hline Atenção ambulatorial & 7 & 31,8 & $76,86,100,101,105,114,115$ \\
\hline Maternidade/BLH & 6 & 27,3 & $39,63,95,97,105,112$ \\
\hline Atenção hospitalar & 4 & 18,2 & $36,76,86,100$ \\
\hline Outros ${ }^{c}$ & 2 & 9,1 & 114,115 \\
\hline Articulação intersetorial & 41 & 50,6 & $\begin{array}{l}35,36,38,44,47-49,52-54,56,58-62, \\
65,66,69,70,73,75,79,81,82,84, \\
87,91,94,98,100-102,104,108,109, \\
111-115\end{array}$ \\
\hline Educação & 31 & 75,6 & $\begin{array}{l}35,36,38,40,44,47-49,52-54,56,58 \\
60,65,66,73,75,79,82,84,87,94 \\
98,101,102,104,108,109,111,112\end{array}$ \\
\hline Desenvolvimento/Assistência Social & 8 & 19,5 & $35,36,53,62,70,104,111,114$ \\
\hline Agricultura/Produtores familiares & 5 & 12,2 & $36,38,53,69,81$ \\
\hline Abastecimento & 4 & 9,8 & $35,47,54,91$ \\
\hline Esporte & 4 & 9,8 & $61,111,114,115$ \\
\hline Comunicação & 2 & 6,4 & 59,115 \\
\hline Transporte & 1 & 2,4 & 87 \\
\hline Cultura & 1 & 2,4 & 87 \\
\hline Segurança Pública & 1 & 2,4 & 97 \\
\hline Construção Civil & 1 & 2,4 & 69 \\
\hline Não menciona & 11 & 26,8 & $35,49,64,71,81-83,99,100,107,113$ \\
\hline
\end{tabular}


Tabela 2 - Detalhamento das ações de alimentação e nutrição na atenção básica aprovadas na IV Mostra de Experiências em Atenção Básica/Saúde da Família. Brasil, 2014.

Continuação

\begin{tabular}{|c|c|c|c|}
\hline Categorias & $\mathbf{N}$ & $\%$ & Referência \\
\hline Realização de parcerias & 47 & 58,0 & $\begin{array}{l}36,38,42-44,47-49,52-54,56,58-61 \\
65,66,69,70,73,75-79,81,82,84,87, \\
90,91,94,96-98,100-102,104-106 \\
109,111-113,115\end{array}$ \\
\hline $\begin{array}{l}\text { Instituições de ensino técnico/superior e } \\
\text { pesquisa }\end{array}$ & 17 & 36,2 & $\begin{array}{l}36,42,44,48,53,58,60,75,78,82, \\
87,94,98,100,101,112,113\end{array}$ \\
\hline Escolas/creches & 15 & 31,9 & $\begin{array}{l}38,47,49,52,54,56,58,61,65,66 \\
79,84,102,109,111\end{array}$ \\
\hline $\begin{array}{l}\text { Organizações não- } \\
\text { governamentais/associações do território }\end{array}$ & 10 & 21,3 & $36,47,61,65,76,77,82,90,91,105$ \\
\hline Instituições religiosas & 7 & 14,9 & $61,65,70,73,82,96,106$ \\
\hline Empresas do território & 7 & 14,9 & $36,54,69,104,112,113,115$ \\
\hline Agricultores familiares/pequenos produtores & 2 & 4,2 & 38,81 \\
\hline Outros $^{d}$ & 4 & 8,5 & $\begin{array}{l}43 \\
59,97,104\end{array}$ \\
\hline Como o público fica sabendo da ação & 56 & 69,1 & $\begin{array}{l}35-38,40,43-47,49,51,52,54-58,64- \\
76,78-84,87,88,91-96,99-102,104- \\
106,108,109,111\end{array}$ \\
\hline $\begin{array}{l}\text { Discussão em equipe/encaminhamento por } \\
\text { outros profissionais }\end{array}$ & 16 & 28,6 & $\begin{array}{l}40,51,55,64,70,71,73,76,80,81, \\
91,92,99,101,105,106\end{array}$ \\
\hline $\begin{array}{l}\text { Durante atividades escolares (aulas, } \\
\text { reuniões de responsáveis, etc) }\end{array}$ & 15 & 26,8 & $\begin{array}{l}38,47,49,52,56,58,65,66,75,79, \\
84,102,108,109,111\end{array}$ \\
\hline Convite realizado pelos profissionais & 13 & 23,2 & $\begin{array}{l}54,57,67-69,78,83,88,95,96,100, \\
102,104\end{array}$ \\
\hline $\begin{array}{l}\text { Participantes de } \\
\text { programas/grupos/atividades específicos }\end{array}$ & 7 & 12,5 & $36,37,44,45,82,93,94$ \\
\hline $\begin{array}{l}\text { Comunicação ou convite realizados pelas } \\
\text { escolas }\end{array}$ & 6 & 10,7 & $47,56,75,87,108,109$ \\
\hline $\begin{array}{l}\text { Materiais de divulgação na UBS (cartazes, } \\
\text { folderes, etc) }\end{array}$ & 6 & 10,7 & $43,57,68,73,74,83$ \\
\hline Demanda espontânea & 3 & 5,4 & $35,74,78$ \\
\hline Enquanto aguardam atendimento & 2 & 3,6 & 46,72 \\
\hline Jornais, mídias sociais & 1 & 1,9 & 43 \\
\hline
\end{tabular}

Nota: $\quad$ asensibilização de gestantes/nutrizes/puérperas, organização de fluxo entre UBS e Banco de Leite Humano/maternidades e apoio para doação de leite materno; oferta de alimentos adquiridos pelo PAA para os participantes de grupos da UBS;

bForam classificadas como atenção nutricional integral, ações que incluíam mais de um tipo de atividade (avaliação nutricional, atendimento individual, atividade em grupo, encaminhamento a outros profissionais/pontos da rede, organização de fluxos de atenção, etc)

cassistência farmacêutica, vigilância sanitária, SAMU

dhorto municipal, bombeiros, Câmara dos Vereadores, Casa de Cultura, cozinha comunitária

Em relação às características gerais das atividades em grupo, 58,2\% abordaram a alimentação saudável, 21,8\%, o preparo e degustação de alimentos/preparações culinárias e 45,6\%, dos que relataram realizar atividades em grupo, mencionaram o uso de metodologias ativas e 40,4\%, atividades lúdicas (Tabela 3). 
Nas atividades em grupo voltadas ao tratamento e controle de doenças, foram realizadas ainda avaliação nutricional e pactuação de metas (dados não apresentados), além de acompanhamento individual e articulação com a RAS em alguns casos (Tabela 3).

No tocante às ações classificadas em acompanhamento nutricional integral, a maioria realizava atenção individual, que incluía avaliação nutricional e orientações nutricionais, além de serem desenvolvidas ações de PAAS e/ou encaminhamento para participação em grupos que abordavam A\&N (Tabela 3). 
Tabela 3 - Caracterização das atividades em grupo e das ações de atenção nutricional integral. Brasil, 2014.

\begin{tabular}{|c|c|c|c|}
\hline Categorias & $\mathbf{N}$ & $\%$ & Referência \\
\hline Temas abordados nas atividades em grupo & 55 & 67,9 & \\
\hline Alimentação saudável & 32 & 58,2 & $\begin{array}{l}38-40,43,45,47,48,54,55,57,62,68,72- \\
79,82,88,91-94,96,104,106,108,110 \\
111\end{array}$ \\
\hline Preparo e degustação de alimentos & 12 & 21,8 & $\begin{array}{l}43,48,74,79,82,89,91,93,96,99,104 \\
115\end{array}$ \\
\hline $\begin{array}{l}\text { Aspectos socioeconomicoculturais e } \\
\text { psicológicos relacionadas à alimentação }\end{array}$ & 10 & 18,2 & $40,43,48,52,54,68,77,92,106,115$ \\
\hline Manipulação e higiene de alimentos & 9 & 16,4 & $45,48,62,72,74,96,99,104,110$ \\
\hline $\begin{array}{l}\text { Amamentação e alimentação complementar } \\
\text { saudável }\end{array}$ & 8 & 14,5 & $37,39,44,46,88,95,99,112$ \\
\hline Construção/cultivo de hortas & 7 & 12,7 & $36,38,54,66,69,78,82$ \\
\hline $\begin{array}{l}\text { Aspectos fisiológicos e consequências da } \\
\text { obesidade e doenças associadas }\end{array}$ & 6 & 10,9 & $40,45,55,56,71,110$ \\
\hline Aproveitamento integral de alimentos & 4 & 7,3 & $45,62,96,104$ \\
\hline Rotulagem e marketing & 4 & 7,3 & $43,72,106,115$ \\
\hline Hábitos alimentares & 4 & 7,3 & $52,54,89,106$ \\
\hline Benefício/malefícios de alimentos/nutrientes & 3 & 5,5 & $38,93,108$ \\
\hline Alimentação alternativa & 3 & 5,5 & $41,57,89$ \\
\hline Ato de comer & 2 & 3,6 & 73,77 \\
\hline Outros $^{a}$ & 3 & 5,5 & $43,68,77,99$ \\
\hline Não menciona & 8 & 14,5 & $35,49,64,80,81,83,100,113$ \\
\hline Metodologia das atividades em grupo & 55 & 67,9 & \\
\hline Uso de metodologias ativas & 26 & 45,6 & $\begin{array}{l}38,39,40,44,49,54,62,64,68,69,71,72, \\
76,80,83,91-94,99,100,104,106,108, \\
113,115\end{array}$ \\
\hline Atividades lúdicas & 23 & 40,4 & $\begin{array}{l}40,43,46,47,49,52,54,62,66,69,71,73, \\
75,79,82,88,94,95,100,106,108,111 \\
115\end{array}$ \\
\hline Rodas de conversa & 15 & 26,3 & $\begin{array}{l}39,40,41,44,57,68,69,71,72,78,80,88 \\
94,110,113\end{array}$ \\
\hline Oficinas & 10 & 17,5 & $41,43,48,57,74,82,91,96,104,115$ \\
\hline Palestras & 7 & 12,3 & $37,43-45,47,56,89$ \\
\hline Concursos/gincanas & 4 & 7,0 & $74,95,111,112$ \\
\hline Não menciona & 5 & 8,8 & $35,36,55,77,81$ \\
\hline \multicolumn{4}{|l|}{ Ações de Atenção Nutricional Integral $(n=16)$} \\
\hline Avaliação nutricional & 15 & 93,8 & $\begin{array}{l}40,49,51,55,61,62,66,70,71,76,87,91 \\
100,101,115\end{array}$ \\
\hline Acompanhamento individual & 14 & 87,5 & $\begin{array}{l}40,49,51,55,61,62,66,70,71,76,87,91 \\
100,101\end{array}$ \\
\hline $\begin{array}{l}\text { PAAS/Atividades em grupo sobre alimentação } \\
\text { e nutrição } \\
\text { Identificação da demanda atenção }\end{array}$ & 13 & 81,3 & $\begin{array}{l}40,49,51,55,61,66,70,71,76,91,100 \\
101,115\end{array}$ \\
\hline $\begin{array}{l}\text { nutricional/encaminhamento pelos } \\
\text { profissionais }\end{array}$ & 8 & 50,0 & $40,51,61,70-72,91,100$ \\
\hline $\begin{array}{l}\text { Encaminhamento para outros pontos da RAS } \\
\text { quando há necessidade }\end{array}$ & 5 & 31,3 & $70,76,100,101,115$ \\
\hline Organização do fluxo de atenção nutricional & 4 & 25,0 & $51,61,81,86$ \\
\hline Distribuição de alimentos & 3 & 18,8 & $62,70,91$ \\
\hline Capacitação de ACS & 1 & 1,8 & 91 \\
\hline
\end{tabular}

Nota: adieta, desintoxicação alimentar, refeições, saúde bucal 
A maior parte das equipes responsáveis pelas ações foram equipes de atenção básica/saúde da família (eAB/eSF) (41,4\%) e NASF (35,7\%), sendo os nutricionistas os principais profissionais de referência (Tabela 4).

Em mais de $80 \%$ havia detalhamento da motivação para a realização da ação, sendo a mais citada o levantamento do perfil alimentar (1,4\%) e nutricional $(14,5 \%)$ da população do território (Tabela 4), com diagnóstico ocorrendo em consultas/rotina da UBS (13,0\%), com uso de dados do Sisvan (5,8\%), avaliação nas escolas (4,3\%) ou a partir de pesquisa solicitada pela gestão municipal $(1,4 \%$ ) (dados não apresentados).

A importância de abordagem multidisciplinar ou o envolvimento de profissionais de diversas áreas na realização das ações foi o aprendizado mais frequentemente relatado $(28,6 \%)$ e a adesão dos participantes e falta de recursos e burocracia corresponderam a mais de $60 \%$ dos desafios para o desenvolvimento das ações (Tabela 4).

Tabela 4 - Características da equipe e profissionais responsáveis, motivação, aprendizados e desafios. Brasil, 2014.

\begin{tabular}{|c|c|c|c|}
\hline Categorias & $\mathbf{N}$ & $\%$ & Referência \\
\hline Equipe responsável & 70 & 86,4 & \\
\hline eAB/ESF & 29 & 41,4 & $\begin{array}{l}36,37,49,51,54,55,57,62-65,67-69 \\
78,83,84,85,88,93,95-97,99,104 \\
105,107,109,113\end{array}$ \\
\hline Nasf & 24 & 34,3 & $\begin{array}{l}35,40,50,54,56,59,62,64,66,71,73 \\
76,77,78,81,83,86-88,92,93,95,102 \\
115\end{array}$ \\
\hline $\begin{array}{l}\text { Bolsistas do pró/pet-saúde, estagiários ou } \\
\text { residentes }\end{array}$ & 11 & 15,7 & $38,42,44,48,52,53,58,61,75,101,108$ \\
\hline Gestão & 5 & 7,1 & $58,66,70,111,114$ \\
\hline Pesquisadores & 4 & 5,7 & $60,82,94,98$ \\
\hline Outros $^{a}$ & 8 & 11,4 & $41,46,63,79,90,97,99,100$ \\
\hline Área de atuação do(s) responsável(is) & 51 & 63,0 & \\
\hline Nutrição & 37 & 72,5 & $\begin{array}{l}38,40-43,45,50,51,54,55,59,60-62 \\
70-76,79,81,83,86,87,89,92,99,100- \\
102,106-108,110,112\end{array}$ \\
\hline Enfermagem & 8 & 15,7 & $58,81,82,83,90,109,112,113$ \\
\hline Agente Comunitário de Saúde & 8 & 15,7 & $55,69,81,84,85,96,109,113$ \\
\hline Medicina & 7 & 13,7 & $41,54,58,68,76,83,101$ \\
\hline Psicologia & 5 & 9,8 & $43,54,58,83,112$ \\
\hline Odontologia & 3 & 5,9 & $54,108,112$ \\
\hline Educação Física & 3 & 5,9 & $54,73,102$ \\
\hline Técnico em Enfermagem & 2 & 3,9 & 105,109 \\
\hline Assistência Social & 2 & 3,9 & 98,112 \\
\hline Fisioterapia & 2 & 3,9 & 40,41 \\
\hline Farmácia & 2 & 3,9 & 81,108 \\
\hline Arte-educação & 1 & 2,0 & 46 \\
\hline Terapia Ocupacional & 1 & 2,0 & 83 \\
\hline
\end{tabular}


Tabela 4 - Características da equipe e profissionais responsáveis, motivação, aprendizados e desafios. Brasil, 2014.

Continuação

\begin{tabular}{|c|c|c|c|}
\hline Categorias & $\mathbf{N}$ & $\%$ & Referência \\
\hline Motivação & 69 & 85,2 & \\
\hline $\begin{array}{l}\text { Perfil nutricional ou alimentar da população do } \\
\text { território }\end{array}$ & 11 & 15,9 & $52,56,62,68,77,80,83,87,91,104,110$ \\
\hline $\begin{array}{l}\text { Reconhecimento da importância da } \\
\text { alimentação saudável/aleitamento } \\
\text { materno/alimentação complementar saudável }\end{array}$ & 9 & 13,0 & $39,41,47,74,89,93,95,99,113$ \\
\hline $\begin{array}{l}\text { Cumprimento de metas/avaliação/atividade de } \\
\text { programas/datas comemorativas }\end{array}$ & 6 & 8,7 & $46,67,84,105,111,112$ \\
\hline $\begin{array}{l}\text { Alta demanda de atendimento para } \\
\text { nutricionistas }\end{array}$ & 6 & 8,7 & $40,71,73,86,100,115$ \\
\hline Planejamento/avaliação de ações & 5 & 7,2 & $35,57,78,107,114$ \\
\hline Cenário epidemiológico nacional & 4 & 5,8 & $66,82,101,106$ \\
\hline Pró/pet-saúde ou atividade de estágio & 3 & 4,3 & $42,58,75$ \\
\hline $\begin{array}{l}\text { Sugestão/escuta da necessidade de usuários } \\
\text { Identificação da necessidade de }\end{array}$ & 3 & 4,3 & $36,44,88$ \\
\hline $\begin{array}{l}\text { EP/sensibilização/apoio aos profissionais de } \\
\text { saúde }\end{array}$ & 3 & 4,3 & $88,90,100$ \\
\hline Cursos realizados por ACS sobre o tema & 2 & 2,9 & 69,96 \\
\hline $\begin{array}{l}\text { Necessidade de doações de leite materno ao } \\
\text { BLH }\end{array}$ & 2 & 2,9 & 6397 \\
\hline Outros $^{b}$ & 7 & 10,1 & $43,60,61,72,76,85,98$ \\
\hline Aprendizados com a ação & 28 & 34,6 & \\
\hline $\begin{array}{l}\text { Importância de abordagem/envolvimento } \\
\text { multidisciplinar }\end{array}$ & 8 & 28,6 & $38,51,61,71,86,101,102,111$ \\
\hline $\begin{array}{l}\text { Importância da articulação intersetorial e } \\
\text { desenvolvimento de parcerias }\end{array}$ & 5 & 17,9 & $58,61,98,102,108$ \\
\hline $\begin{array}{l}\text { Importância de escutar/construir ações com } \\
\text { usuários/equipes }\end{array}$ & 4 & 14,3 & $42,51,86,103$ \\
\hline $\begin{array}{l}\text { Importância do uso de metodologias ativas, } \\
\text { atividades lúdicas, linguagem simples }\end{array}$ & 3 & 10,7 & $46,57,104$ \\
\hline $\begin{array}{l}\text { Necessidade de sensibilizar equipes para paas } \\
\text { e acs }\end{array}$ & 2 & 7,1 & 42,51 \\
\hline $\begin{array}{l}\text { ACS tem papel fundamental no } \\
\text { desenvolvimento das ações }\end{array}$ & 2 & 7,1 & 57,104 \\
\hline $\begin{array}{l}\text { Necessidade de realizar ações de promoção da } \\
\text { saúde, não focando em doenças ou coleta de } \\
\text { dados }\end{array}$ & 2 & 7,1 & 66,78 \\
\hline Outros ${ }^{c}$ & 4 & 14,3 & $35,55,63,75$ \\
\hline Desafios para desenvolvimento da ação & 53 & 65,4 & \\
\hline Adesão dos participantes/responsáveis & 17 & 32,1 & $\begin{array}{l}35-37,39,45,52,54,56,68,71,82,88 \\
92,94,99,100,108\end{array}$ \\
\hline $\begin{array}{l}\text { Falta de recursos (físicos, financeiros ou } \\
\text { materiais)/burocracia para conseguir recursos }\end{array}$ & 17 & 32,1 & $\begin{array}{l}44,50,59,65,69,74,79,80,92,96,97 \\
99,100,105,111,113,114\end{array}$ \\
\hline $\begin{array}{l}\text { Resistência/Necessidade de sensibilização dos } \\
\text { profissionais }\end{array}$ & 8 & 15,1 & $35,53,65,67,86,97,103,111$ \\
\hline Trabalho interdisciplinar & 6 & 11,3 & $40,58,86,99,108,115$ \\
\hline $\begin{array}{l}\text { Condições } \\
\text { socioeconômicas/demográficas/culturais }\end{array}$ & 5 & 9,4 & $37,56,61,84,91$ \\
\hline Realização de parcerias & 5 & 9,4 & $78,87,88,108,111$ \\
\hline $\begin{array}{l}\text { Aplicação dos conhecimentos à } \\
\text { prática/expansão do tema para fora da UBS }\end{array}$ & 4 & 7,5 & $45,66,89,112$ \\
\hline Falta de conhecimento pelos profissionais & 4 & 7,5 & $35,40,49,98$ \\
\hline Abordagem para diferentes públicos/idades & 3 & 5,7 & $35,93,101$ \\
\hline Falta de recursos humanos & 2 & 3,8 & 80,97 \\
\hline Falta de apoio/sensibilização da gestão & 2 & 3,8 & 69,80 \\
\hline Outros $^{d}$ & 3 & 5,7 & $74,85,102$ \\
\hline
\end{tabular}


Notas: a Equipe do DSEI, equipe de arte-educadores, Núcleo de Apoio em Práticas Integrativas, profissionais da maternidade e ambulatórios e equipe de saúde da criança e adolescente.

b Tempo de espera para atendimento nas UBS, necessidade de adequação do fluxo de atendimento às crianças com obesidade e desnutrição e de organização do cuidado para crianças, alto índice de abandono do acompanhamento nutricional, ausência das famílias para acompanhamento das condicionalidades de saúde do PBF e desconhecimento sobre atuação do nutricionista na AB e se os profissionais conhecem o PBF.

c Sair da UBS para alcançar a população, importância da organização do cuidado e da adesão dos participantes e necessidade de tornar a educação alimentar e nutricional constante nas escolas.

d Dificuldade de falar com cacique na aldeia, esquecimento de documentos pelos estudantes e excesso de trabalho dos professores durante atividades escolares e desenvolvimento de projetos simultaneamente.

\section{DISCUSSÃO}

Verificaram-se relatos de ações provenientes, principalmente, das regiões Sudeste, Nordeste e Sul, voltadas tanto à PAAS, quanto ao controle e tratamento de agravos nutricionais, especialmente a obesidade.

Em relação ao local de origem, revisões da produção científica em nutrição na AB6 e de grupos de pesquisa em A\&N na ESF77, que avaliaram publicações até 2011 e entre 2002 e 2012, respectivamente, verificaram predomínio das mesmas regiões, justificado pelo maior investimento e grupos de pesquisa existentes nessas localidades. ${ }^{6,7}$ No caso dos relatos da IV Mostra tais explicações não se adequam, visto que o foco não era relatos provenientes da academia e poucos relacionados a pesquisas foram encontrados. As cotas estabelecidas por região podem ter influenciado também as aprovações na área de $A \& N$, não sendo possível identificar se as outras regiões estariam mais representadas se a distribuição das cotas fosse diferente.

No tocante ao predomínio de ações locais ou com abrangência municipal, verifica-se adequação à proposta da IV Mostra. Contudo, gestores e as ações desenvolvidas por esses foram pouco representadas, apontando para a necessidade da criação de mecanismos que estimulem maior divulgação de experiências da gestão.

O público-alvo e o tipo de ações encontrados diferem dos achados das revisões já mencionadas, que identificaram como principais sujeitos crianças e gestantes ${ }^{6}$ ou crianças e profissionais da saúde ${ }^{7}$ e como tipo de ação, a realização de diagnóstico $0^{6,7}$. Os relatos trouxeram, principalmente, ações de PAAS e controle e tratamento de agravos nutricionais, voltados, principalmente, à comunidade e indivíduos com 
excesso de peso, o que sugere desarticulação entre pesquisa e serviço ou timing inadequado das pesquisas às necessidades da gestão/serviço.

Estudos mostram que pesquisadores não são preparados para elaborar intervenções de impacto para políticas ou envolver-se com gestores e não são recompensados por isso nas universidades. Além disso, a comunicação científica restringe-se à comunidade acadêmica, dificultando o acesso aos gestores de evidências geradas, o que reafirma a necessidade de aproximação entre academia e gestão. $^{8}$

Em relação à temática e ao público-alvo encontrados, verifica-se que estão alinhados ao cenário epidemiológico, que tem mostrado tendência de crescimento do excesso de peso entre a população brasileira ${ }^{9}$, explicada, entre outros fatores, pelo inadequado padrão alimentar. ${ }^{10}$

A reversão desse quadro exige aliar ações que ajam sobre o ambiente físico, econômico e sociocultural para desestimular comportamentos não saudáveis e facilitar a adoção de comportamentos saudáveis, a ações relacionadas à motivação, informação adequada, para promover poder de escolha consciente e reduzir vulnerabilidades ao ambiente obesogênico, além de ser ofertada atenção à saúde, com vistas ao tratamento e controle de doenças. ${ }^{11,12}$

A AB tem como principal escopo o desenvolvimento de ações em âmbito micro, sendo espaço estratégico para a PAAS. Esses foram os tipos de ações mais relatados, realizados, em geral, como atividades ou grupos abertos à comunidade, que abordavam alimentação saudável, preparo de alimentos, além de questões sócioeconômico-culturais e psicológicas. Porém, foram poucos os que relataram tratar sobre rotulagem, marketing e ato de comer. Cabe também destacar que, entre as ações de controle e tratamento, mais de $80 \%$ realizavam atividades de PAAS como parte do acompanhamento nutricional integral.

Apesar de não haver informações que permitissem detalhar a abordagem dos temas, verifica-se alinhamento de alguns desses às recomendações do Guia Alimentar para a População Brasileira, as quais têm como foco refeições, ressaltam a importância de resgatar habilidades culinárias e apresentam formas de superar obstáculos $^{13}$. Destaca-se que a versão revisada do Guia Alimentar foi lançada posteriormente à IV Mostra, sugerindo que as equipes já consideravam a importância desses assuntos; assim, infere-se que a existência de publicação nacional que os 
aborde, se apropriada pelas equipes, possa estimular a incorporação de temas pouco identificados à prática profissional.

No tocante às atividades em grupo, metodologias ativas e atividades lúdicas predominaram. Apesar de não ter sido possível verificar como as metodologias foram aplicadas, estudos mostram que, mesmo conhecendo a importância de ações educativas promotoras da saúde, profissionais ainda utilizam de métodos e conceitos tradicionais em suas práticas e culpabilizam os sujeitos por sua situação de saúde. ${ }^{14}$

As práticas educativas são formas eficientes de promover a autonomia do sujeito na promoção de sua saúde. No entanto, podem levar ao empoderamento ou ser meio de dominação. ${ }^{15}$ Métodos educativos em saúde devem levar à reflexão sobre a realidade e promover o entendimento de saúde como direito, estimulando a participação crítica. ${ }^{16,17}$

Ações de apoio à PAAS também foram mencionadas, como a garantia de oferta de alimentos da agricultura familiar nos grupos, articulação com maternidades para a doação de leite materno ou indução de mudanças em alimentos ofertados por cantinas escolares.

A visão holística sobre o território pelas eAB é fundamental para promover a saúde de seus adscritos. No campo da $A \& N$, essa visão corresponde à observação de como se dá a oferta de alimentos, custo e condições econômicas das famílias, existência de equipamentos de alimentação e espaços para implantação de hortas, etc. ${ }^{18}$ Nesse contexto, a AB pode contribuir para modificar também o ambiente da comunidade, não agindo somente sobre determinantes individuais, porém, isso implica a realização de articulações intersetoriais e parcerias com instituições do território.

No tocante a esses aspectos, a maior parte dos relatos mencionou a realização de articulações intersetoriais e parcerias, demonstrando que os profissionais envolvidos reconhecem que o setor saúde não dá conta de todos os determinantes da $A \& N{ }^{19}$

A realização de ações de apoio e incentivo nas escolas foram as mais citadas e podem ser eficazes por criar um ambiente que induz escolhas saudáveis e contribui para o controle e prevenção da obesidade. ${ }^{20}$ Nesse contexto e sendo as escolas parte do território de responsabilidade das eAB, a atuação nesses espaços é fundamental para a promoção da saúde e identificação de estudantes que necessitam de encaminhamento para acompanhamento contínuo. 
Ainda destaca-se a realização de parcerias com instituições e lideranças do território. O envolvimento da comunidade na realização das ações, especialmente quando esta participa de sua construção, é uma forma, não só de apoiar participação social e dar visibilidade às ações, mas também pode induzir mobilização de outros atores e aumento da demanda por ações na área, além de possibilitar apoio para implementação de ações e políticas mais amplas e efetivas. ${ }^{21}$

Em relação às ações de acompanhamento nutricional integral, aquelas voltadas ao tratamento e controle do excesso de peso predominaram e a realização da avaliação nutricional periódica e o acompanhamento individual, com orientações nutricionais específicas, aliados às atividades em grupos e PAAS, foram as atividades mais mencionadas.

A combinação de aconselhamento individual e em grupo pode ser eficaz para prevenção e controle do excesso de peso na $A B^{22}$ e o uso de meios inovadores de oferta de cuidados multidisciplinares em saúde podem ter maior impacto ${ }^{23}$, sendo as intervenções de longo prazo as mais eficientes. ${ }^{24,25}$

Nesse sentido, a partir dos relatos, verificou-se que a maior parte das ações foram desenvolvidas de forma multidisciplinar, tendo as eAB/ESF ou NASF como responsáveis e nutricionistas como protagonistas da ação. Contudo, este foi um dos principais desafios para desenvolvimento da ação, assim como a resistência e dificuldade de sensibilização dos demais profissionais.

Nos últimos anos, houve crescimento da incorporação de nutricionistas nas equipes de atenção básica, sendo reconhecida sua importância nas equipes. ${ }^{26,27}$ Nutricionistas na $A B$ podem potencializar estas ações, por seus conhecimentos técnicos e possibilidade de compartilhamento com os demais profissionais ${ }^{27,28,29}$.

Dentre as ações de prevenção, duas foram relacionadas a doenças na infância, uma, a obesidade e duas, a carências nutricionais e desnutrição. Apesar da implementação de políticas que levaram o Brasil a erradicar a fome e reduzir a desnutrição ${ }^{30}$, a doença ainda persiste em bolsões de pobreza e populações específicas $^{31,32}$, exigindo que as equipes tenham maior com estes grupos populacionais.

Somente um terço, dentre os relatos que mencionaram sua motivação, referiram o perfil alimentar e nutricional da população local, o que pode indicar que as equipes não têm utilizado essas informações para a organização, planejamento e oferta de ações, as quais podem não ter como base as necessidades e implicar pouca 
adesão às atividades desenvolvidas. Destaca-se que a adesão, assim como a falta de recursos financeiros, físicos e materiais e a burocracia para seu uso, foram as principais dificuldades mencionadas para realização das ações.

Em estudo realizado por Flisch ${ }^{33}$, a adesão dos participantes e a falta de recursos também foram verificadas como dificuldades de atividades educativas na $A B$. A adesão foi relacionada à aceitação da comunidade à proposta de atividade, ao vínculo criado com equipe e outros participantes e ao método utilizado.

No tocante à falta de recursos, muitas vezes os profissionais de saúde realizam as atividades com recursos próprios, colaboração de colegas da equipe e da comunidade, por militância ou para ter trabalho reconhecido, o que leva à desmotivação desses profissionais. ${ }^{34}$

Este estudo apresenta algumas limitações: as ações são autorreferidas, podendo não representar o realizado e, apesar de haver formulário padrão para inscrição das experiências e os relatos serem homogêneos, nem todos os campos foram preenchidos por todos os autores, o que reduziu possibilidade de aprofundamento de conhecimento das ações desenvolvidas.

\section{CONSIDERAÇÕES FINAIS}

As experiências apresentadas na IV Mostra Nacional de AB/SF permitem obter retrato do cenário nacional do que equipes têm desenvolvido no âmbito da $A \& N$ e possibilitam reflexões sobre suas práticas, necessidades e dificuldades para a realização das ações.

Foram identificados temas que ainda precisam ser priorizados pela gestão e pelas equipes por terem sido pouco mencionados, como cuidado à obesidade, questões relacionadas à influência da publicidade e da rotulagem na alimentação, o ato de comer e a comensalidade e o uso de metodologias problematizadoras.

A partir dos relatos encontrados também foi possível identificar pouca articulação da $A B$ com outros pontos da RAS e de articulação intersetorial com setores diferentes da educação, sendo necessário que a organização e oferta dos serviços sejam realizadas de forma mais integrada para a garantia do cuidado integral da população.

É importante ressaltar que as ações aqui identificadas correspondem a um cenário resultante de um grupo seleto de relatos aprovados na IV Mostra, podendo 
não representar o que acontece em âmbito nacional. Contudo, já representam uma rica variedade de ações que têm sido desenvolvidas na área de $A \& N$ na $A B$ e demonstram o empenho das equipes de $A B$ para a promoção dos direitos à saúde $e$ à alimentação. Contudo, para que tais ações continuem sendo desenvolvidas e novas sejam implementadas, é fundamental comprometimento, priorização e realização de investimentos em políticas públicas de saúde e de segurança alimentar e nutricional, sem as quais, os esforços das equipes de saúde para resolver os problemas relacionados à $A \& N$ serão limitados.

\section{REFERÊNCIAS}

1. Food and Agriculture Organization of the United Nations. World Health Organization. Rome Declaration on Nutrition: Second International Conference on Nutrition. Rome: FAO/WHO, 2014

2. Ministério da Saúde (BR). Política Nacional de Alimentação e Nutrição. Brasília, DF: Ministério da Saúde, 2012.

3. Pimentel et al. Alimentação e nutrição no contexto da atenção básica e da promoção da saúde: a importância de um diálogo. Demetra. 2013;8(3):48798.

4. Ministério da Saúde (BR). Secretaria de Atenção à Saúde. Departamento de Atenção Básica. Memorial da IV Mostra de Experiências em Atenção Básica/Saúde da Família. Brasília, DF: MS, 2016. [Série C. Projetos, Programas e Relatórios].

5. Ministério da Saúde (BR). Matriz de Ações de Alimentação e Nutrição na Atenção Básica à Saúde. Brasília, DF: 2009.

6. Canella DS, Silva ACFS, Jaime PC. Produção científica sobre nutrição no âmbito da atenção primária à saúde no Brasil: uma revisão da literatura. Cien Saude Coletiva. 2013;18(2):297-308.

7. Vasconcelos IAL, Sousa MF, Santos LMP. Evolução do quantitativo de nutricionistas na Atenção Básica do Brasil: a contribuição dos Núcleos de Apoio à Saúde da Família e da Estratégia Saúde da Família de 2007 a 2013. Rev Nutr.2015;28(4):431-450.

8. Brownell KD, Roberto CA. Strategic science with policy impact. The Lancet. 2015;385:2445-6. 
9. Instituto Brasileiro de Geografia e Estatística. Pesquisa de orçamentos familiares 2008-2009: antropometria e estado nutricional de crianças, adolescentes e adultos. Rio de Janeiro: IBGE; 2010a.

10. Martins APB et al. Participação crescente de produtos ultraprocessados na dieta brasileira (1987-2009).Rev Saúde Pública.2013;47(4): 656-65.

11. Egger G, Swinburn B. An "ecological" approach to the obesity pandemic. BMJ.1997;23;315(7106):477-80.

12. Roberto $\mathrm{CA}$ et al. Patchy progress on obesity prevention: emerging examples, entrenched barriers, and new thinking. Lancet.2015;385:240009

13. Ministério da Saúde (BR). Guia Alimentar para a População Brasileira. 2 ${ }^{\mathrm{a}}$ ed. Brasília, DF: Ministério da Saúde, 2014.

14. Alves GG, Aerts D. As práticas educativas em saúde e a Estratégia Saúde da Família. Cien Saúde Coletiva.2011;16(1):319-325.

15. Chiesa AM, Westphal MF. A sistematização de oficinas educativas problematizadoras no contexto dos serviços públicos de saúde. Saúde em debate.1995;46:19-22.

16. Oliveira DL. A 'nova' saúde pública e a promoção da saúde via educação: entre a tradição e a inovação. Rev Latinoam Enferm.2005;13(3):423-31.

17. Toledo MM, Rodrigues SC, Chiesa AM. Educação em saúde no enfrentamento da hipertensão arterial: uma nova ótica para um velho problema. Texto Contexto Enferm.2007;16(2):233-38.

18. Ferreira VA, Magalhães R. Nutrição e promoção da saúde: perspectivas atuais. Cad. Saúde Pública.2007;23(7):1674-81.

19. Ferreira VA, Magalhães R. Nutrição e promoção da saúde: perspectivas atuais. Cad. Saúde Pública.2007;23(7):1674-81.

20. Hawkes et al. Smart food policies for obesity prevention. Lancet.2015;385:2410-21

21. Huang et al. Mobilization of public support for policy actions to prevent obesity. Lancet. 2015;385:2422-31

22. Anderson P. Reducing overweight and obesity: closing the gap between primary care and public health. Fam Pract.2008;25Suppl 1:i10-6.

23. Dietz WH et al. Management of obesity: improvement of health-care training and systems for prevention and care. Lancet.2015;385:2521-33 
24. Donini LM et al. Multidisciplinary approach to obesity. Eat Weight Disord.2009;14(1):23-32.

25. Snethen JA, Broome ME, Cashin SE. Effective weight loss for overweight children: a meta-analysis of intervention studies. J Pediatr Nurs.2006;21(1):45-56

26. Camossa ACA, Telarolli Jr R, Machado MLT. O fazer teórico-prático do nutricionista na estratégia saúde da família: representações sociais dos profissionais das equipes. Rev. Nutr.2012;25(1):89-106.

27. Vasconcelos IAL, Sousa MF, Santos LMP. Evolução do quantitativo de nutricionistas na Atenção Básica do Brasil: a contribuição dos Núcleos de Apoio à Saúde da Família e da Estratégia Saúde da Família de 2007 a 2013. Rev. Nutr.2015;28(4):431-450

28. Jaime $P C$ et al. Ações de alimentação e nutrição na atenção básica: a experiência de organização no Governo Brasileiro. Rev. Nutr. 2011; 24(6):809-824.

29. Boreli et al A inserção do nutricionista na Atenção Básica: uma proposta para 0 matriciamento da atenção nutricional. Ciên Saúde Coletiva.2015;20(9):2765-2778.

30. FAO. O Estado da Segurança Alimentar e Nutricional no Brasil: um retrato multidimensional. Brasília, DF: FAO, 2014

31. Ministério do Desenvolvimento Social e Combate à Fome (BR). Chamada nutricional quilombola 2006: sumário executivo. Brasília,DF:MDS, 2007.

32. Ministério da Saúde (BR). I Inquérito Nacional de Saúde e Nutrição dos Povos Indígenas. Brasília, DF: MS, 2010b

33. Flisch TMP. Práticas coletivas de educação em saúde na atenção primária à saúde em Contagem. [dissertação]. Minas Gerais: Escola de Enfermagem, 2013.

34. Pekelman R. Caminhos para uma ação educativa emancipadora: a prática educativa no cotidiano dos serviços de atenção primária em saúde. Revista de APS.2008;11(3): 295-302. 
35. Almeida $\mathrm{C}$ et al. Na rua, na chuva, na fazenda: possibilidades de educação em saúde construídas pelo NASF Caetés-PE. In: IV Mostra de Experiências em Atenção Básica/Saúde da Família. 2013[acessado 2016Jun6]. Disponível em: https://novo.atencaobasica.org.br/relato/3481

36. Almeida VP, Bontempo IL, Reis EA. Horta comunitária: semeando inclusão para colher cidadania. In: IV Mostra de Experiências em Atenção Básica/Saúde da Família. 2013[acessado 2016Jun6] Disponível em: https://novo.atencaobasica.org.br/relato/446

37. Amador BM. Promovendo o Aleitamento Materno Exclusivo na USF Vila Sinhá II-Bragança-PA. In: IV Mostra de Experiências em Atenção Básica/Saúde da Família.2013[acessado 2016Jun6]. Disponível em: https://novo.atencaobasica.org.br/relato/436

38. Araujo CZ, Paula A. Crescer com saúde: experiência em educação nutricional e implantação de cantina saudável em uma escola do Município de Muqui-ES. In: IV Mostra de Experiências em Atenção Básica/Saúde da Família. 2013 [acessado 2016Jun6].Disponível em: https://novo.atencaobasica.org.br/relato/2268

39. Assunção $A A B$, Oliveira FN. II amamentAÇÃO de Fátima do Sul-MS. In: IV Mostra Nacional de Experiências em AB/SF. 2013 [acessado 2016Jun6]. Disponível em: https://novo.atencaobasica.org.br/relato/1258

40. Assunção NC. Grupo de Redução de Peso. In: IV Mostra Nacional de Experiências em AB/SF. 2013 [acessado 2016Jun6]. Disponível em: https://novo.atencaobasica.org.br/relato/2655

41. Azevedo RSWS. Encontros sobre Alimentação Vegetariana: experiência pioneira no SUS Recife. In: IV Mostra Nacional de Experiências em AB/SF. 2013 [acessado 2016 Jun 06]. Disponível em: https://novo.atencaobasica.org.br/relato/794

42. Barbosa AM. Experiências de uma estudante na Atenção Básica. In: IV Mostra Nacional de Experiências em AB/SF. 2013[acessado 2016Jun6].Disponível em: https://novo.atencaobasica.org.br/relato/3420

43. Bodemuller M, Lago S. Grupo controle de peso de Taió: O Peso da Saúde. In: IV Mostra Nacional de Experiências em AB/SF. 2013[acessado 2016Jun6]. Disponível em: https://novo.atencaobasica.org.br/relato/3615 
44. Brasil GB, Santos DKA. Metodologia ativa: uma ferramenta para promoção do aleitamento materno exclusivo. In: IV Mostra Nacional de Experiências em AB/SF.2013[acessado 2016Jun6]. Disponível em: https://novo.atencaobasica.org.br/relato/4243

45. Campos Jr RM, Romualdo MP, Oliveira RG. Acompanhamento Nutricional nos grupos de Práticas Corporais do município de Ponte Nova/MG. In IV Mostra Nacional de Experiências em AB/SF.2013[acessado 2016Jun6].Disponível em: https://novo.atencaobasica.org.br/relato/4020

46. Canario TF. Fazendo arte para a arte de amamentar. In: IV Mostra Nacional de Experiências em AB/SF. 2013 [acessado 2016Jun6]. Disponível em: https://novo.atencaobasica.org.br/relato/4543

47. Carezzato C. O grande jogo. In: IV Mostra Nacional de Experiências em Atenção Básica/Saúde da Família.2013[acessado 2016Jun6].Disponível em: https://novo.atencaobasica.org.br/relato/3554

48. Carvalho RS et al. Cozinha comunitária experimental como espaço de educação popular. In: IV Mostra Nacional de Experiências em AB/SF. 2013 [acessado 2016Jun6]. Disponível em: https://novo.atencaobasica.org.br/relato/1819

49. Castillo LDR et al. Floripa Saudável 2040: Impacto do monitoramento e da educação em saúde nos indicadores nutricionais de crianças de 2 a 6 anos. In: IV Mostra Nacional de Experiências em AB/SF. 2013[acessado 2016Jun6]. Disponível em: https://novo.atencaobasica.org.br/relato/2787

50. Caus C. Atenção Nutricional na Atenção Básica. In: IV Mostra Nacional de Experiências em AB/SF.2013[acessado 2016Jun6]. Disponível em: https://novo.atencaobasica.org.br/relato/2264

51. Costa JM. Papel do nutricionista na visita domiciliar. In: IV Mostra Nacional de Experiências em AB/SF. 2013 [acessado 2016Jun6]. Disponível em: https://novo.atencaobasica.org.br/relato/2088

52. Costa PFM et al. Alimentação saudável: incentivo a partir de ações educativas na escola. In: IV Mostra Nacional de Experiências em AB/SF.2013[acessado 2016Jun6]. Disponível em: https://novo.atencaobasica.org.br/relato/3180

53. Costa RR, Pinto MAS, Matos VT. Grupos de convivência apoiados pelo programa de aquisição de alimentos. In: IV Mostra Nacional de Experiências 
em AB/SF.2013[acessado 2016 Jun 06]. Disponível em: https://novo.atencaobasica.org.br/relato/1923

54. Comparin FP, Pelissari A. Eu curto Ser Saudável. In: IV Mostra Nacional de Experiências em AB/SF.2013[acessado 2016Jun6]. Disponível em: https://novo.atencaobasica.org.br/relato/3539

55. Corso V. Perca peso ganhe saúde. In IV Mostra Nacional de Experiências em AB/SF.2013[acessado 2016Jun6]. Disponível em: https://novo.atencaobasica.org.br/relato/3994

56. Cruz VS, Santos MM, Macedo AO. Projeto Perder Brincando. In: IV Mostra Nacional de Experiências em AB/SF.2013[acessado 2016Jun6]. Disponível em: https://novo.atencaobasica.org.br/relato/1354

57. Cunha MD et al. Saúde da Cozinha. In: IV Mostra Nacional de Experiências em AB/SF.2013[acessado 2016Jun6]. Disponível em: https://novo.atencaobasica.org.br/relato/2604

58. Cunha SB et al. PSE e PET-Saúde: uma integração possível? In: IV Mostra Nacional de Experiências em AB/SF.2013[acessado 2016Jun6]. Disponível em: https://novo.atencaobasica.org.br/relato/233

59. Doria RL. Alimentação Saudável para menores de dois anos: uma proposta de apoio matricial. In: IV Mostra Nacional de Experiências em AB/SF. 2013[acessado 2016Jun6].Disponível

em: https://novo.atencaobasica.org.br/relato/2744

60. Fagundes A. A atuação do nutricionista nos Núcleos de Apoios à Saúde da Família. In: IV Mostra Nacional de Experiências em AB/SF. 2013 [acessado 2016Jun6]. Disponível em: https://novo.atencaobasica.org.br/relato/1854

61. Ferreira AS, Barbosa RA. Muito além do peso: o papel da intersetorialidade no acompanhamento e tratamento da desnutrição infantil. In: IV Mostra Nacional de Experiências em AB/SF.2013[acessado 2016Jun6]. Disponível em: https://novo.atencaobasica.org.br/relato/1039

62. Fitipaldi AL, Santos DP, Pires B. Grupo vigilância em saúde infantil: uma estratégia multiprofissional de intervenção nutricional. In: IV Mostra Nacional de Experiências em AB/SF.2013[acessado 2016Jun6]. Disponível em: https://novo.atencaobasica.org.br/relato/3199 
63. Flores VS et al. Amigos do leite no município de Palmas. In: IV Mostra Nacional de Experiências em AB/SF.2013[acessado 2016Jun6]. Disponível em: https://novo.atencaobasica.org.br/relato/2695

64. Freitas AC, Souza CR, Xavier MF. Educação Nutricional e Atividade Física: parceria ideal para a promoção de hábitos saudáveis e tratamento da obesidade infantil. In: IV Mostra Nacional de Experiências em AB/SF. 2013[acessado 2016Jun6]. Disponível em: https://novo.atencaobasica.org.br/relato/3689

65. Galindo EMV et al. Promoção de saúde na escola. In: IV Mostra Nacional de Experiências em AB/SF.2013[acessado 2016Jun6]. Disponível em: https://novo.atencaobasica.org.br/relato/3291

66. Galvão GKC, Galindo S, Souza MA. Promoção de alimentação saudável em creches municipais. In: IV Mostra Nacional de Experiências em AB/SF. 2013 [acessado 2016Jun6].

Disponível

em: https://novo.atencaobasica.org.br/relato/3059

67. Guimarães $\mathrm{KM}$ et al. Avaliação dos índices de aleitamento materno em UBS. In: IV Mostra Nacional de Experiências em AB/SF. 2013[acessado 2016Jun6]. Disponível em: https://novo.atencaobasica.org.br/relato/3950

68. Gonçalves LSP. Orientação nutricional em atividade de grupo como terapêutica da obesidade na ESF: um relato de experiência. In: IV Mostra Nacional de Experiências em AB/SF.2013[acessado 2016Jun6]. Disponível em: https://novo.atencaobasica.org.br/relato/185

69. Graff A et al. Criatividade, Paisagismo Produtivo e Segurança Alimentar. In: IV Mostra Nacional de Experiências em AB/SF.2013[acessado 2016Jun6]. Disponível em: https://novo.atencaobasica.org.br/relato/901

70. Handte M. Programa Municipal de Suplementação Alimentar para Gestantes. In: IV Mostra Nacional de Experiências em AB/SF.2013[acessado 2016Jun6]. Disponível em: https://novo.atencaobasica.org.br/relato/3239

71. Hirano AR. Acompanhamento nutricional: reeducação alimentar e perda de peso. In: IV Mostra Nacional de Experiências em AB/SF. 2013 [acessado 2016Jun6]. Disponível em: https://novo.atencaobasica.org.br/relato/3017

72. Ivonete et al. Acolhendo com saúde- Experiência da Equipe de Nutrição da UBS Mirassol/Natal/RN. In: IV Mostra Nacional de Experiências em 
AB/SF.2013[acessado

2016Jun6].

Disponível

em:

https://novo.atencaobasica.org.br/relato/4076

73. Juliana. Projeto Cintura Fina: parceria entre educação física e nutrição no estímulo ao emagrecimento saudável. In: IV Mostra Nacional de Experiências em AB/SF.2013[acessado 2016Jun6]. Disponível em: https://novo.atencaobasica.org.br/relato/10988

74. Lima AP. A culinária como ferramenta para a promoção da alimentação saudável. In: IV Mostra Nacional de Experiências em AB/SF. 2013 [acessado 2016Jun6].

Disponível

em:

https://novo.atencaobasica.org.br/relato/3920

75. Mattos APP et al. Programa Saúde na Escola - Ação Integrada para Promoção da Saúde em Estudantes em Colombo-PR. In: IV Mostra Nacional de Experiências em AB/SF.2013[acessado 2016Jun6]. Disponível em: https://novo.atencaobasica.org.br/relato/3004

76. Miquelanti VP et al. Projeto PIPAS: Programa Infantil para Alimentação Saudável. In: IV Mostra Nacional de Experiências em AB/SF.2013[acessado 2016Jun6]. Disponível em: https://novo.atencaobasica.org.br/relato/3274

77. Melo KSY, Garcia FLC, Neto CS. Projeto "Apetite por Saúde: Alimentação Saudável, Auto estima e Práticas corporais". In: IV Mostra Nacional de Experiências em AB/SF.2013[acessado 2016Jun6]. Disponível em: https://novo.atencaobasica.org.br/relato/587

78. Moura MV et al. I Shopping da Saúde: Experimente, Viva, Transforme. In: IV Mostra Nacional de Experiências em AB/SF.2013[acessado 2016Jun6]. Disponível em: https://novo.atencaobasica.org.br/relato/4104

79. Nascimento RF, Caio MFF, Silva SM. Mandalas de Frutas e Arteterapia no PSE. In: IV Mostra Nacional de Experiências em AB/SF.2013[acessado 2016Jun6]. Disponível em: https://novo.atencaobasica.org.br/relato/1820

80. Neves AS, Gonzaga MAL. Grupo de reeducação alimentar da UAS Santa Antonieta. In: IV Mostra Nacional de Experiências em AB/SF.2013[acessado 2016Jun6]. Disponível em: https://novo.atencaobasica.org.br/relato/4231

81. Nunes EM et al. Grupo Reeducar para Emagrecer. In: IV Mostra Nacional de Experiências em AB/SF. 2013[acessado 2016Jun6].Disponível em: https://novo.atencaobasica.org.br/relato/1467 
82. Nunes SFL, Chagas DC, Pereira ABS. Um olhar a terceira idade: promovendo nutrição e saúde. In: IV Mostra Nacional de Experiências em AB/SF.2013[acessado 2016Jun6]. Disponível em: https://novo.atencaobasica.org.br/relato/4230

83. Obara AA, Tamarindo EM, Jimenez GA. Viver bem, sem dieta: uma proposta de intervenção em obesidade na Atenção Básica. In: IV Mostra Nacional de Experiências em AB/SF.2013[acessado 2016Jun6]. Disponível em: https://novo.atencaobasica.org.br/relato/3910

84. Oliveira AC, Palharin L. Escola e Saúde um olhar Diferenciado - MS. In: IV Mostra Nacional de Experiências em AB/SF.2013[acessado 2016Jun6]. Disponível em: https://novo.atencaobasica.org.br/relato/2254

85. Oliveira $A C$ et al. Ação Bolsa Família na Atenção Integral as famílias cadastradas nas Micros do ESF Vila Pinheiro-MS. In: IV Mostra Nacional de Experiências em AB/SF. 2013[acessado 2016Jun6] Disponível em: https://novo.atencaobasica.org.br/relato/4219

86. Oliveira JAN et al. Desfazendo o nó no cuidado nutricional em uma UBS: é possível construir laços e redes? In: IV Mostra Nacional de Experiências em AB/SF. 2013 [acessado 2016Jun6]. Disponível em: https://novo.atencaobasica.org.br/relato/3744

87. Oliveira JRG et al. Projeto de Combate à obesidade Infantil. In: IV Mostra Nacional de Experiências em AB/SF.2013[acessado 2016Jun6]. Disponível em: https://novo.atencaobasica.org.br/relato/4124

88. Oliveira MLM, Tavares A, Lys N, Vasconcelos T. Gestantes: Uma experiência de amor e saúde. In: IV Mostra Nacional de Experiências em AB/SF.2013 [acessado 2016Jun6]. Disponível em: https://novo.atencaobasica.org.br/relato/2636

89. Oliveira MR et al. Horta vertical: uma estratégia de estímulo para uma vida saudável, um novo estilo de vida. In: IV Mostra Nacional de Experiências em AB/SF.2013[acessado 2016Jun6]. Disponível em: https://novo.atencaobasica.org.br/relato/3927

90. Oliveira RL. Disco de monitoramento nutricional e estado vacinal para crianças de 0 a 12 meses de idade. In: IV Mostra Nacional de Experiências em AB/SF.2013[acessado 2016Jun6]. Disponível em: https://novo.atencaobasica.org.br/relato/139 
91. Palombo CNT et al. Acompanhamento e Orientação Nutricional: da desnutrição à obesidade. In: IV Mostra Nacional de Experiências em AB/SF.2013[acessado 2016Jun6]. Disponível em: https://novo.atencaobasica.org.br/relato/1565

92. Paula FAA, Lima AP. Grupo de obesos. In: IV Mostra Nacional de Experiências em AB/SF.2013[acessado 2016Jun6]. Disponível em: https://novo.atencaobasica.org.br/relato/3658

93. Pedílio LS et al. Grupo itinerante de alimentação saudável da UBS Jardim Mitsutani. In: IV Mostra Nacional de Experiências em AB/SF.2013[acessado 2016Jun6]. Disponível em: https://novo.atencaobasica.org.br/relato/1437

94. Pereira CM, Santos DAA, Silva TX. Promoção de Educação Alimentar e Nutricional com Usuários do Grupo de Educação em Saúde da USF de Fazenda Coutos II/Salvador/BA. In: IV Mostra Nacional de Experiências em AB/SF.2013[acessado 2016Jun6]. Disponível em: https://novo.atencaobasica.org.br/relato/3635

95. Perez JSL et al. "Não quero chá, quero mamá!" In: IV Mostra Nacional de Experiências em AB/SF.2013[acessado 2016Jun6]. Disponível em: https://novo.atencaobasica.org.br/relato/3539

96. Perez JSL et al. Mais saúde: alimentação saudável com receitas alternativas. In: IV Mostra Nacional de Experiências em AB/SF.2013[acessado 2016Jun6]. Disponível em: https://novo.atencaobasica.org.br/relato/3721

97. Pires MAF et al. De Gota em Gota Alimentando Vidas: Coleta de Leite Humano que Remete a Continuidade da Amamentação. In: IV Mostra Nacional de Experiências em AB/SF.2013[acessado 2016Jun6]. Disponível em: https://novo.atencaobasica.org.br/relato/3849

98. Prata NCS et al. Acompanhamento das condicionalidades do Programa Bolsa Família pela saúde e assistência social. In: IV Mostra Nacional de Experiências em AB/SF.2013[acessado 2016Jun6]. Disponível em: https://novo.atencaobasica.org.br/relato/3801

99. Quintans AM. Alimentação Complementar - Um desafio para as mamães. In: IV Mostra Nacional de Experiências em AB/SF.2013[acessado 2016Jun6]. Disponível em: https://novo.atencaobasica.org.br/relato/3592 
100. Rodrigues APS, Silveira EA, Rosa LPS. Obesidade e $(m)$ grupo: o compartilhar de uma experiência. In: IV Mostra Nacional de Experiências em AB/SF. 2013[acessado 2016Jun6]. Disponível em: https://novo.atencaobasica.org.br/relato/1784

101. Santos ER et al. Integralidade no cuidado à saúde da criança: clínica compartilhada de nutrição. In: IV Mostra Nacional de Experiências em AB/SF. 2013 [acessado 2016Jun6]. Disponível em: https://novo.atencaobasica.org.br/relato/404

102. Santos ERSX et al. Mexe Galante: saúde, educação e assistência, ação intersetorial com participação efetiva do NASF. In: IV Mostra Nacional de Experiências em AB/SF.2013[acessado 2016Jun6]. Disponível em: https://novo.atencaobasica.org.br/relato/2993

103. Santos $M N$ et al. Mapeamento das ações de Vigilância Alimentar e Nutricional na Atenção Básica em Campina Grande/PB. In: IV Mostra Nacional de Experiências em AB/SF.2013[acessado 2016Jun6]. Disponível em: https://novo.atencaobasica.org.br/relato/2194

104. Santos LM, Barbosa AS, Queiroga VE. "Reaproveitamento alimentar":evitando o desperdício! In: IV Mostra Nacional de Experiências em AB/SF.2013[acessado 2016Jun6]. Disponível em: https://novo.atencaobasica.org.br/relato/4176

105. Santos ZMAF. A importância do técnico de enfermagem no acolhimento voltado para amamentação e doação de leite humano. In: IV Mostra Nacional de Experiências em AB/SF.2013[acessado 2016Jun6]. Disponível em: https://novo.atencaobasica.org.br/relato/1271

106. Silva SV, Schäffer C, Führ J. Educação nutricional através de dinâmicas utilizadas em um Grupo de Reeducação Alimentar do município de Dois Irmãos/RS. In: IV Mostra Nacional de Experiências em AB/SF.2013[acessado 2016Jun6]. Disponível em: https://novo.atencaobasica.org.br/relato/3581

107. Sousa AC. Experiência de uma semana de peso no município de Eunápolis/BA. In: IV Mostra Nacional de Experiências em AB/SF.2013[acessado 2016Jun6]. Disponível em: https://novo.atencaobasica.org.br/relato/2915 
108. Sousa LRM et al. Grupo educativo como ferramenta para o cuidado nutricional de pré-escolares e escolares com excesso de peso. In: IV Mostra Nacional de Experiências em AB/SF. 2013 [acessado 2016Jun6]. Disponível em: https://novo.atencaobasica.org.br/relato/1448

109. Souza $D$ et al. A saúde em nossa escola infantil. In: IV Mostra Nacional de Experiências em Atenção Básica/Saúde da Família. 2013 [acessado 2016Jun6]. Disponível em: https://novo.atencaobasica.org.br/relato/624

110. Souza VB. Atendimento Nutricional Coletivo. In: IV Mostra Nacional de Experiências em AB/SF.2013[acessado 2016Jun6]. Disponível em: https://novo.atencaobasica.org.br/relato/4543

111. Tasca PC, Weber AP, Costacurta FC. Gincana de Promoção e Educação em Saúde vinculada ao Programa Saúde na Escola desenvolvida na Rede Municipal e Estadual de ensino no município de Santa Helena/SC através das equipes de saúde NASF e ESF e da Rede Intersetorial. In: IV Mostra Nacional de Experiências em AB/SF.2013[acessado 2016Jun6]. Disponível em: https://novo.atencaobasica.org.br/relato/3589

112. Vasconcelos JL. Amamentar é Doar Saúde: Os desdobramentos de uma ação educativa de equipe multiprofissional na promoção do aleitamento materno. In: IV Mostra Nacional de Experiências em AB/SF.2013[acessado 2016Jun6]. Disponível em: https://novo.atencaobasica.org.br/relato/1291

113. Vasconcelos JLA et al. Grupo de grávidas amamentando com amor. In: IV Mostra Nacional de Experiências em AB/SF. 2013 [acessado 2016 Jun 06]. Disponível em: https://novo.atencaobasica.org.br/relato/3971

114. Zaicaner $R$ et al. As ações de alimentação e nutrição: Um dispositivo para o fortalecimento da rede de cuidado. In: IV Mostra Nacional de Experiências em AB/SF.2013[acessado 2016Jun6]. Disponível em: https://novo.atencaobasica.org.br/relato/3891

115. Zimmermann $\mathrm{C}$ et al. Projeto Saberes e Sabores: Uma abordagem transdisciplinar e crianças com sobrepeso e obesidade. In: IV Mostra Nacional de Experiências em AB/SF.2013[acessado 2016Jun6]. Disponível em: https://novo.atencaobasica.org.br/relato/2177 


\section{CONSIDERAÇÕES FINAIS}

O presente trabalho permitiu obtenção do retrato nacional do que pesquisadores e equipes têm desenvolvido na atenção básica e quais os fatores que influenciam a realização de ações pelas equipes, possibilitando reflexões sobre suas práticas, necessidades e dificuldades, que direcionem a ação de gestores e temas a serem priorizados na realização de pesquisas na área.

Os resultados mostram crescimento no interesse de pesquisadores pela agenda, porém ainda com enfoque em pesquisas voltadas, principalmente, à realização de diagnóstico nutricional, tendo como público-alvo mulheres; enquanto o observado, a partir dos relatos da IV Mostra de Experiências em Atenção Básica/Saúde da Família, mostra maior desenvolvimento de ações que respondem às necessidades do perfil alimentar e nutricional da população brasileira, ou seja, ações de promoção da alimentação adequada e saudável e prevenção, controle e tratamento do excesso de peso direcionadas à comunidade do território e a sujeitos com excesso de peso, sendo realizadas de forma multidisciplinar e com articulação intersetorial.

Esses dados sugerem que a articulação entre gestão, atenção e ensino ainda é insuficiente, apesar de ser tão fundamental para o SUS e para as instituições de ensino e pesquisa, por permitir realização conjunta de diagnóstico local, formulação de soluções baseadas em evidências, implementação de ações para enfrentamento dos problemas e avaliação de intervenções. $O$ constante contato com a gestão e serviço é necessário às instituições para que a educação superior e profissional, a produção de conhecimentos e o desenvolvimento de pesquisas sejam pautados na realidade local e nas RAS e estejam alinhados às necessidades de cuidado da população.

Destaca-se que metade das equipes que desenvolviam atividades em grupo de PAAS e prevenção e controle de doenças relataram utilizar metodologias ativas e atividades lúdicas, o que também foi encontrado entre as intervenções realizadas pelos pesquisadores com usuários da $A B$ com o mesmo objetivo, o que sugere que as equipes de $A B$ estão aplicando à prática metodologias e estratégias que são cientificamente comprovadas como mais efetivas.

Outro aspecto relevante é o predomínio de pesquisas e relatos das regiões Sudeste, Sul e Nordeste nos dois primeiros artigos, podendo ainda ser observado que 
a região Norte apareceu como menos prevalente entre os estudos, o que indica que há grande desigualdade regional também quando se pensa em pesquisa e ações de $A \& N$ na $A B$.

Tais dados reafirmam a importância de adoção de estratégias que considerem as diferenças existentes entre os municípios brasileiros, semelhantes no âmbito da alimentação e nutrição, de forma a garantir o princípio de equidade do SUS para que a população tenha acesso com qualidade às ações e serviços ofertados.

O artigo descritivo dos relatos da IV Mostra ainda trouxe a pouca articulação com a RAS, o que também não apareceu na revisão da literatura, indicando importante lacuna para garantia do cuidado tanto em relação às evidências, quanto ao que as equipes relatam desenvolver. Da mesma forma, houve predomínio de ações intersetoriais realizadas com escolas e creches tanto nos relatos da IV Mostra quanto na produção científica, indicando a necessidade de ampliar pesquisas e ações que incluem articulação intersetorial com outros setores, como abastecimento e agricultura, com objetivo de minimizar determinantes que impeçam a garantia dos direitos à saúde e à alimentação.

Ainda, foi possível a identificação de que fatores relacionados à gestão e à organização da atenção básica podem influenciar a realização de ações de alimentação e nutrição pelas equipes, aparecendo nos relatos da IV Mostra e em alguns artigos da revisão, com profissionais e equipes indicando que a falta de articulação da gestão com a equipe e de financiamento, recursos humanos, materiais e estruturais são os principais desafios para o desenvolvimento das ações.

Nesse sentido, a garantia de uma atenção básica que dê conta de cumprir as funções de ser base, resolutiva, coordenadora do cuidado e ordenadora de redes com vistas à garantia do cuidado integral e voltado às necessidades dos usuários, exige uma organização do serviço que contemple a identificação de riscos e das necessidades do território, a utilização de tecnologias de cuidado, a organização de fluxos de usuários e de protocolos de atenção e a atuação como centro de comunicação da rede, a informatização das unidades de saúde, a realização de parcerias intersetoriais, sendo tais aspectos fundamentais para a organização e oferta de todas ações na atenção básica, incluindo as de A\&N.

Com base nos resultados e lacunas identificadas na área de $A \& N$ na $A B$, sugere-se: 
- Para a academia e pesquisadores: maior articulação com o serviço e gestão, incluindo-os no planejamento das pesquisas; realização de pesquisas que tenham como público-alvo idosos, adolescentes, sujeitos com excesso de peso e DCNT; superem a realização de diagnóstico alimentar e nutricional e proponham intervenções inovadoras, viáveis e efetivas ou avaliem ações e programas existentes, especialmente relacionados à prevenção, controle e tratamento da obesidade em todas as faixas etárias, especialmente em crianças; descrevam e proponham métodos de aprimorar a articulação da $A B$ com outros pontos da RAS e com outros setores; abordem as necessidades alimentares especiais e a terapia nutricional neste ponto de atenção; identifiquem as lacunas da gestão e desenvolvam ferramentas que a auxiliem a superá-las; proponham métodos inovadores para a educação permanente, discutam sobre recursos humanos para além de nutricionistas; explorem as potencialidades dos NASF; e desenvolvam avaliações de impacto das ações e análises econômicas sobre o tema.

- Para as equipes e profissionais da $\mathrm{AB}$ : basear as ações nas necessidades dos usuários e no perfil alimentar e nutricional do território; utilização de metodologias ativas problematizadoras nas atividades; realização de busca ativa e registro de todas as gestantes, crianças até dois anos e pessoas com HAS, DM e obesidade; realização de articulação com outros pontos da RAS para garantia da continuidade do cuidado; realização de articulação intersetorial e parcerias com setores como abastecimento e agricultura; maior desenvolvimento de ações de PAAS que abordem questões relacionadas à influência da publicidade $e$ da rotulagem na alimentação, o ato de comer e a comensalidade, e aleitamento materno.

- Para gestores: garantia de financiamento e maior aproximação com a academia para realização de pesquisas na área de $A \& N$ na $A B$ alinhadas às necessidades; oferta de educação permanente aos profissionais da $A B$, principalmente, sobre o cuidado à obesidade e superação de obstáculos da alimentação adequada e saudável, ato de comer, comensalidade e NBCAL; avaliação da necessidade de inclusão de nutricionistas no NASF, a partir da realidade local; reconhecimento da 
importância da inserção das ações de $A \& N$ nas práticas das equipes de saúde, com sua qualificação e disponibilização de apoio técnico; garantia de vitaminas, minerais e medicamentos em quantidade suficiente e equipamentos antropométricos essenciais à realização da avaliação do estado nutricional; adoção de estratégias que considerem as diferenças existentes entre os municípios brasileiros e maior apoio às regiões Norte, Nordeste e Centro-Oeste.

Além dessas recomendações específicas, a implementação efetiva de ações de alimentação e nutrição demandam priorização política e técnica, com a realização de aporte orçamentário suficiente pelas três esferas de gestão com uso adequado e transparente dos recursos públicos; boa organização e estruturação das redes de atenção à saúde e comunicação entre os diversos pontos de atenção; e garantia de estrutura e recursos humanos valorizados e apoiados em contratações que garantam direitos trabalhistas e previdenciários.

Destaca-se ainda a necessidade de garantia da plena participação e controle social em todo ciclo de políticas públicas, desde a geração de evidências baseadas em necessidades das comunidades, até o planejamento e implementação de tais políticas. Assim, a efetividade de ações no SUS que contribuam para melhoria das condições de nutrição e saúde da população, exige também o respeito à democracia, com a implementação e não ruptura de projetos políticos votados pela maioria da população, que garantam os direitos estabelecidos na Constituição Federal.

Com relação a esse aspecto, destaca-se que, em 2016, ocorreu impeachment da presidenta da República, reeleita democraticamente em 2014. Os atuais governantes, aliados à ala conservadora e maioria do Congresso Nacional, têm aprovado legislações e implementado ações, as quais priorizam o mercado e vão de encontro à garantia de direitos sociais básicos, como saúde e educação. Nesse contexto, destaca-se a aprovação da Proposta de Emenda à Constituição oㅜ 95, de autoria da Presidência da República, que institui novo regime fiscal propondo, entre outras medidas, o congelamento por 20 anos de recursos do orçamento da saúde. Mesmo que haja crescimento econômico, o SUS terá perdas proporcionais de recursos, que já não são suficientes para garantia do direito à saúde (Doniec, Dall'Alba e King, 2016; Vieira e Benevides, 2016). 
Em um cenário de atual insuficiência de aplicação de recursos na saúde, aliado ao crescimento e envelhecimento populacional, que demandará maior necessidade de investimentos, a implementação de uma nova regra que reduzirá o financiamento do SUS implicará oferta de serviços ainda mais precarizada, com menor cobertura e qualidade, e piora na situação de saúde da população, impactando também na economia (Vieira e Bevevides, 2016). Considerando que estados e municípios não darão conta de absorver a redução do financiamento federal e que o financiamento da atenção básica já vem sofrendo consequências diretas do corte orçamentário desde 2015 (Vieira e Bevevides, 2016; Ministério da Saúde, 2016e), a EC no95 pode afetar os avanços descritos no SUS, na atenção básica, na área de alimentação e nutrição do SUS e nas políticas de segurança alimentar e nutricional, inclusive, levando a retrocessos.

Por meio da análise desta dissertação, foi possível verificar diversas ações e reconhecer o empenho e trabalha realizado por pesquisadores, equipes e gestores na área de alimentação e nutrição. Contudo, por mais que haja esforços pelas equipes, por pesquisadores e gestores bem intencionados, a alimentação e nutrição na atenção básica somente poderá ser efetiva com a priorização, investimento e implementação de políticas de saúde e de segurança alimentar e nutricional, sem as quais as ações das equipes e as ações setoriais terão alcance e impactos limitados. 


\section{REFERÊNCIAS DA DISSERTAÇÃO}

Alves KPS, Jaime PC. A Política Nacional de Alimentação e Nutrição e seu diálogo com a Política Nacional de Segurança Alimentar e Nutricional. 2014. Cien Saúde Coletiva, 19(11):4331-40.

Aquino R, Oliveira NF, Barreto ML. Impact of the Family Health Program on Infant Mortality in Brazilian Municipalities. Am J Public Health. 2009; 99(1): 87-93.

Aquino R, Medina MG, Abdon C. Monitoramento e avaliação: reflexos visíveis na atenção primária à saúde no Brasil. In: Sousa MF, Franco MS, Mendonça AVM (org.). Saúde da Família nos municípios brasileiros: os reflexos dos 20 anos no espelho do futuro. Campinas, SP: Saberes Editora, 2014.

Arruda BKG, Arruda IKG. Políticas de alimentação e nutrição no Brasil: breve enfoque dos delineamentos conceituais e propositivos. In: Taddei JAAC, Lang RMF, LongoSilva G, Toloni MHA, organizadores. Nutrição em saúde pública. Rio de Janeiro: Editora Rubio; 2011. p. 397-422.

Barros MSC, Tartaglia JC. A política de alimentação e nutrição no brasil: Breve histórico, avaliação e perspectivas. Alim. Nutr. 2003;14(1): 109-121.

Barufaldi LA, et al. ERICA: prevalência de comportamentos alimentares saudáveis em adolescentes brasileiros. Rev. Saúde Pública. 2016; 50(supl.1):6s.

Bezerra IN, Souza AM, Pereira RA, Sichieri R. Consumo de alimentos fora do domicílio no Brasil. Rev. Saúde Pública. 2013; 47(supl.1): 200S-11S.

Bloch KV et al. ERICA: prevalências de hipertensão arterial e obesidade em adolescentes brasileiros. Rev Saúde Pública.2016;50(supl 1):9s.

Boreli et al A inserção do nutricionista na Atenção Básica: uma proposta para o matriciamento da atenção nutricional. Ciên Saúde Coletiva.2015;20(9):2765-2778.

Bortolini GA, Gubert MB, Santos LMP. Consumo alimentar entre crianças brasileiras com idade de 6 a 59 meses. Cad. Saúde Pública. 2012; 28(9):1759-1771.

Bortolini GA, Vitolo MR, Gubert MB, Santos LMP. Early cow's milk consumption among Brazilian children: results of a national survey. J Pediatr. 2013; 89 (6): 608-613. 
Brasil. Constituição da República Federativa do Brasil de 1988. DOU. 5/10/1988

Brasil. Lei ํo 8.080, de 19 de setembro de 1990. Dispõe sobre as condições para a promoção, proteção e recuperação da saúde, a organização e o funcionamento dos serviços correspondentes e dá outras providências. DOU. 20/9/1990.

Brasil. Constituição (1988). Emenda Constitucional no64, de 4 de fevereiro de 2010. Altera 0 art. $6^{\circ}$ da Constituição Federal, para introduzir a alimentação como direito social. DOU. 4/2/2010. 2010a.

Brasil. Constituição (1988). Emenda Constitucional no90, de 15 de setembro de 2015. Dá nova redação ao art. 60 da Constituição Federal, para introduzir o transporte como direito social. DOU. 16/9/2015. 2015.

Brasil. Lei oㅜ 13.249, de 13 de janeiro de 2016. Institui o Plano Plurianual da União para o período de 2016 a 2019. [internet]. [acesso em: 12 jun 2016]. Disponível em: http://portal.imprensanacional.gov.br/destaques/ppa/2016_01_14_p_suplementoppa. pdf 2016

Buss PM. Uma introdução ao conceito de promoção da saúde. p.15-38. In: Czeresnia D, Freitas CM. (org). Promoção da saúde: conceitos, reflexões, tendências. Rio de Janeiro: Fiocruz, 2003.

Buss PM, Pellegrini Filho A. A Saúde e seus Determinantes Sociais. PHYSIS Rev. Saúde Coletiva. 2007; 17(1):77-93.

Caisan - Câmara Interministerial de Segurança Alimentar e Nutricional (BR). Plano Nacional de Segurança Alimentar e Nutricional 2016-2019: aprovado pelo pleno executivo da Câmara Interministerial de Segurança Alimentar e Nutricional em 05.05.2016. [internet] [acesso em 12 jun 2016]. Disponível em: https://issuu.com/informecaisan/docs/plansan_2016-19_10_05_2016_vers_o 2016 Campino ACC, Machado FMS. O papel da saúde na formação de capital humano e na promoção do crescimento econômico no Brasil. Informações FIPE. 2005, 303(12):12-17.

Canella DS; Silva ACFS; Jaime PC. Produção científica sobre nutrição no âmbito da atenção primária à saúde no Brasil: uma revisão da literatura. Cien Saude Coletiva. 2013; 18(2):297-308. 
Canella DS et al. Ultra-processed food products and obesity in Brazilian households (2008-2009). PLoS One. 2014;.9(3).

Canella DS, Novaes HMD, Levy RB. Influência do excesso de peso e da obesidade nos gastos em saúde nos domicílios brasileiros. Cad. Saúde Pública.2015;31(11):2331-2341.

Castro IRRC, Castro LMC, Gugelmin SA. Ações educativas, programas e políticas envolvidos nas mudanças alimentares. In: Diez-Garcia RW, Cervato-Macuso AM (coord). Rio de Janeiro: Guanabara-Koogan; 2012.

Comunidade de Práticas [internet]. Brasília, DF: c2012. [acesso em 02 ago 2016]. Disponível em: https://novo.atencaobasica.org.br/

Conde WL, Rinaldi AEM, Enes CC. Is the secular trend in height delaying overweight rise among adolescents? The Brazilian case. PHN. 2016; 18:1-7.

Claro RM, Santos MA, Oliveira TP, Pereira CA, Szwarcwald CL, Malta DC. Consumo de alimentos não saudáveis relacionados a doenças crônicas não transmissíveis no Brasil: Pesquisa Nacional de Saúde, 2013. Epidemiol. Serv. Saúde. 2015; 24(2): 257265.

CNDSS - Comissão Nacional de Determinantes Sociais da Saúde. As causas sociais das iniquidades em saúde no Brasil: Relatório Final da Comissão Nacional de Determinantes Sociais da Saúde. Brasília, DF: CNDSS, 2008.

Consea - Conselho Nacional de Segurança Alimentar e Nutricional. Documento de Referência da $5^{\mathrm{a}}$ Conferência Nacional de Segurança Alimentar e Nutricional. Brasília, DF: Consea; 2015.

Declaração de Curitiba: Garantir a Democracia e os Direitos Humanos em todos os países. 22ª Conferência Mundial de Promoção da Saúde da IUPES; 22-26 mai 2016; Curitiba: UIPES; 2016.

Declaração de Helsinque sobre Saúde em Todas as Políticas. $8^{\text {a }}$ Conferência Internacional de Promoção da Saúde; 10-14 jun 2013; Helsinque. Brasília (DF): UIPES/ORLA; 2013.

Dietz WH, Baur LA, Hall K, Puhl RM, Taveras EM, Uauy R, Kopelman P. Management of obesity: improvement of health-caretraining and systems for prevention and care. Lancet 2015; 385: 2521-33. 
Doniec K, Dall'Alba R, King L. Austerity threatens universal health coverage in Brazil. 2016; 388(10047): 867-868.

Donini LM et al. Multidisciplinary approach to obesity. Eat Weight Disord.2009; 14(1): 23-32.

Egger G, Swinburn B. An "ecological" approach to the obesity pandemic. BMJ.1997;23;315(7106):477-80.

Euromonitor International. Top 20 Soda-Drinking Countries In 2014. In: Silver M. Guess Which Country Has The Biggest Increase In Soda Drinking. NPR [internet]. 19 jun 2015 [acesso em 8 ago 2016]. Disponível em: http://www.npr.org/sections/goatsandsoda/2015/06/19/415223346/guess-whichcountry-has-the-biggest-increase-in-soda-

drinking?utm_source=facebook.com\&utm_medium=social\&utm_campaign=npr\&utm _term=nprnews\&utm_content=20150620.

FAO - Organização das Nações Unidas para a Alimentação e a Agricultura. O Estado da Segurança Alimentar e Nutricional no Brasil: Um retrato multidimensional: Relatório 2014. Brasília, DF: FAO, 2014a.

FAO - Food and Agriculture Organization of the United Nations. The State of Food Insecurity in the World: Strengthening the enabling environment for food security and nutrition. Rome: FAO, 2014b.

FAO/WHO - Food and Agriculture Organization of the United Nations. World Health Organization. Rome Declaration on Nutrition: Second International Conference on Nutrition. Rome: FAO/WHO, 2014a.

FAO/WHO - Food and Agriculture Organization of the United Nations. World Health Organization. Framework for Action: Second International Conference on Nutrition. Rome: FAO/WHO, 2014.

Faria Neto JR et al. ERICA: prevalência de dislipidemia em adolescentes brasileiros. Rev Saúde Pública. 2016;50(supl 1):10s.

Ferreira VA, Magalhães R. Nutrição e promoção da saúde: perspectivas atuais. Cad. Saúde Pública.2007;23(7):1674-81. 
Flor LS, Campos MR, Oliveira AF, Schramm JMA. Carga de diabetes no Brasil: fração atribuível ao sobrepeso, obesidade e excesso de peso. Rev Saúde Pública. 2015;49:29.

Gervas J, Fernandez MP. Uma atenção primária forte no Brasil: relatório sobre como fortalecer os acertos e corrigir as fragilidades da Estratégia Saúde da Família. Madri, Espanha: 2011.

Hartley L, et al. Increased consumption of fruit and vegetables for the primary prevention of cardiovascular diseases. Cochrane Database of Systematic Reviews. 2013; 6(CD009874).

Hawkes et al. Smart food policies for obesity prevention. Lancet.2015;385:2410-21

Hollands GJ, et al. Portion, package or tableware size for changing selection and consumption of food, alcohol and tobacco. Cochrane Database of Systematic Reviews. 2015; 9.

Hone T, Rasella D, Barreto M, Atun R, Majeed A, Millet C. Large Reductions In Amenable Mortality Associated With Brazil's Primary Care Expansion And Strong Health Governance. Health Aff. 2017; 36(1):149-158.

Horton S, RH Steckel. Malnutrition: Global Economic Losses Attributable to Malnutrition 1900-2010 and Projections to 2050. In: Lomborg B (ed.). How Much Have Global Problems Cost the World? A Scorecard from 1900 to 2050. Cambridge, UK: Cambridge University; 2013. p. 247-272.

IFPRI - International Food Policy Research Institute. Global Nutrition Report 2015: Actions and Accountability to Advance Nutrition and Sustainable Development. Washington, DC: IFPRI, 2015.

IFPRI - International Food Policy Research Institute. Global Nutrition Report 2016: From Promise to Impact: Ending Malnutrition by 2030. Washington, DC: IFPRI, 2016a. IFPRI - International Food Policy Research Institute. Global Nutrition Report 2016: From Promise to Impact: Ending Malnutrition by 2030. Washington, DC: IFPRI, $2016 \mathrm{~b}$. Chapter 1 - The new challenge: end all forms of malnutrition by 2030; p.1-13. Instituto Brasileiro de Geografia e Estatística. Pesquisa de orçamentos familiares 2008-2009: antropometria e estado nutricional de crianças, adolescentes e adultos. Rio de Janeiro: IBGE; 2010. 
Instituto Brasileiro de Geografia e Estatística. Pesquisa de orçamentos familiares 2008-2009: análise do consumo alimentar pessoal no Brasil. Rio de Janeiro: IBGE; 2011 .

Instituto Brasileiro de Geografia e Estatística. Pesquisa Nacional por Amostra de Domicílios: segurança alimentar 2013. Brasília, DF: IBGE;2014.

Instituto Brasileiro de Geografia e Estatística. Pesquisa Nacional de Saúde 2013. Rio de Janeiro: IBGE; 2015.

Keefe M. Chapter 11 - Nutrition and Equality Brazil's Success in Reducing Stunting among the Poorest. In: International Food Policy Research Institute. Nourishing millions: Stories of change in nutrition. Washington, DC: IFPRI, 2016.

Jaime PC, Silva ACS, Lima AMC, Bortolini GA. Ações de alimentação e nutrição na atenção básica: a experiência de organização no Governo Brasileiro. Rev. Nutr. 2011; 24(6):809-824.

Jaime PC et al. Desnutrição em crianças de até cinco anos beneficiárias do Programa Bolsa Família: análise transversal e painel longitudinal de 2008 a 2012. In: Sousa MF, Ximenez DA, Jaime PC. Cadernos de Estudos Desenvolvimento Social em Debate: Resultados, avanços e desafios das condicionalidades de saúde do Bolsa Família. Brasília, DF: 2014.

Jaime PC, Santos LMP. Transição nutricional e a organização do cuidado em alimentação e nutrição na Atenção Básica em saúde. Rev Divulgação em Saúde para Debate. 2014; 51: 72-85.

Jaime PC, Stopa SR, Oliveira TP, Vieira ML, Szwarcwald CL, Malta DC. Prevalência e distribuição sociodemográfica de marcadores de alimentação saudável, Pesquisa Nacional de Saúde, Brasil 2013. Epidemiol. Serv. Saúde.2015; 24(2): 267-276.

Jaime PC, Frias PG, Monteiro HOC, Almeida PVB, Malta DC. Assistência em saúde e alimentação não saudável em crianças menores de dois anos: dados da Pesquisa Nacional de Saúde, Brasil, 2013. Rev. Bras. Saude Mater. Infant. 2016;16(2): 159167.

Kuschnir MCC et al. ERICA: prevalência de síndrome metabólica em adolescentes brasileiros. Rev Saúde Pública. 2016;50(supl 1):11s. 
Louzada MLC, et al. Impacto de alimentos ultraprocessados sobre o teor de micronutrientes da dieta no Brasil. Rev Saúde Pública. 2015;49:45.

Macinko $\mathrm{J}$ et al. Major Expansion of Primary Care in Brazil Linked To Decline In Unnecessary Hospitalization. Health Affairs. 2010; 29: 2149-2160.

Macinko J, De Oliveira VB, Turci MA, Bonolo PF, Lima-Costa MF, Guanais FC. The Influence of Primary Care and Hospital Supply on Ambulatory Care-Sensitive Hospitalizations Among Adults in Brazil, 1999-2007. Am J Public Health.2011; 101(10): 1963-1970.

Magalhães Junior HM, Pinto HA. Atenção Básica enquanto ordenadora da rede e coordenadora do cuidado: ainda uma utopia? Divulgação em Saúde para Debate. 2014; 51:14-29

Malta et al. Tendência temporal dos indicadores de excesso de peso em adultos nas capitais brasileiras, 2006-2013. Cien Saúde Coletiva.2016;21(4):1061-1069.

Martins APB, Levy RB, Claro RM, Mourabac JC, Monteiro CA. Participação crescente de produtos ultraprocessados na dieta brasileira (1987-2009). Rev Saúde Pública.2013; 47(4): 656-65.

Ministério da Saúde (BR). Secretaria de Atenção à Saúde. Departamento de Atenção Básica. Política Nacional de Atenção Básica. Brasília, DF: MS, 2006.

Ministério da Saúde (BR). Centro Brasileiro de Análise e Planejamento. Pesquisa Nacional de Demografia e Saúde da Criança e da Mulher 2006. Brasília, DF: MS; 2009a. [Série G. Estatística e Informação em Saúde].

Ministério da Saúde (BR). Secretaria de Atenção à Saúde. Departamento de Atenção Básica. Matriz de Ações de Alimentação e Nutrição na Atenção Básica à Saúde. Brasília, DF: 2009b.

Ministério da Saúde (BR). Fundação Nacional de Saúde. I Inquérito Nacional de Saúde e Nutrição dos Povos Indígenas. Brasília, DF: FUNASA; 2010.

Ministério da Saúde (BR). Secretaria de Vigilância em Saúde. Departamento de Análise de Situação de Saúde. Plano de ações estratégicas para o enfrentamento das doenças crônicas não transmissíveis (DCNT) no Brasil 2011-2022. Brasília, DF: MS; $2011 \mathrm{a}$. 
Ministério da Saúde (BR). Secretaria de Atenção à Saúde. Departamento de Atenção Básica. Política Nacional de Atenção Básica. Brasília: Ministério da Saúde, 2011b.

Ministério da Saúde (BR). Portaria no 1654, de 19 de julho de 2011. Institui, no âmbito do Sistema Único de Saúde, o Programa Nacional de Melhoria do Acesso e da Qualidade da Atenção Básica (PMAQ-AB) e o Incentivo Financeiro do PMAQ-AB, denominado Componente de Qualidade do Piso de Atenção Básica Variável - PAB Variável. [internet] [acesso em 27 abr 2014]. Disponível em: <http://bvsms.saude.gov.br/bvs/saudelegis/gm/2011/prt1654_19_07_2011.html>. 2011c.

Ministério da Saúde (BR). Secretaria de Atenção à Saúde. Departamento de Atenção Básica. Documento Síntese para Avaliação Externa do PMAQ-AB. Brasília (DF): Ministério da Saúde, 2011d.

Ministério da Saúde (BR). Secretaria de Atenção à Saúde. Departamento de Atenção Básica. Política Nacional de Alimentação e Nutrição. Brasília, DF: MS; 2012a.

Ministério da Saúde (BR). Secretaria de Atenção à Saúde. Secretaria Especial de Saúde indígena. Secretaria de Vigilância em Saúde. Guia de Consulta para Vigilância Epidemiológica, Assistência e Atenção Nutricional dos Casos de Beribéri. Brasília, DF: Ministério da Saúde, 2012b. [Série A. Normas e Manuais Técnicos]

Ministério da Saúde (BR). Portaria no 3.124, de 28 de dezembro de 2012. Redefine os parâmetros de vinculação dos Núcleos de Apoio à Saúde da Família (NASF) Modalidades 1 e 2 às Equipes Saúde da Família e/ou Equipes de Atenção Básica para populações específicas, cria a Modalidade NASF 3, e dá outras providências. [internet]. [acesso em 20 jul 2016]. Disponível em: http://bvsms.saude.gov.br/bvs/saudelegis/gm/2012/prt3124_28_12_2012.html. 2012c.

Ministério da Saúde (BR). Secretaria de Atenção à Saúde. Departamento de Atenção Básica. Edital da IV Mostra Nacional de Experiências em Atenção Básica / Saúde da Família. Brasília, DF: 2013a.

Ministério da Saúde (BR). Secretaria de Atenção à Saúde. Departamento de Atenção Básica. Manual instrutivo: Saúde Mais Perto de Você - Acesso e Qualidade Programa de Melhoria do Acesso e da Qualidade na Atenção Básica (PMAQ). Brasília, DF: Ministério da Saúde, 2013b. 
Ministério da Saúde (BR). Secretaria de Vigilância em Saúde. Secretaria de Atenção à Saúde. Política Nacional de Promoção da Saúde: revisão da Portaria MS/GM no 687, de 30 de março de 2006. Brasília, DF: MS; 2014a

Ministério da Saúde (BR). Secretaria de Atenção à Saúde. Departamento de Atenção Básica. Guia Alimentar para a população brasileira. 2.ed. Brasília, DF: Ministério da Saúde, 2014b.

Ministério da Saúde (BR). Secretaria de Atenção à Saúde. Departamento de Atenção Básica. PMAQ transforma realidades (Segundo episódio). 2014. Disponível em: < http://dab.saude.gov.br/portaldab/pmaq_realidades.php >. Acesso em 27 abr. 2014c.

Ministério da Saúde (BR). Secretaria de Atenção à Saúde. Departamento de Atenção Básica. Coordenação-Geral de Alimentação e Nutrição. Marco de Referência em Vigilância Alimentar e Nutricional na Atenção Básica. Brasília, DF: Ministério da Saúde, 2015a.

Ministério da Saúde (BR). Secretaria de Atenção à Saúde. Departamento de Atenção Básica. Nota Metodológica da Certificação das Equipes de Atenção Básica. Brasília, DF: Ministério da Saúde, 2015b.

Ministério da Saúde (BR). Secretaria de Atenção à Saúde. Departamento de Atenção Básica. Coordenação-Geral de Alimentação e Nutrição. Relatório de Gestão 2011 2014: Coordenação-Geral de Alimentação e Nutrição. Brasília, DF: Ministério da Saúde, 2016a. [no prelo].

Ministério da Saúde (BR). Secretaria de Atenção à Saúde. Departamento de Atenção Básica. Coordenação-Geral de Alimentação e Nutrição. Relatório de Gestão 2015. Brasília, DF: Ministério da Saúde, 2016b. [no prelo].

Ministério da Saúde (BR). Secretaria de Atenção à Saúde. Departamento de Atenção Básica. Memorial da IV Mostra Nacional de Experiências em Atenção Básica/Saúde da Família. Brasília, DF: Ministério da Saúde, 2016c. [Série C. Projetos, Programas e Relatórios].

Ministério da Saúde (BR). Secretaria de Atenção à Saúde. Departamento de Atenção Básica. Contribuições dos Núcleos de Apoio à Saúde da Família para a Atenção Nutricional Brasília: Ministério da Saúde, 2016d. [no prelo] 
Ministério da Saúde (BR). Secretaria de Atenção à Saúde. Relatório de Gestão - 2015. Brasília: Ministério da Saúde, 2016e.

MDS- Ministério do Desenvolvimento Social e Combate à Fome (BR). Secretaria de Avaliação e Gestão da Informação. Chamada nutricional quilombola 2006: sumário executivo. Brasília, DF: MDS, 2007.

MDS - Ministério do Desenvolvimento Social e Combate à Fome (BR). SecretariaExecutiva da Câmara Interministerial de Segurança Alimentar e Nutricional. Balanço do Plano de Segurança Alimentar e Nutricional 2012-2015. Brasília, DF: MDS; 2013. MDS - Ministério do Desenvolvimento Social e Combate à Fome (BR). Ministério da Saúde. Avaliação da Evolução Temporal do Estado Nutricional das crianças de 0 a 5 anos beneficiárias do Programa Bolsa Família (PBF), acompanhadas nas condicionalidades de saúde: Sumário Executivo. Brasília, DF: MDS/MS, 2014.

Moher D, Liberati A, Tetzlaff J, Altman DG, The PRISMA Group (2009). Preferred Reporting Items for Systematic Reviews and Meta-Analyses: The PRISMA Statement. PLoS Med 6(7): e1000097. doi:10.1371/journal.pmed1000097

Monteiro CA (org.). Velhos e novos males da saúde no Brasil: a evolução do país e de suas doenças. 2 ed. São Paulo: Hucitec/Nupens-USP; 2000.

Monteiro CA, Benicio MHDA, Konno SC, Silva ACF, Lima ALL, Conde WL. Causas do declínio da desnutrição infantil no Brasil, 1996-2007. Rev Saúde Pública. 2009;43(1):35-43.

Oliveira ML. Estimativa dos custos da obesidade para o Sistema Único de Saúde do Brasil. 2013. Tese (Doutorado em Nutrição Humana)—Universidade de Brasília, Brasília, 2013.

Oliveira MM, Malta DC, Santos MA, Oliveira TP, Nilson EAF, Claro RM. Consumo elevado de sal autorreferido em adultos: dados da Pesquisa Nacional de Saúde, 2013. Epidemiol. Serv. Saúde. 2015; 24(2): 249-256.

OMS - Organização Mundial da Saúde. Diretriz: Uso de formulações em pó de múltiplos micronutrientes para fortificação caseira de alimentos consumidos por bebês e crianças de 6-23 meses de vida. Genebra: Organização Mundial da Saúde; 2013. 
PAHO - Pan American Health Organization. Ultra-processed food and drink products in Latin America: Trends, impact on obesity, policy implications. Washington, DC: PAHO, 2015.

Pereira TN, Silva KC, Pires ACL, Alves KPS, Lemos ASP, Jaime PC. Perfil das demandas judiciais para fornecimento de fórmulas nutricionais encaminhadas ao ministério da saúde do Brasil. DEMETRA. 2014; 9: 199-214.

Portal do Departamento de Atenção Básica [internet]. Brasília, DF: c2012. [acesso em 20 jul 2016]. Disponível em:

http://dab.saude.gov.br/portaldab/historico_cobertura_sf.php

Pinto HA, Souza AN, Florêncio AR. O Programa Nacional de Melhoria do Acesso e da Qualidade da Atenção Básica: Reflexões sobre o seu desenho e processo de implantação. Rev Eletr de Com Inf Inov Saúde [internet]. 2012 [acesso em 27 abr 2014]; 6(2). Sup. Disponível em: <www.reciis.icict.fiocruz.br>.

Rasella D, Aquino R, Barreto ML. Reducing childhood mortality from diarrhea and lower respiratory tract infections in Brazil. Pediatrics. 2010; 126(3):534-40.

Rasella D, Aquino R, Santos CAT, Paes-Sousa R, Barreto ML. Effect of a conditional cash transfer programme on childhood mortality: a nationwide analysis of Brazilian municipalities. The Lancet. 2013; 382 (9886): 57-64.

Rasella D, Harhay MO, Pamponet ML, Aquino R, Barreto ML. Impact of primary health care on mortality from heart and cerebrovascular diseases in Brazil: a nationwide analysis of longitudinal data. BMJ. 2014; 349. doi: 10.1136/bmj.g4014.

Rauber F, Campagnolo PD, Hoffman DJ, Vitolo MR. Consumption of ultraprocessed food products and its effects on children's lipid profiles: a longitudinal study. Nutr Metab Cardiovasc Dis. 2015;25(1):116-22.

Rigon SA, Schmidt ST, Bógus CM. Desafios da nutrição no Sistema Único de Saúde para construção da interface entre a saúde e a segurança alimentar e nutricional. Cad. Saúde Pública. 2016; 32(3):e00164514.

Roberto CA et al. Patchy progress on obesity prevention: emerging examples, entrenched barriers, and new thinking. Lancet.2015;385: 2400-09.

Rocha C, Jaime PC, Rea MF. Panel 1.5 How Brazil's Political Commitment To Nutrition Took Shape. In: International Food Policy Research Institute. Global Nutrition Report 
2016: From Promise to Impact: Ending Malnutrition by 2030. Washington, DC: IFPRI; 2016; p.11-12.

Saldiva SR, Venancio SI, Santana AC, Castro ALS, Escuder MM, Giugliani ER. The consumption of unhealthy foods by Brazilian children is influenced by their mother's educational level. Nutrition Journal. 2014; [doi:10.1186/1475-2891-13-33].

Saldiva SR, Venancio SI, Santana AC, Castro ALS, Escuder MM, Giugliani ER. The consumption of unhealthy foods by Brazilian children is influenced by their mother's educational level. Nutrition Journal. 2014; 13(33).

Schmidt Ml et al. Doenças crônicas não transmissíveis no Brasil: carga e desafios atuais. Lancet.2011: 61-74.

Segal-Correa AM, Marin-Leon L. A Segurança Alimentar no Brasil: Proposição e Usos da Escala Brasileira de Medida da Insegurança Alimentar (EBIA) de 2003 a 2009. Segurança Alimentar e Nutricional.2009;16(2):1-19.

Shamseer L, Moher D, Clarke M, Ghersi D, Liberati A, Petticrew M, Shekelle P, Stewart LA, the PRISMA-P Group. Preferred Reporting Items for Systematic Review and MetaAnalysis Protocols (PRISMA-P) 2015: elaboration and explanation. BMJ 2015.349:g7647. doi: 10.1136/bmj.g7647

Sisvan - Sistema de Vigilância Alimentar e Nutricional. [internet]. Brasília, DF: Ministério da Saúde [acesso em 13 jun 2016]. Disponível em: http://dabsistemas.saude.gov.br/sistemas/sisvan/relatorios_publicos/relatorios.php Snethen JA, Broome ME, Cashin SE. Effective weight loss for overweight children: a meta-analysis of intervention studies. J Pediatr Nurs. 2006;21(1):45-56.

Souza AM, Pereira RA, Yokoo EM, Levy RB, Sichieri R. Alimentos mais consumidos no Brasil: Inquérito Nacional de Alimentação 2008-2009. Rev. Saúde Pública. 2013; 47 (suppl.1):190S-9S.

Souza AM et al. ERICA: ingestão de macro e micronutrientes em adolescentes brasileiros. Rev. Saúde Pública. 2016; 50(supl.1):5s.

Tavares LF, Fonseca SC, Garcia Rosa ML, Yokoo EM. Relationship between ultraprocessed foods and metabolic syndrome in adolescents from a Brazilian Family Doctor Program. Public Health Nutr. 2012;15(1):82-7. 
UN - United Nations. United Nations Decade of Action on Nutrition (2016-2025) [internet]. New York: UN; 2016. [A/RES/70/259, draft A/70/L.42]. [acesso em 10 jun 2016].

Disponível

em:

http://www.un.org/en/ga/search/view_doc.asp?symbol=A/70/L.42

Vasconcelos FAG, Batista Filho MB. História do campo da Alimentação e Nutrição em Saúde Coletiva no Brasil. Cien Saúde Coletiva. 2011;16(1):81-90.

Vasconcelos IAL, Santos LMP. Research potential of food and nutrition in the Family Health Strategy: A structured review.Rev. Nutr.2014;27(1):107-126.

Vasconcelos IAL, Sousa MF, Santos LMP. Evolução do quantitativo de nutricionistas na Atenção Básica do Brasil: a contribuição dos Núcleos de Apoio à Saúde da Família e da Estratégia Saúde da Família de 2007 a 2013. Rev. Nutr.2015;28(4):431-450.

Venancio SI, Saldiva SRDM, Monteiro CA. Tendência secular da amamentação no Brasil. Rev Saúde Pública. 2013;47(6):1205-8.

Vieira RCS, Ferreira HS. Prevalência de anemia em crianças brasileiras, segundo diferentes cenários epidemiológicos. Rev Nutr. 2010; 23(3): 433-444.

Vieira RS, Bevevides RPS. Os impactos do Novo Nota Técnica oㅡ28: Regime Fiscal para o financiamento do Sistema Único de Saúde e para a efetivação do direito à saúde no Brasil. Brasília, DF: IPEA; 2016.

Vieira RS, Bevevides RPS. O Direito à Saúde no Brasil em Tempos de Crise Econômica, Ajuste Fiscal e Reforma Implícita do Estado. Revista de Estudos e Pesquisas sobre as Américas [internet]. 2016 [acesso em 23 jan 2017]; 10(3). Disponível em: http://cebes.org.br/site/wp-content/uploads/2017/01/21860-68023-1PB.pdf

WCRF/AICR - World Cancer Research Fund/American Institute for Cancer Research. Food, Nutrition, Physical Activity, and the Prevention of Cancer: a Global Perspective. Washington, DC: AICR, 2007.

WHO - World Health Organization. Diet, nutrition and the prevention of chronic diseases: Report of a joint WHO/FAO expert consultation. Geneva: WHO, 2003. [WHO Technical Report Series 916].

WHO - World Health Organization. Fiscal Policies for Diet and Prevention of Noncommunicable Diseases: Technical Meeting Report. Geneva: WHO, 2016. 
WHO - World Health Organization. Sixty-ninth World Health Assembly update [internet]. Geneva: WHO; 2016 [acesso em 02 jan 2017]. Disponível em: http://www.who.int/mediacentre/news/releases/2016/wha69-27-may-2016/en/

Yan J, Liu L, Zhu Y, Huang G, Wang PP. The association between breastfeeding and childhood obesity: a meta-analysis.BMC Public Health. 2014; 14: 1267. 
ANEXO - APROVAÇÃO DO COMITÊ DE ÉTICA EM PESQUISA

FACULDADE DE CIÊNCIAS DA
UnB
SAÚDE DA UNIVRSIDADE DE
BRASIILIA - CEPIFS-UNB

PARECER CONSUBSTANCIADO DO CEP

\section{DADOS DO PROJETO DE PESQUISA}

Título da Pesquisa: Repercussäo do Acesso e da qualidade da atenção básica na implemtação de acões de alimentação e nutriçäo no SUS

Pesquisador: Tatiane Nunes Pereira

Area Temática:

Versão: 2

CAAE: 50264514.1 .0000 .0030

Instituição Proponente:Departamento de Saúde Coletiva

Patrocinador Principal: Financiamento Próprio

\section{DADOS DO PARECER}

Número do Parecer: 1.400 .730

Apresentação do Projeto:

De acordo com o resumo apresentado na Plataforma Brasil (PB): "O monitoramento e a avaliaçäo da atençäo básica são essenciais para implementação efetiva das políticas públicas. Nesse sentido, o Programa de Melhoria do Acesso e da Qualidade da Atenção Básica pode constituir-se como um instrumento de monitoramento e avaliação da implementação de politicas de saúde. Assim, esse projeto tem como objetivo avaliar a repercussão da melhoria do acesso e da qualidade da atenção básica na implementação de ações de alimentação e nutrição entre 2012 e 2014 . Trata-se de um estudo transversal, de natureza quantitativa, realizado a partir de dados secundários, obtidos no primeiro e segundo ciclo do Programa Nacional de Melhoria do Acesso e da Qualidade da Atenção Básica (PMAQ-AB) ocorridos em $2011 / 2012$ e 2013/2014. Neste estudo seräo considerados apenas os municípios e as equipes participantes dos dois ciclos do PMAQ-AB, comparados de acordo com estrato do municipio e escore utilizado para certificaçăo das equipes de atenção básica. Para a caracterização dos municípios, serảo coletadas informações relacionadas a açöes de alimentação e nutrição realizadas na atenção básica. A descriçäo da implementaçäo dessas açōes nos municípios aderidos ao PMAQ-AB dar-se-á por meio da consolidação de indicadores existentes em sistemas públicos de informação. Os municípios seräo agrupados, além dos estratos, de acordo com percentual de eAB classificadas em ótimo, bom, regular e insatisfatório no

\begin{tabular}{|c|c|}
\hline $\begin{array}{l}\text { Enderego: Faculdade de Cienclas da Sasde } \\
\text { Balrro: Aas Norte } \\
\text { UF: DF } \\
\text { Tolofone: }\end{array}$ & $\begin{array}{l}\text { eiro } \\
\text { a-900 } \\
\text { E-mall; ceptopromgmal com }\end{array}$ \\
\hline
\end{tabular}




FACULDADE DE CIÊNCIAS DA
UnB
SAÚDE DA UNIVERSIDADE DE
BRASILIA - CEP/FS-UNB

Conthuaç̧o do Peracere: 1.400.730

município, considerando o número de eAB contratualizadas, a fim de avaliar se o desempenho do conjunto de equipes nos municipios reflete no conjunto de indicadores das ações de alimentaçăo e nutrição na atenção básica. Essa análise também possibilitará avaliar a repercussão da melhoria do acesso e da qualidade da atençäo básica nas ações de alimentaçäo e nutrição entre 2012 e 2014 , tendo como centro os municípios. Para o armazenamento e análise estatística dos dados serão utilizados os programas Excelø

3.1 e SPSSB-14, respectivamente".

Para a pesquisadora responsável, a hipótese é de que "a melhoria do acesso e da qualidade da atençäo básica implicam na realização de ações de alimentação e nutrição". De acordo com as informaçỏes descritas na PB, "trata-se de um estudo transversal, de natureza quantitativa, realizado a partir de dados obtidos no primeiro e segundo ciclo do Programa Nacional de Melhoria do Acesso e da Qualidade da Atenção Básica (PMAQ-AB) ocorridos em 2011/2012 e 2013/2014". A pesquisadora esclarece que "os bancos de dados gerados pelo PMAQ-AB referentes ao primeiro e segundo ciclo, estão livremente disponiveis no Portal do Departamento de Atenção Básica da Secretaria de Atenção à Saúde do Ministério da Saúde. Demais dados municipais relacionados às açôes de alimentação e nutrição seräo obtidos em sistemas de informaçäo públicos do Ministério da Saúde".

A pesquisadora reitera solicitação de dispensa de TCLE. Como justificativa, afirma: "todos os dados seräo obtidos por fonte secundária publicizados, constantes em sistemas de informação públicos ou em planilhas de acesso livre disponiveis no portal do Departamento de Atençäo Básica".

Objetivo da Pesquisa:

Segundo a pesquisadora, os objetivos säo:

Objetivo Primário:

- Avaliar a repercussão da melhoria do acesso e da qualidade da atenção básica na implementação de ações de alimentação e nutrição entre 2012 e 2014".

Objetivo Secundário:

'Descrever as açōes de alimentação e nutriçäo realizadas pelas equipes de atenção básica participantes do PMAQ-AB;

Verificar se há diferença na realização de ações pelas equipes de atençäo básica tradicionais e pela estratégia saúde da familia;

Avaliar se o desempenho geral por equipes de atençäo básica repercute na realização de açöes de alimentação e nutriçäo;

Caracterizar as ạ̧ôes de alimentação e nutrição na atenção básica nos municipios aderidos ao PMAQ-AB;

Enderepo: Faculdade de Cienclas da asode - Campus Darcy Rbein

Balro: Asa Norte
CEP: $70.910-900$

UF: DF Munlolplo: BRABUIA

Telefone: (61) 3107-1947

E-mall: ceptounbogamal.com

Pagina $\cos$ on $\infty$ 


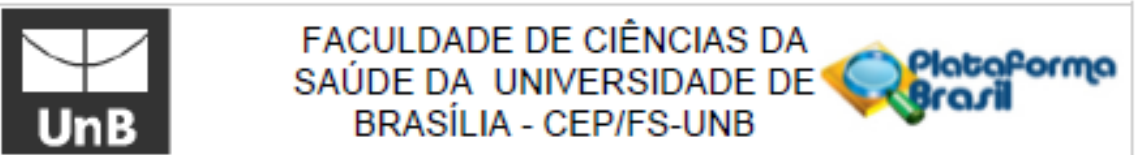

Conthuaç̧⿻ do Parecer: 1.400 .730

Avaliar se o desempenho do conjunto de equipes de atenção básica nos municípios reflete na realização de açöes de alimentação e nutriçäo".

Avaliação dos Riscos e Benefícios:

Em relação aos riscos, a pesquisadora afirma: "Como dissertação pode induzir tomada de decisảo por gestores, a avaliaçäo equivocada dos dados pode levar à tomada de decisão errada e impactar na populaçäo atendida pela atenção básica".

Os benefícios identificados pelo pesquisador săo: "Oferecer subsidios aos gestores para tomada de decisäo, com impacto positivo para a saúde e segurança alimentar e nutricional da população".

Comentários e Considerações sobre a Pesquisa:

Trata-se de segunda versão de projeto de mestrado do Programa de Pós-Graduação em Saúde Coletiva da aluna Tatiane Nunes Pereira, realizado sob orientaçäo da Profa. Leonor Maria Pacheco Santos. De acordo com a pesquisadora, trata-se de "estudo transversal, de natureza quantitativa, realizado a partir de dados secundários, obtidos pelo Programa de Melhoria do Acesso e da Qualidade da Atenção Básica do Ministério da Saúde". O cronograma de execução apresentado na PB prevê realizaçảo da pesquisa no periodo de $18 / 10 / 2015$ a 30/6/2016. O valor total do orçamento financeiro descrito na PB é de R\$ $1.167,88$, que seräo custeados pela própria pesquisadora.

Considerações sobre os Termos de apresentação obrigatória:

Documentos apresentados e analisados para emissão deste parecer:

1) Informaçōes básicas do projeto: "PB_INFORMAÇŌES_BÁSICAS_DO_PROJETO_420735.pdf", postado em $31 / 12 / 2015$

2) Folha de rosto assinada pela diretora da FS/UnB, Maria Fátima de Sousa: "Folha de Rosto_TNP.pdf", postado em 1/12/2014

3) Projeto detalhado: "ProjetoCEP.docx", postado em 31/12/2015

4) Curriculo Lattes das pesquisadoras Leonor Maria Pacheco Santos e Tatiane Nunes Pereira: "Curriculo do Sistema de Currículos Lattes (Leonor Maria Pacheco Santos).pdf, "LattesTati.pdf', postados em 19/7/2015 e 19/10/2015, respectivamente

5) Termo de responsabilidade e compromisso do pesquisador responsável: "TemoRespComprom.pdf" postado em $19 / 10 / 2015$

6) Carta de encaminhamento de projeto ao CEP assinada pela pesquisadora responsável e pela orientadora: "cartaencaminhprojeto.pdf", postado em 19/10/2015

7) Carta de solicitaçäo de dispensa de TCLE: " DispensaTCLE.pdf ", postado em 19/10/2015

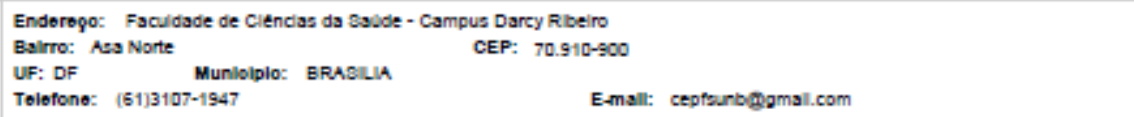




FACULDADE DE CIÊNCIAS DA
UnB
SAÚDE DA UNIVERSIDADE DE
BRASILIA - CEPIFS-UNB

Conthuaçiso do Parecier. 1.400.730

8) Carta para encaminhamento de pendências: "CartaRespostaCEP.pdf", postado em 31/12/2015

Recomendações:

Näo se aplica.

Conclusões ou Pendências e Lista de Inadequações:

1) Considerando que os dados que serão acessados são públicos, mas não publicizados. Solicita-se apresentar resposta do Ministério da Saúde ao pedido de acesso à informaçäo.

ANÁLISE: Na carta para encaminhamento de pendências, a pesquisadora esclarece que: "Em relação aos dados secundários, somente os dados referentes ao segundo ciclo do Programa de Melhoria do Acesso e da Qualidade da Atenção Básica näo estavam disponiveis quando da submissäo do projeto. Contudo, estes já foram publicizados no portal do Departamento de Atençäo Básica [...]. Na segunda versão do protocolo de pesquisa, a pesquisadora afirma que utilizará apenas dados de domínio público de acesso irrestrito. PENDÉNCIA ATENDIDA.

2) De acordo com a Resolução CNS 468/2012 (item II.22), risco da pesquisa é "a possibilidade de danos à dimensão física, psiquica, moral, intelectual, social, cultural ou espiritual do ser humano, em qualquer pesquisa e dela decorrente". Nos riscos descritos no projeto da Plataforma Brasil, a pesquisadora apresenta problemas que, na sua concepção, podem ocorrer caso o seu estudo não seja realizado. Năo apresenta possiveis riscos ao participante de pesquisa. Solicita-se adequação.

ANÁLISE: Em relaçäo aos riscos descritos na versão anterior, a pesquisadora acrescentou o seguinte trecho em destaque: "Como dissertaçäo pode induzir tomada de decisäo por gestores, a avaliaçäo equivocada dos dados pode levar à tomada de decisão errada E IMPACTAR NA POPULAÇÄO ATENDIDA PELA ATENÇÄO BÁSICA*. A pesquisadora näo fez modificações substanciais na descrição dos riscos. Assim como na primeira versão, há somente uma exposição das consequências da näo realização da pesquisa. No entanto, tendo em vista a metodologia proposta ("Todos os dados serão obtidos por fonte secundária publicizados [...]"), considera-se a PENDÉNCIA ATENDIDA.

3) No projeto detalhado ("ProjetoCEP.docx", postado em 18/10/2015), página 7 de 12, item "4. Método", subitem "Aspectos Éticos", a pesquisadora afirma: "Atendendo à Resoluçäo $n^{\circ} 196$, de 10 de outubro de 1996, do Conselho Nacional de Saúde, esta pesquisa levará em conta os principios éticos de respeito pela autonomia das pessoas [...]". As diretrizes e normas regulamentadoras de pesquisas envolvendo seres humanos EM VIGOR são as que constam na Resolução CNS 466/2012. Solicita-se adequaçäo.

\begin{tabular}{|c|c|}
\hline $\begin{array}{l}\text { Balrro: Aes Norte } \\
\text { UF: DF } \\
\text { Tolofone: } \quad \text { (61) } 3107-1947\end{array}$ & $\begin{array}{l}\text { CEP: } 70.910-900 \\
\text { E-mall: cepfounbgamal.com }\end{array}$ \\
\hline
\end{tabular}


FACULDADE DE CIÊNCIAS DA SAÚDE DA UNIVERSIDADE DE BRASILIA - CEP/FS-UNB

Conthuaçads do Paracer: 1.400 .730

ANÁLISE: A pesquisadora modificou o projeto detalhado, conforme solicitado. PENDÉNCIA ATENDIDA.

A segunda versảo do protocolo de pesquisa está de acordo com a Resoluçäo $n^{\circ} 466 / 12$.

Considerações Finais a critério do CEP:

De acordo com a Resolução 466/12 CNS, itens X.1.- 3.b. e XI.2.d, os pesquisadores responsáveis deveräo apresentar relatórios parcial semestral e final do projeto de pesquisa, contados a partir da data de aprovação do protocolo de pesquisa.

Este parecer foi elaborado baseado nos documentos abaixo relacionados:

\begin{tabular}{|c|c|c|c|c|}
\hline Tipo Documento & Arquivo & Postagem & Autor & Situaçăo \\
\hline $\begin{array}{l}\text { Informaçóes Básicas } \\
\text { do Projeto }\end{array}$ & $\begin{array}{l}\text { PB_INFORMAÇ_EES_BASICAS_DO_P } \\
\text { ROJETO 420735.pdf }\end{array}$ & $\begin{array}{c}31 / 12 / 2015 \\
14: 13: 48 \\
\end{array}$ & & Aceito \\
\hline Outros & CartaRespostaCEP.pdf & $\begin{array}{c}31 / 12 / 2015 \\
14: 12: 21 \\
\end{array}$ & $\begin{array}{l}\text { Tatiane Nunes } \\
\text { Pereira }\end{array}$ & Aceito \\
\hline $\begin{array}{l}\text { Projeto Detalhado I } \\
\text { Brochura } \\
\text { Investigador }\end{array}$ & ProjetoCEP.docx & $\begin{array}{c}31 / 12 / 2015 \\
14: 09: 47\end{array}$ & $\begin{array}{l}\text { Tatiane Nunes } \\
\text { Pereira }\end{array}$ & Aceito \\
\hline Outros & LattesTati.pdf & $\begin{array}{c}19 / 10 / 2015 \\
15: 27: 50\end{array}$ & $\begin{array}{l}\text { Tatiane Nunes } \\
\text { Pereira }\end{array}$ & Aceito \\
\hline $\begin{array}{l}\text { TCLE / Termos de } \\
\text { Assentimento / } \\
\text { Justificativa de } \\
\text { Ausência } \\
\end{array}$ & DispensaTCLE.pdf & $\begin{array}{c}19 / 10 / 2015 \\
15: 26: 59\end{array}$ & $\begin{array}{l}\text { Tatiane Nunes } \\
\text { Pereira }\end{array}$ & Aceito \\
\hline Outros & TermoRespComprom.pdf & $\begin{array}{c}19 / 10 / 2015 \\
15: 23: 29\end{array}$ & $\begin{array}{l}\text { Tatiane Nunes } \\
\text { Pereira }\end{array}$ & Aceito \\
\hline Outros & cartaencaminhprojeto.pdf & $\begin{array}{c}19 / 10 / 2015 \\
15: 22: 39 \\
\end{array}$ & $\begin{array}{l}\text { Tatiane Nunes } \\
\text { Pereira }\end{array}$ & Aceito \\
\hline Outros & $\begin{array}{l}\text { Currículo do Sistema de Currículos } \\
\text { Lattes (Leonor Maria Pacheco } \\
\text { Santos S.pdf }\end{array}$ & $\begin{array}{l}19 / 07 / 2015 \\
13: 23: 07\end{array}$ & & Aceito \\
\hline Folha de Rosto & Folha de Rosto_TNP.pdf & $\begin{array}{c}01 / 12 / 2014 \\
12: 30: 26 \\
\end{array}$ & & Aceito \\
\hline Outros & Concordancia_TNP.pdf & $\begin{array}{c}01 / 12 / 2014 \\
12: 30: 17\end{array}$ & & Aceito \\
\hline
\end{tabular}

Situação do Parecer:

Aprovado

Necessita Apreciação da CONEP:

Nă้

Enderogo: Faculdade de Cienclas da Savde - Campus Darcy Rbeiro

Balrro: Aes Norte CEP: $70.910-900$

MF: DF
Tolofone: (61)3107-1947 


\section{Y \\ UnB}

Corthuacto do Parecier 140073
FACULDADE DE CIÊNCIAS DA

SAÚDE DA UNIVERSIDADE DE BRASÍLIA - CEPIFS-UNB
Platoforma Brasil

BRASILIA, 02 de Fevereiro de 2016

Assinado por:

Keila Elizabeth Fontana

(Coordenador)

Enderepo: Faculdade de Ciencias da Sadde - Campus Darey Ribeiro

Balrro: Aes Norte CEP: 70.910-900

UF: DF Muniolplo: BRABLIA

Tolofone: (61)3107-1947

E-mall: cepfounbgamal.com

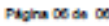

